\title{
Transparent insulation for thermal storage walls
}

\author{
Olsen, Lars; Paludan-Müller, Casper
}

Publication date:

1983

Document Version

Publisher's PDF, also known as Version of record

Link back to DTU Orbit

Citation (APA):

Olsen, L., \& Paludan-Müller, C. (1983). Transparent insulation for thermal storage walls. Technical University of Denmark, Department of Civil Engineering.

\section{General rights}

Copyright and moral rights for the publications made accessible in the public portal are retained by the authors and/or other copyright owners and it is a condition of accessing publications that users recognise and abide by the legal requirements associated with these rights.

- Users may download and print one copy of any publication from the public portal for the purpose of private study or research.

- You may not further distribute the material or use it for any profit-making activity or commercial gain

- You may freely distribute the URL identifying the publication in the public portal

If you believe that this document breaches copyright please contact us providing details, and we will remove access to the work immediately and investigate your claim. 


\section{THERMAL INSULATION LABORATORY}

TECHNICAL UNIVERSITY OF DENMARK

\section{TRANSPARENT INSULATION FOR THERMAL STORAGE WALLS}

FINAL REPORT

LARS OLSEN , CASPER PALUDAN-MÜLLER

JULY 1983 , MEDDELELSE NR. 142
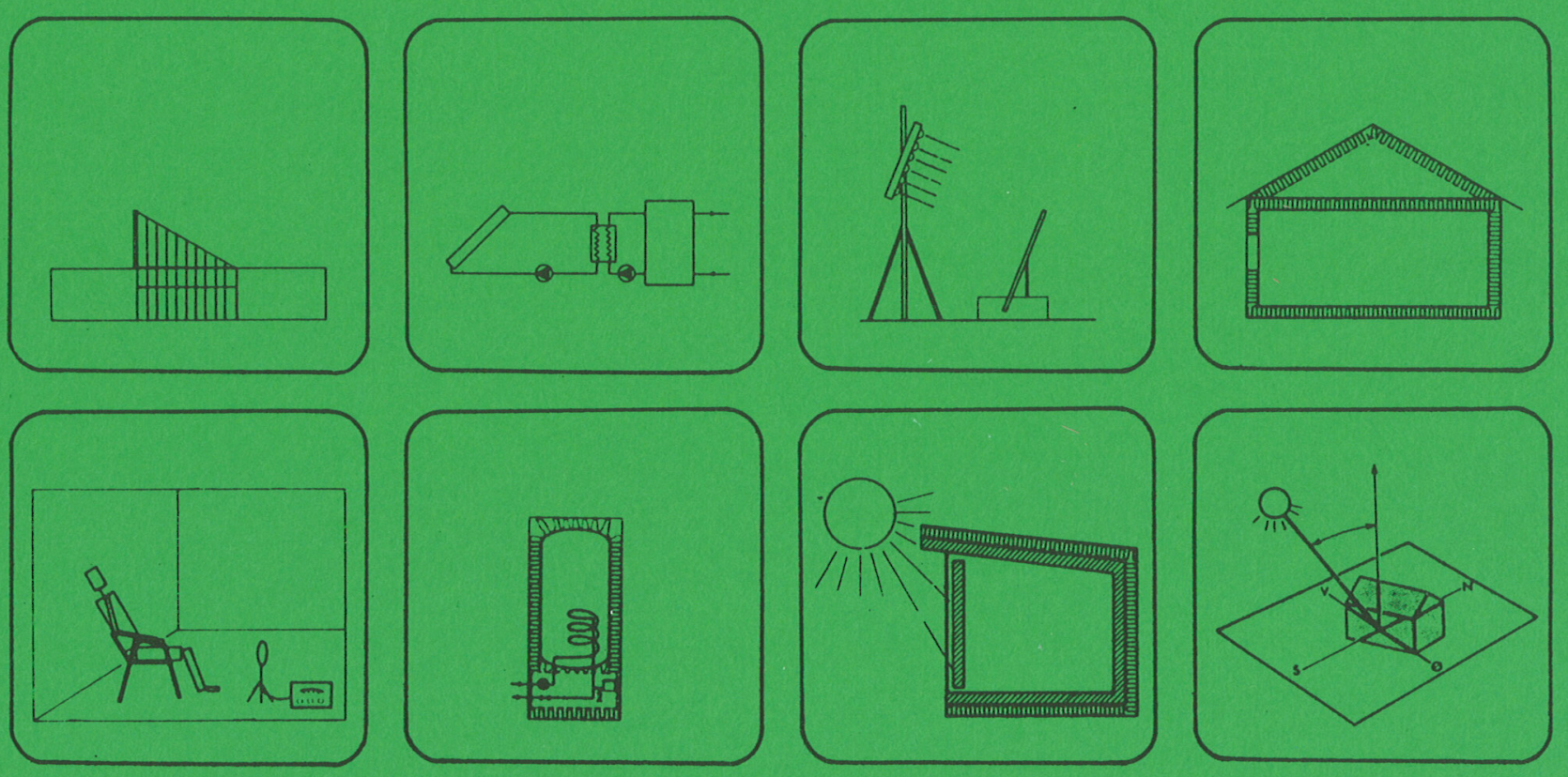
THERMAL INSULATION LABORATORY

TECHNICAL UNIVERSITY OF DENMARK

TRANSPARENT INSULATION FOR THERMAL

STORAGE WALLS

CONTRACT NO. ESA-PS-146-DK(G)

JANUARY 1. 1982 - JUNE 30, 1983

LARS OLSEN

CASPER PALUDAN-MÜLLER

MEDDELELSE NR。 142, JULY 1983 


\section{Projectgroup}

Casper Paludan-Můller, M.Sc.

Lars Olsen, M.Sc.

Lars Saust Christensen, M.Sc.

Flemming Karn, technican

Bertil Morelli, technican

Kirsten Weishaupt, secretary

Elin van Kooten, secretary

Ida Frandsen, secretary

Lone Dønskov, secretary

Kenneth sørensen, draughtsman 


\section{PREFACE}

The Commission of the European Communities has initiated a Solar Energy $R$ and D Programme. Project $A$ under this programme deals with solar heating and cooling of buildings. This programme is expanded to also include activities on passive solar energy.

In March 1981 a call for tenders on development of passive solar components was published.

The scope of the programme was development of radically new components and development of more cost-effective versions of existing components. The call was specifically directed towards two types of passive solar components: architectural components and auxiliary heating systems. In this project the aim is to develop a permanent transparent insulation, primarily for thermal storage walls, in order to improve the ratio of solar transmission and reduce the heat loss coefficient.

The project was started in January 1982. The expenditure for the project is shared on a $50 \%$ basis between the Commission and the Danish Government.

This report represents the final report of the CEC contract number ESA-PS-I46-DK (G).

July 1983

Thermal Insulation Laboratory

Technical University of Denmark

$\mathrm{V}$. Korsgaard

Professor 



\section{TABLE OF CONTENTS}

PREFACE

TABLE OF CONTENTS

ABSTRACT

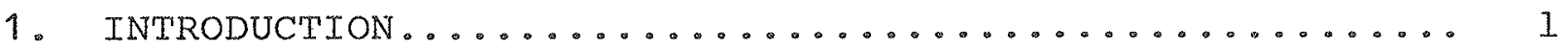

2. THE DESIGN OF THE HONEYCOMBS AND THE TEST SOLAR

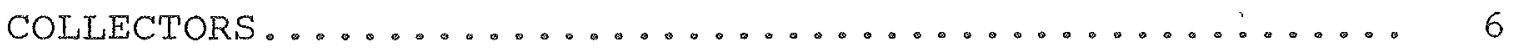

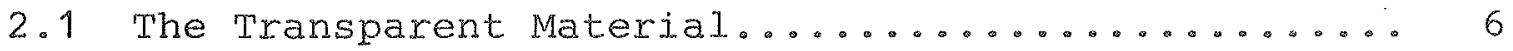

2.2 Design and Manufacturing of the Honeycombs for the Test collectors ....................... 9

2.3 Construction of the Test collectors ............ 15

3. MEASUREMENTS OF THE TEST SOLAR COLLECTORS ........... 23

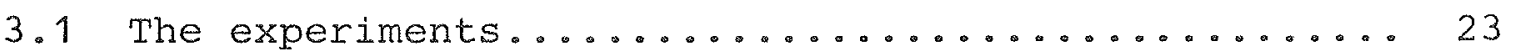

3.2 Discussion of the Results from Indoor Measurements. 29

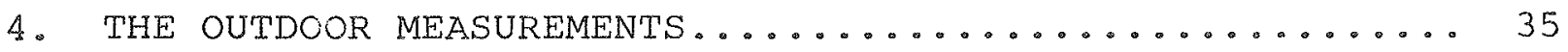

4.1 Description of the Test House and the Thermal

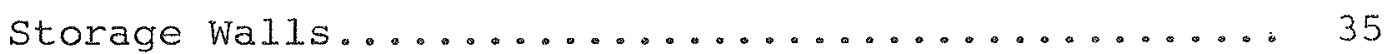

4.2 Results from the outdoor Experiments............ 43

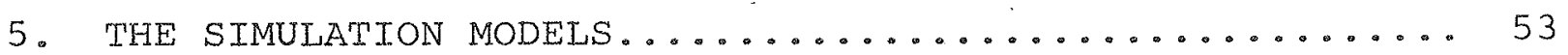

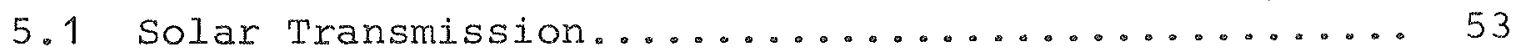

5.2 Calculation Model for the Thermal Heat Loss through

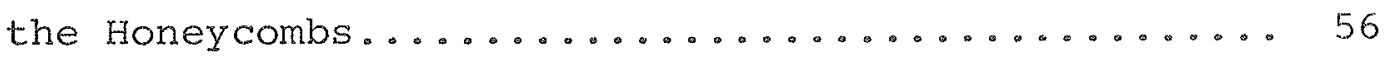

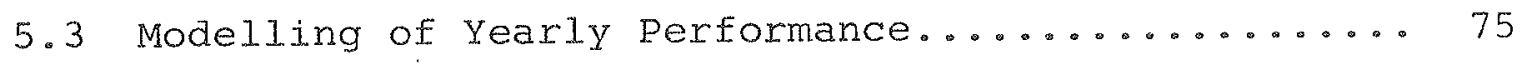

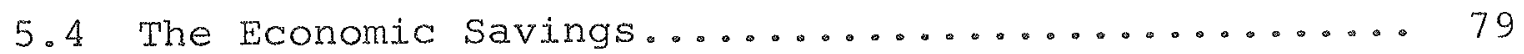

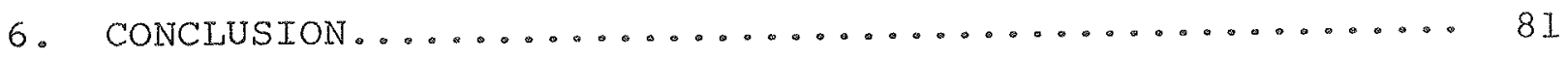

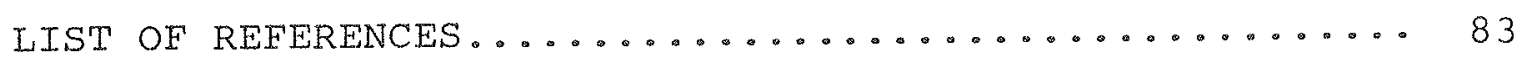
APPENDIX

A Thermal Expansion of the Honeycombs............. 85

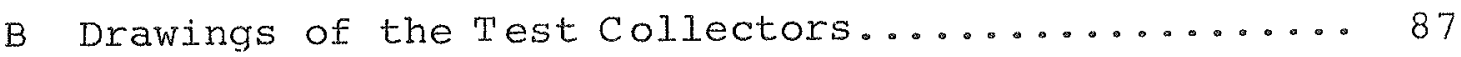

C Results from the testing of the Test Collectors... 89

$D$ The correction terms and the uncertainty of the

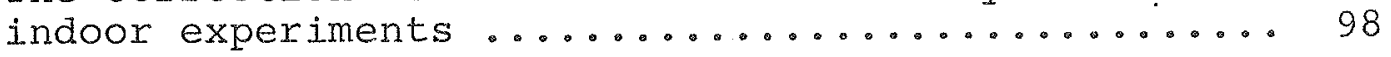

$\mathrm{E}$ The measuring equipment for the outdoor experiments 104

$F$ Correction of the results from the test cell A ... 110 


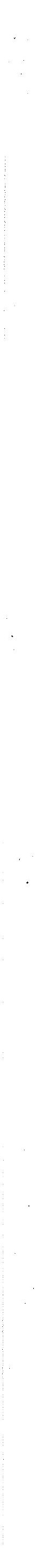




\section{ABSTRACT}

Thermal storage walls are an integrated part of the building structure. The central part is a wall model of a material which is able to accumulate heat. The outer side of the wall is used as absorber and a cavity is formed by placing a collector cover on a frame mounted at the wall. This cavity can be filled with transparent insulation. Different types have been investigated:

- Slatted honeycomb

- V-corrugated honeycomb

- Triangular shaped cylinders covered witi a reflective film

The performance has been calculated. The transparent insulation has been constructed and placed in test collectors which are tested in a solar simulator. The test results are compared with the calculations.

The V-corrugated honeycomb has been built into a thermal storage wall in a test building. The results are compared with a thermal storage wall without honeycomb.

The yearly performance of thermal storage walls used in dwellings has been calculated with a computer simulation model. 



\section{INTRODUCTION}

The building envelope is a part of the building which in most cases is used only for protection of the inhabitants against the elements. But it is also possible to use it as an energy producing system. In the heating season a considerable amount of solar radiation is striking a vertical wall facing south. This potential can be exploited by using the wall as a combined collector, storage and space heater. A thermal storage wall combines these characteristics. A drawing showing the principle is shown in fig. 1.1. It is often called an unvented thermal storage wall. In this report it is identified as a thermal storage wall or a solar wall.

When there is solar irradiation at the wall, the radiation is transmitted through the collector cover and absorbed on the outer side of the wall. The absorbed heat is conducted into the wall and accumulated. The accumulated heat can be stored for later use, typically with a time lag of four hours to two days.

Heat transfer will take place from the wall by heat conduction through the wall combined with natural convection and radiation from the inner side of the wall to the room.

Solar walls are an integrated part of the building structure. The central part is a wall made of a material which is able to accumulate heat. Towards the outer side of the wall is mounted a collector cover which can transmit solar radiation and at the same time insulate against heat loss. Both with and without incident solar radiation it is necessary to reduce the heat transfer through the wall from the room to the outside air. This can be done by using a number of glazing layers or by use of movable insulation. By increasing the number of glazing layers, the solar transmission will be reduced. Movable insulation will in the best cases only reduce the heat loss at times with no solar irradiation. 


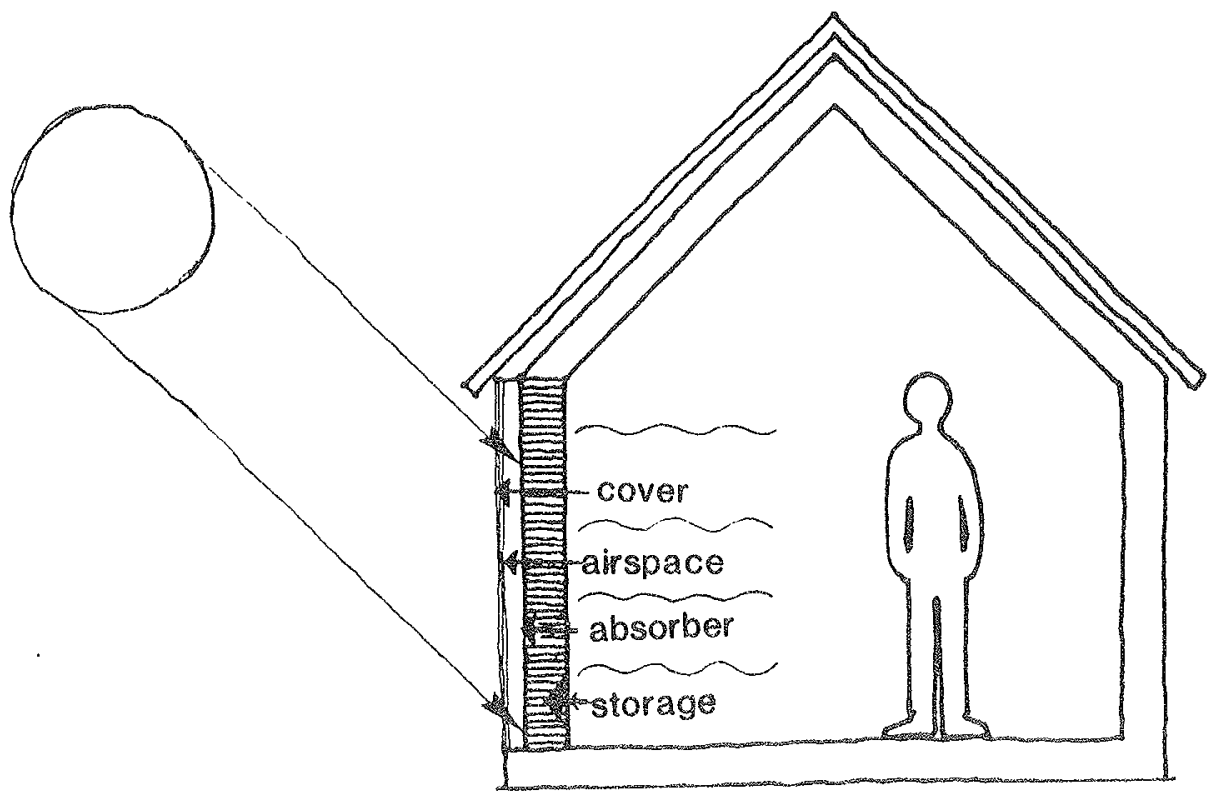

Fig. 1.1 The principle of a thermal storage wall.

A solution is to use honeycomb structures. These are characterized by having thin walls which are perpendicular or almost perpendicular to the outer glazing. If the honeycomb material is highly reflective or transparent, most of the solar radiation will be transmitted through the honeycomb structure. It is therefore possible to construct the honeycomb in such a way that the transmittance is better than by using a single layer of glazing. The heat transfer by infrared radiation will be reduced and the convective heat transfer can either be reduced or amplified by using honeycombs. A careful design is therefore necessary to secure the proper function of the honeycomb.

In this project different types of honeycombs have been considered. Three types can be identified:

- Rectangular square-celled honeycomb

- Slatted honeycomb

- V-corrugated honeycomb 
The square-celled honeycomb has the advantage of low convective heat transfer, but it cuts off more of the solar radiation than the other types. This is due to the daily movement of the sun.

The slatted honeycomb is made of parallel walls (see fig. 1.2a). The walls can be sloping and have a horizontal line of intersection with the vertical storage wall.

The $V$-corrugated honeycomb is another possibility (see fig. 1.2b). This honeycomb is made of a folded sheet of polycarbonate. The advantage of the $\mathrm{V}$-corrugated honeycomb, compared to the slatted honeycomb, is that the cavity is divided into two cells, and that structurally it is easy to support.

The slatted and the $V$-corrugated honeycomb have no vertical partitions. Placing of the structures in horizontal rows in vertical thermal storage walls facing south will be favourable. This is due to the low solar altitude during winter and to the small sensitivity of the transmission to the azimuth variation of the incident solar radiation. One more type of transparent insulation has been investigated:

- Triangular shaped cylinders of insulation placed in rows at the exterior side of the plane storage wall. The cylinders are covered with a reflective surface in order to reflect the irradiation to the absorber area between the cylinders.

A cross section of this type is shown in fig. 1.3. The reflective surfaces will concentrate the incident solar raaiation. The advantage of this solution is that the absorber surface is limited causing a reduction of both the convection and the radiation loss. However the reduction of the convection loss showed to be less than expected and therefore it is necessary to place slatted or V-corrugated honeycombs in the space between the absorber and the glass. 


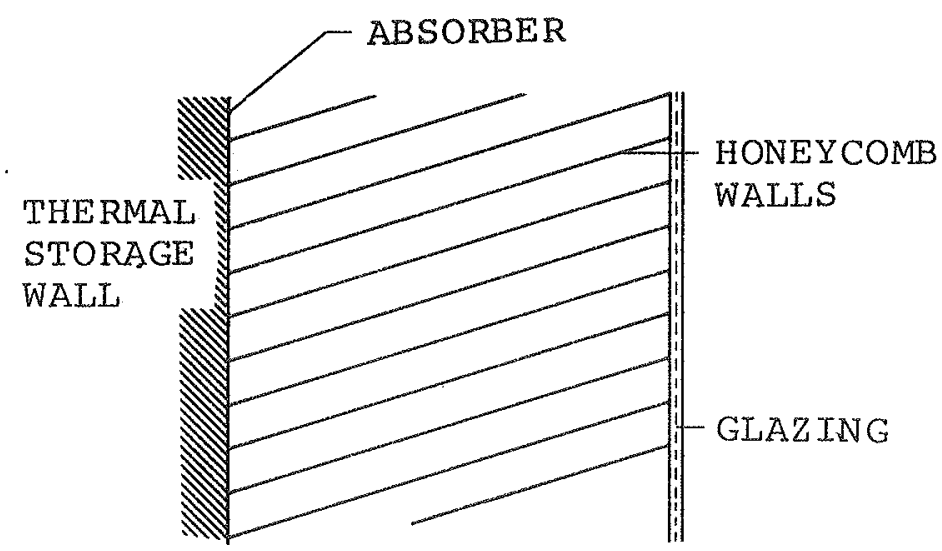

(a)

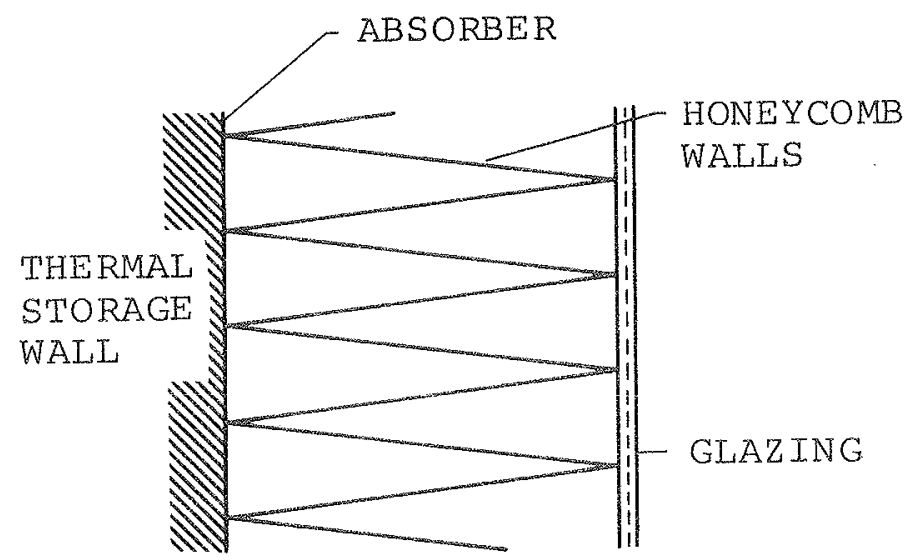

(b)

Fig. 1.2 The principles of slatted and V-corrugated honeycomb.

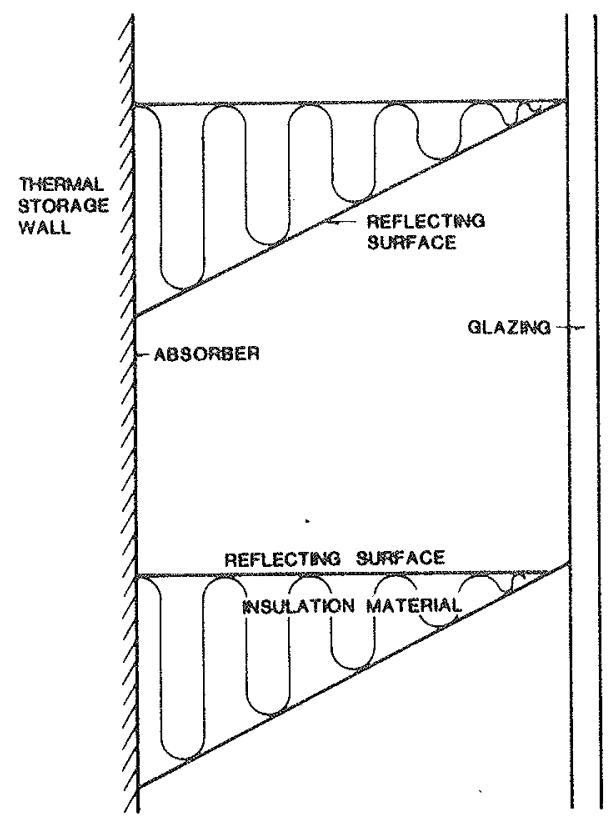

Fig. 1.3 Transparent insulation with triangle shaped cylinders of insulation material. 
In order to evaluate the different types of transparent insulation, the theory of honeycomb has been investigated. Four different test collectors have been constructed and tested in a solar simulator.

The V-corrugated type of honeycomb has been chosen for outdoox testing in a test house with thermal storage walls. The results have been compared with a thermal storage wall without honeycomb.

The yearly performance has been modelled for selected types of honeycomb. 
2. THE DESIGN OF THE HONEYCOMBS AND THE TEST SOLAR COLIECTORS

In the early phase of the project the different possibilities concerning a suitable transparent material for the honeycombs were studied. Also some considerations were made in connection with the manufacturing of the honeycombs for the test solar collectors. These initial investigations and the construction of the test solar collectors are described in this section.

\subsection{The Transparent Material}

The transparent material for the honeycomb must fulfil a number of requirements. optically the material should have only a limited absorption of solar radiation, the surface reflection should rather be specular than diffuse, the material should not be transparent for infrared radiation and the long term optical stability should be sufficient.

The strength of the material should be sufficient to withstand its own weight, and the material should not be brittle. Regarding temperature stability, the material should be able to resist temperatures of about approx. $80^{\circ} \mathrm{C}$ at short periods and have a low thermal conductivity. It should be easy to form and join together and it should not be easily loaded with static electricity. The cost of the material should be reasonable. Some of the relevant data are shown in table 2.1 .

It is very difficult to meet all these requirements for a certain material. An important parameter is the thickness of the material. It should be as thin as possible for optical and price reasons whereas a thicker material would improve the structural performance.

The transparent material used for the honeycomb is a foil made from polycarbonate. The transparency of this material is quite good although this does not appear clearly from 


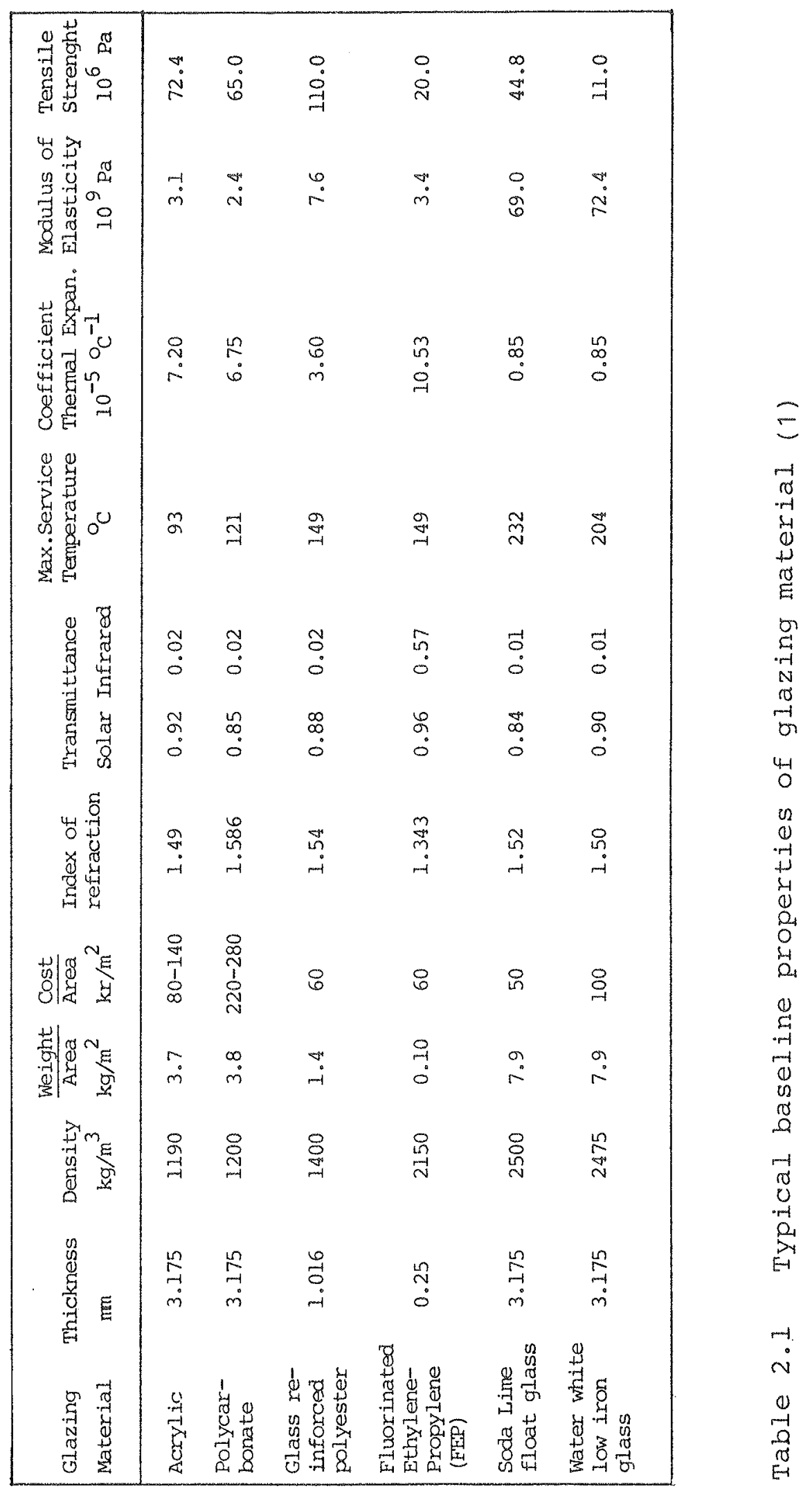


the table. A reason is the large index of refraction. which gives a large reflection. This is not a problem when the material is used for honeycomb because the main part of the reflected radiation hits the absorber. The material is only slightly transparent for infrared radiation.

A certain stiffness of the material is a plus as the structures are intended to be selfsupporting to some degree. The modulus of elasticity (bending) is not especially high but it is on a level which is comparable to other thermoplastics.

The coefficient of thermal expansion is rather low in comparison with other plastic materials and the temperature stability is fairly good. Furthermore, polycarbonate is rather easy to cut, glue, bend and form. A disadvantage is the rather high price of approx. $70 \mathrm{kr} /$ $\mathrm{m}^{2}$ for a thickness of $0.25 \mathrm{~mm}$ and approx. $100 \mathrm{kr} / \mathrm{m}^{2}$ for $0.38 \mathrm{~mm}$. However, the price can be reduced if the material is bought in large quantities. 


\subsection{Design and Manufacturing of the Honeycombs for} the Solar Collectors

\section{General_discussion}

In connection with manufacturing of the honeycombs for the solar collectors some general demands were to be met. These demands are mentioned in the following. Because of the statics of the honeycombs, they should be fixed in such a way that they are able to span almost one meter across the collector when being charged by their own weight. The thickness $(0.25 \mathrm{~mm}$ or $0.38 \mathrm{~mm})$ of the plane plastic foil is far from suitable to manage the span and therefore either a profiling of the plastic in order to make a stiffer cross section, or some kind of fastening in the vertical direction, is necessary. Furthermore some kind of guides are needed to keep the distances between the layers of plastic.

Against the edge insulation as well against the absorber and the glazing, the plastic should be placed as tightly as possible in order to prevent air from circulating through the cracks, as this would tend to increase the convective heat loss.

Finally, it is important that the material has the possibility of expanding with the temperature changes without any consegeunces, such as buckling of the plastic. The temperature movements are calculated in appendix $A$.

In order to investigate how the above mentioned demands are to be met, a model illustrating part of the collector in full scale was built and it was possible to test different solutions before the construction of the solar collectors.

To meet the demands, the below mentioned solutions were generally found. In order to fix the honeycombs on each side of the absorber, strips of $3 \mathrm{~mm}$ thick transparent 
polycarbonate were used. The honeycombs were kept in position by cuts in the strips and these were made deep enough to allow expansions due to temperature changes. The tightness along the edges was prevented by placing of a very soft and elastic type of glass wool.

The $\mathrm{v}$-corrugated honeycoms

For the v-corrugated honeycombs, the shape of the cross section managed to give the structure a rather good stiffness, and so the static demands were not difficult to satisfy. In this case the honeycombs were fixed with clips to the absorber plate and the glass was mounted tightly to the honeycombs. However, because of deviations from the manufacturing, cracks of about $1-2 \mathrm{~mm}$ between the glazing and the honeycombs were frequent. A sketch of the mounting of this type of honeycomb is shown in fig. 2.1.

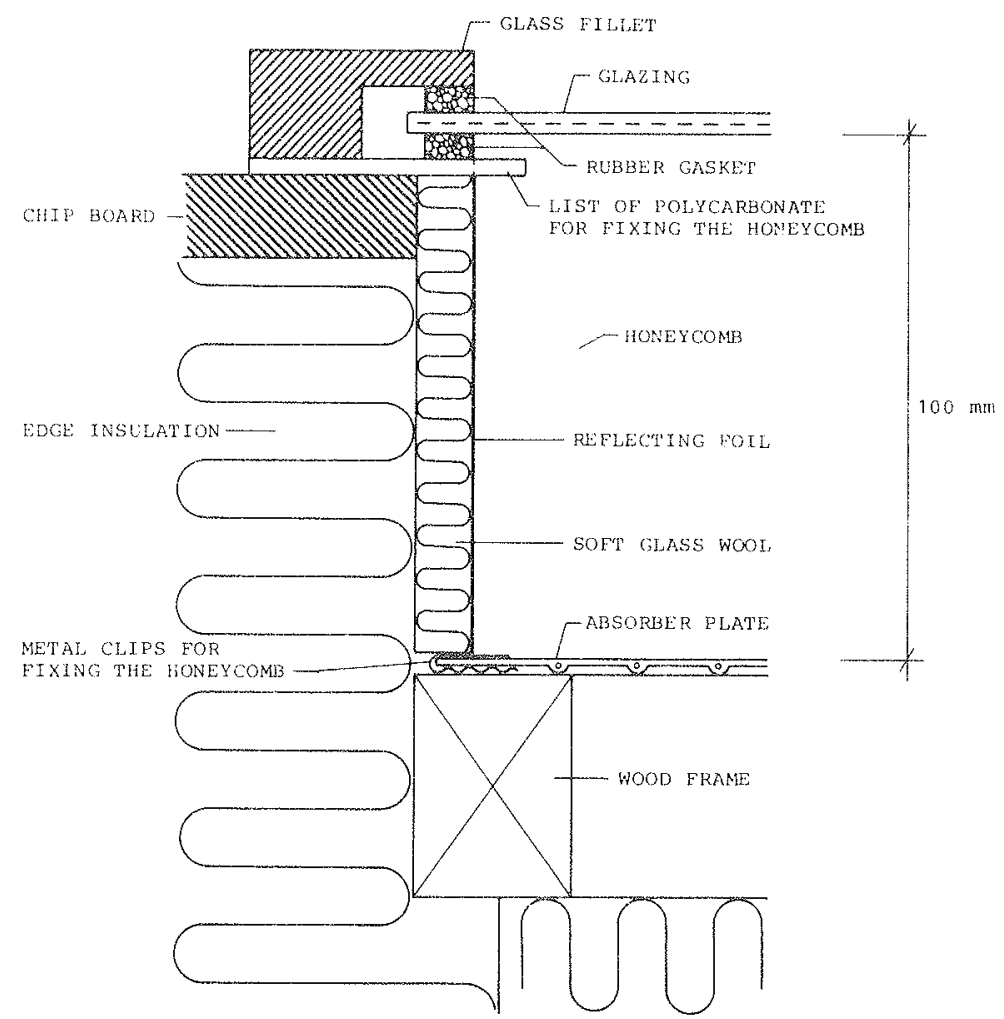

Figure 2.1 The mounting of the V-corrugated honeycombs. 
The plastic sheets were bent by use of a bending machine, and in order to obtain a sufficiently sharp edge, the bended edge was pressed afterwards. A thermostatically controlled electric iron was used for this purpose. During the manufacturing of the solar collectors, this way of shaping the plastic proved to be very difficult and slow. For each square meter of the absorber (corresponding to $10 \mathrm{~m}^{2}$ plastic) it took about 6 days for one workman. When manufacturing the honeycombs for the outdoor measurements, another method was used and this is described in chapter 4.1 .

The bended sheets were glued together with a transparent and heat resistant adhesive. This process was not so difficult and it was done by using simple templates to keep the plastic in position when gluing.

The slatted honeycombs

For the slatted honeycombs, the situation was more complicated. The plane slatted honeycombs did not have the stiffness for them to span lengthwise without any support from the absorber or the glass unless a considerable thickness of the material was used. Two different solutions were investigated: The stiffness could be improved by profiling the cross section (as shown in fig. 2.2) or the honeycomb should be fixed along the absorber or the glazing. The latter of the two solutions was the less attractive because it had been an ambition that the structure should be a separate unit which could be fitted with a modest use of time: the process of fixing the honecombs to the absorber proved to be rather time-consuming. Nevertheless, this method was chosen because the experiments with the first solution were not successful, as explained on the following pages.

Fig. 2.2 shows some of the cross sections of the honeycombs which have been made in connection with these experiments. 
In all the cases the angle $u$ (shown on the figure) should be made a little too big, so that it would be pressed together when mounting the glass. This way, the honeycomb would be in contact with the surfaces of the absorber and the glass, and the tightness would be ensured.

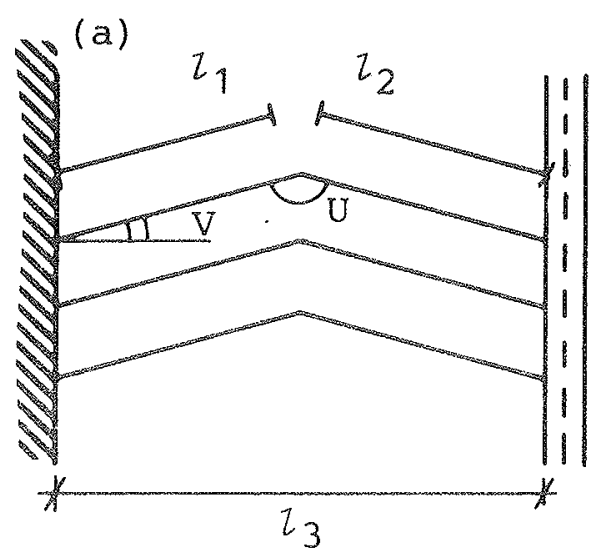

(c)

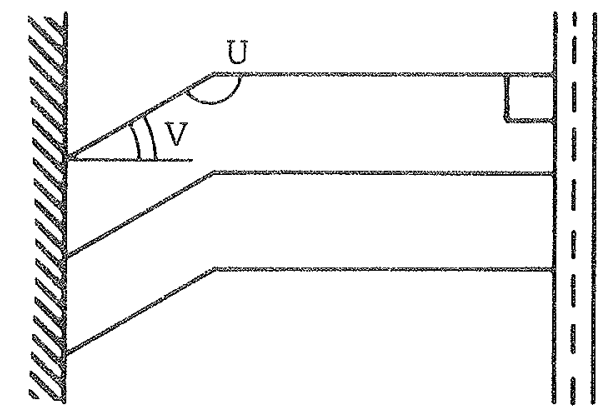

(b)

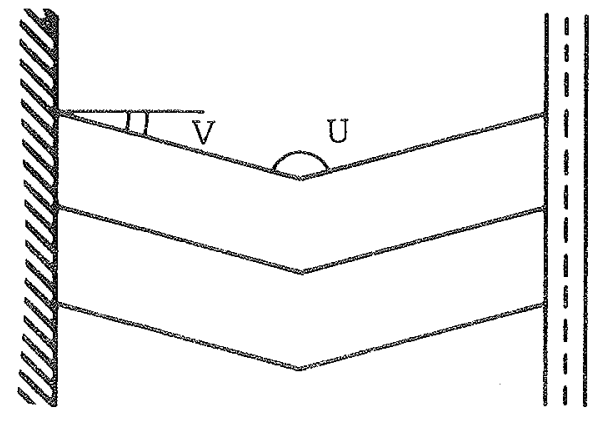

(d)

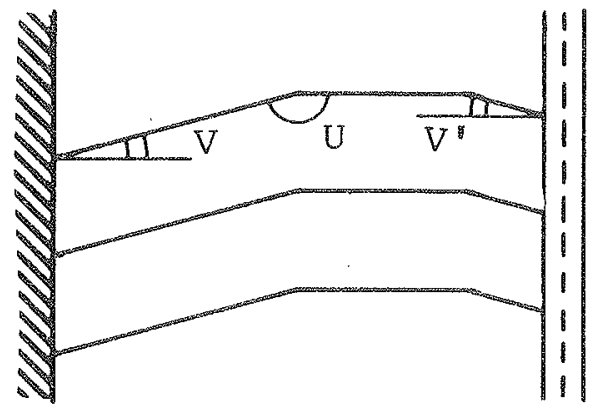

Figure 2.2 Different kinds of slatted honeycombs, some dimensions mentioned in the text are shown.

It was generally experienced that it was difficult to obtain a uniform shaping of the angle $u$; when using the bending machine, considerable variations in the size of $u$ for the different bendings could not be avoided. It was also experienced that if the angle betwen the honeycomb and the normal to the glass or to the absorber $v$ was close to $0^{\circ}$ "the consequence would be that it was impossible to keep the plastic edge straight along the contact surface to the glass and the absorber. "Waves" were formed 
due to small variations (about $1 \mathrm{~mm}$ ) in the distance between the glazing and the absorber or of the dimensions $\ell_{1}, l_{2}$ and $\ell_{3}$. It was found that $v$ should be bigger than $15^{\circ}$ in order to obtain a regular course of the edges of the honeycomb.

The configuration (a) was rejected because it was considered that with $v$ as big as $15^{\circ}$ the transmission of solar radiation would be too poor. The qualities concerning the transmission were found to be acceptable when using the configuration (b) with $v=15^{\circ}$; however, in this case there will be stress at the edges of the honeycombs as they are pointing upwards and the plastic will tend to bulge. To avoid bulging it was found that $v$ should be bigger than approx. $22^{\circ}$, but then the transmission could be expected to be too poor. The solution (c) was rejected due to the right angles between the honeycombs and the glazing $\left(v=0^{\circ}\right)$. Instead it was proposed to bend the edge of the plastic as shown on configuration (d), but when shaping the edge by use of the bending machine, the angle $v^{\prime}$ turned out to be quite different every now and then, resulting in the connection between the honeycombs and the glass being rather leaky.

Next, the possibility of supporting the plastic at the absorber with some kind of adhesive was tried. The pieces of plastic were cut out and mounted as shown in fig. 2.3. The plastic is leaning on the glass and the angle with the horizontal $\left(17^{\circ}\right)$ is favourable in relation to the angle of incidence for the beam radiation during the winter time. It was considered important that the adhesive should be rather elastic because of the difference in the temperature movements of the absorber and the plastic, and therefore silicone was chosen. A silicone that seemed to have a good transparency was applied with a spray gun as a thin stripe (about $2 \mathrm{~mm}$ ) . 


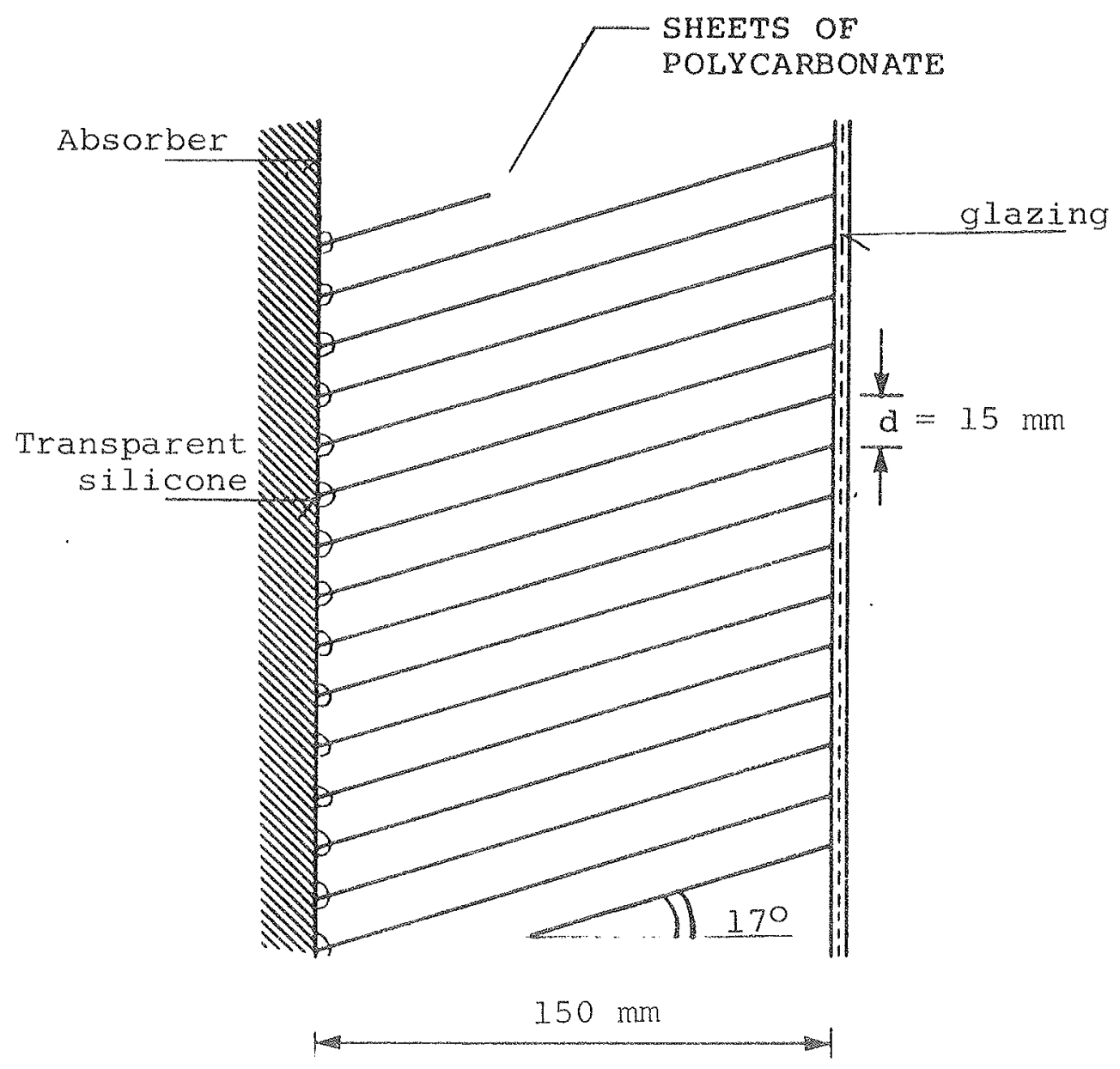

Fig. 2.3 The mounting of the slatted honeycombs.

The suitability of the silicone combined with consideration to the thermal expansions was checked experimentally by using the model of the collector. The absorber was heated to about $70^{\circ} \mathrm{C}$ a couple of times by use of an electric heat foil, and afterwards it could be seen that the join was intact. When performing the same test with a non-elastic adhesive, it was observed that the plastic and the absorber plate had come apart at several places. 


\subsection{Construction of the test solar collectors}

\section{The four different collectors}

In this section the construction of the test solar collectors is described. The collectors were designated $\mathrm{TC}-1, \mathrm{TC}-2, \mathrm{TC}-3$ and $\mathrm{TC}-4$.

TC-1 This one was used as a reference collector (no honeycombs).

TC-2 This collector was equipped with $\mathrm{v}$-corrugated honeycombs.

TC-3 In this collector slatted honeycombs were used. The angle between the honeycombs and the horizontal plan was $17^{\circ}$.

TC-4 In this collector about 45\% of the absorber was covered with triangular shaped cylinders of insulation foam with reflecting surfaces. Between the cylinders the space was filled with the $v$-shaped honeycombs.

On figure 2.4 is shown the dimensions of the different honeycombs for the test collectors. These dimensions were selected from an initial analysis of the convective heat transfer in the honeycombs. 

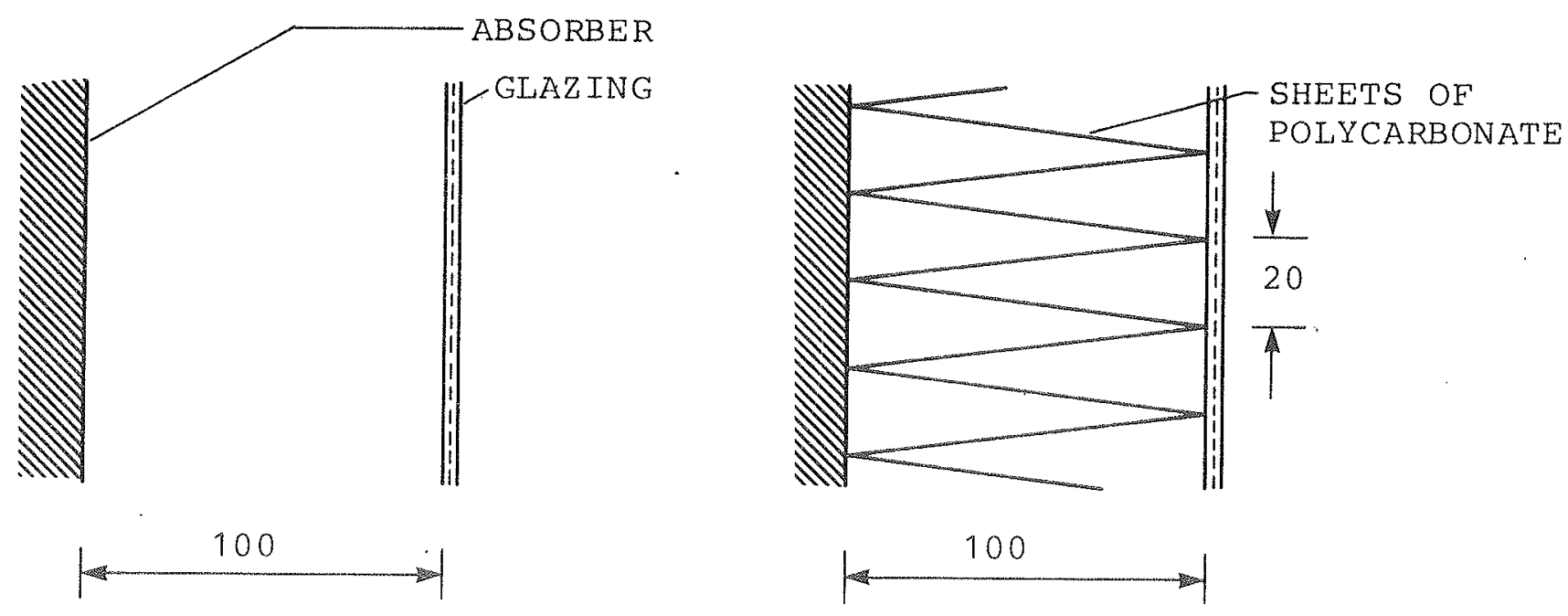

$T C-1$

$\mathrm{TC}-2$
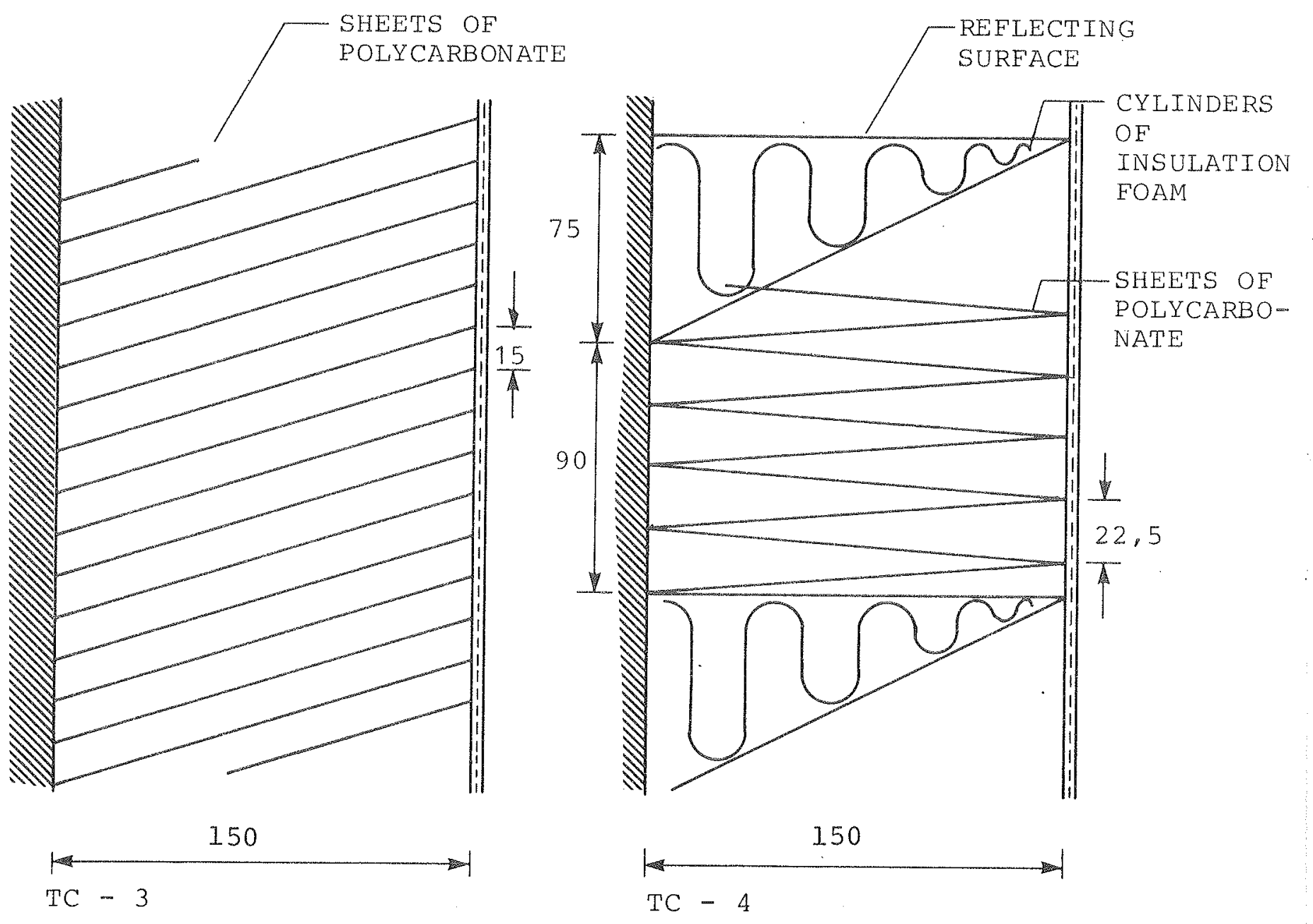

Fig. 2.4 Dimensions concerning the different solar collectors (measures in $\mathrm{mm}$ ) 


\section{Materials and construction of the col lectors}

Drawings of one of the solar collectors are shown on figures in appendix $B$. The construction of the other collectors is similar, except for the space between the absorber and the glazing. The collector $\mathrm{TC}-1$ appeared by simply removing the honeycombs from $\mathrm{TC}-2$.

The sides around the collector were made from chipboard which is a sufficient good material for indoor use.

The edge insulation of the collectors was made very effective in order to reduce the heat loss through this area as much as possible, and the heat loss to the bottom of the collector was almost eliminated by placing an electric heat foil between the bottom and the absorber within the insulation.

All the insulation in the collectors consisted of Rockwool and the conductivity (for practical use) was informed to be $0.039 \mathrm{~W} / \mathrm{m}^{2}{ }^{\circ} \mathrm{C}$ at $10^{\circ} \mathrm{C}$. The heat foil was made of thin metal strings laminated between two layers of polyester foil and in order to ensure an equal contribution of the heat between the strings an aluminium plate was placed underneath the foil. Before the measurements of the collectors in the solar simulator the temperature distribution over the area of the heating foil was measured and it was found to be quite uniform. During the measurements the heat foil was kept at about the same temperature as the absorber plate by help of a thermostate. that provided an on/off regulation of the power supply. The temperature of the heat foil was registrated by four $\mathrm{Pt}-100$ censors.

Between the edge insulation and the honeycombs was placed 10-20 mm of the soft quality of glasswool as mentioned in the 
previous section, and on the inside of the glasswool was plaw ced a reflective foil. The purpose of this foil is to reflect the solar radiation when the angle of incidence is not equal to zero degrees, and compensate for the shading effects.

The metal foil that was used consisted of a chromium-layer protected by two layers of transparent plastic and the reflective qualities were apparently good. Several kinds of refleco tive foils were investigated before the chromium foil was found. For an ordinary alumunium foil for housekeeping it was considered that, if used outdoors in a solar wall, the reflectance would be decreased because of corrosion of the thin unprotec ted layex of aluminium. For other products the metal layer was protected with plastic films but the reflectance of the visible light seemed to be too poor. Further, it is important that the reflecting layer is as thin as possible, so it does not contribute with an additional heat loss. It was calculated that for a typical aluminium foil with thickness $20 \cdot 10^{-3} \mathrm{~mm}$ the heat flow from the absorber to the glass through the foil would be about $50 \%$ bigger than the edge loss in case of the test collectors. For the chromium foil (thickness $3 \cdot 10^{-3} \mathrm{~mm}$ ) this ad= ditional heat loss would be less than $10 \%$ of the edge loss.

The absorber plate was a "Ro11 Bond" aluminum plate - it is shown on figure 2.5 .

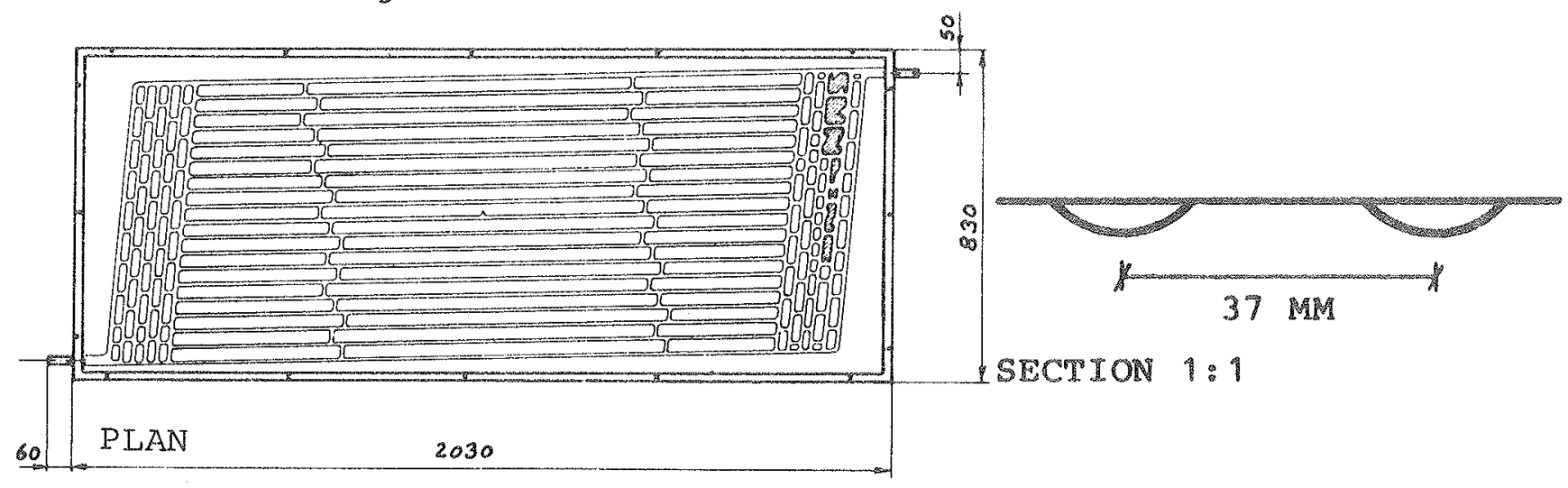

Figure 2.5. The absorber plate. 
This type of absorber provides a very good heat transfer to the fluid (the fin efficiency is close to one), and by that the temperature change along the fin between the channels could be ignored. The upper side of the absorber is plane. $i . e$. the channels could only be seen on the underside which was necessary regarding the tightness between the absorber and the honeycombs. On the other hand the absorber was not very straight along the edges, here and there some bulges could be noticed. By fastening the plate to a wooden frame by screws it was possible to get a good planeness all over the area. The frame was pressed by the edge insulation (a rather hard type of insulation) and in that way the absorber was kept in position. The frame is seen on figure 2.6 .

The absorbers were coated with a selective nickel foil. According to the manufacturer this coating has an absorption coefficient of about 0.97 for solar radiation, and the emissivity for long wave radiation was close to 0.10 . For TC-3 the emissivity was increased to about 0.23 due to the strips.

The cover consisted of ordinary window glass with the thickness of $4 \mathrm{~mm}$. The glass was layed on an elastic weather strip and the distance between the glass and the absorber was adjusted by help of 0 - 2 layers of a thin hard weather strip. The glass was kept in position by a wooden frame. The process of manufacturing the honeycombs is described earlier.

For TC-4 the triangular shaped cylinders were made from poIyurethan foam and covered with the reflecting chromium foil. The cylinders were fastened to the absorber plate by glue and the foil could be applied by help of an adhesive on the back.

On the next pages some pictures from the construction phase are shown. (Figure 2.6-2.11). 


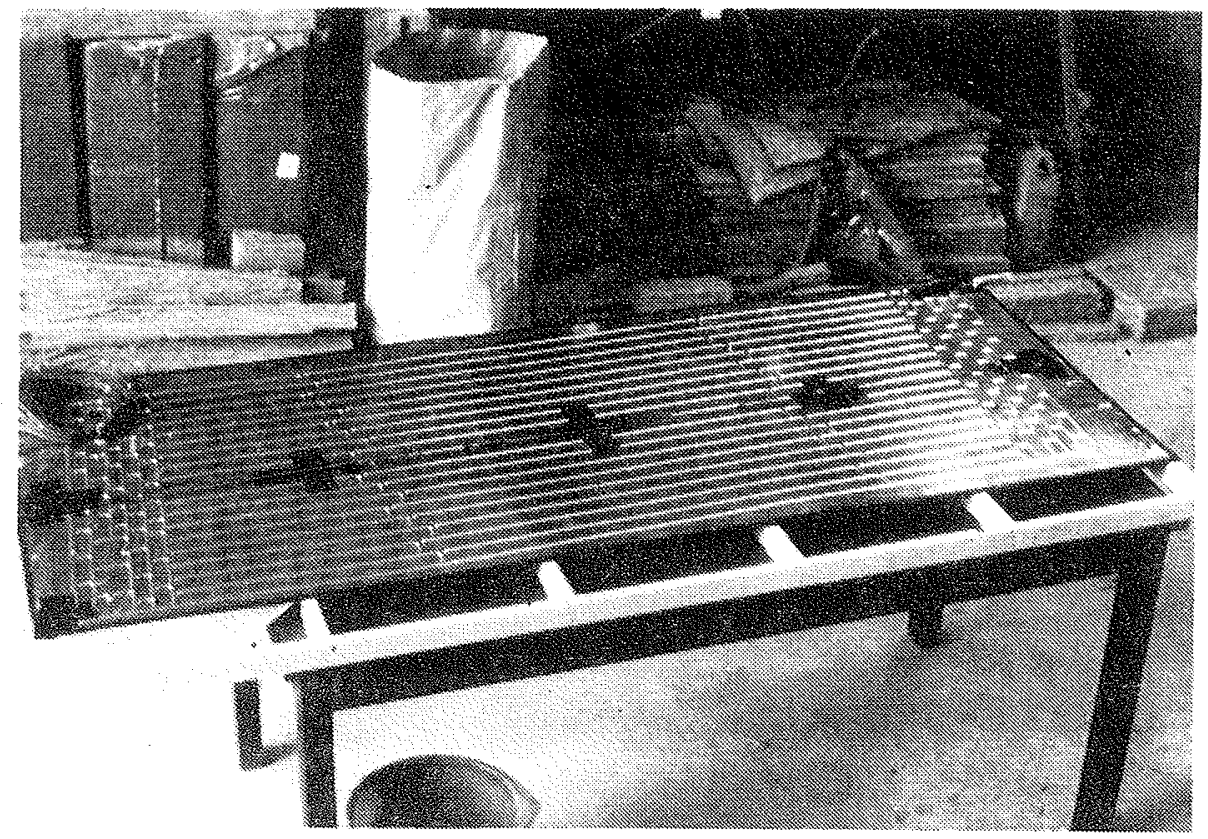

Fig. 2.6 One of the absorber plates. Thermoelements have been installed on the backside. The frame can be seen underneath the absorber plate.

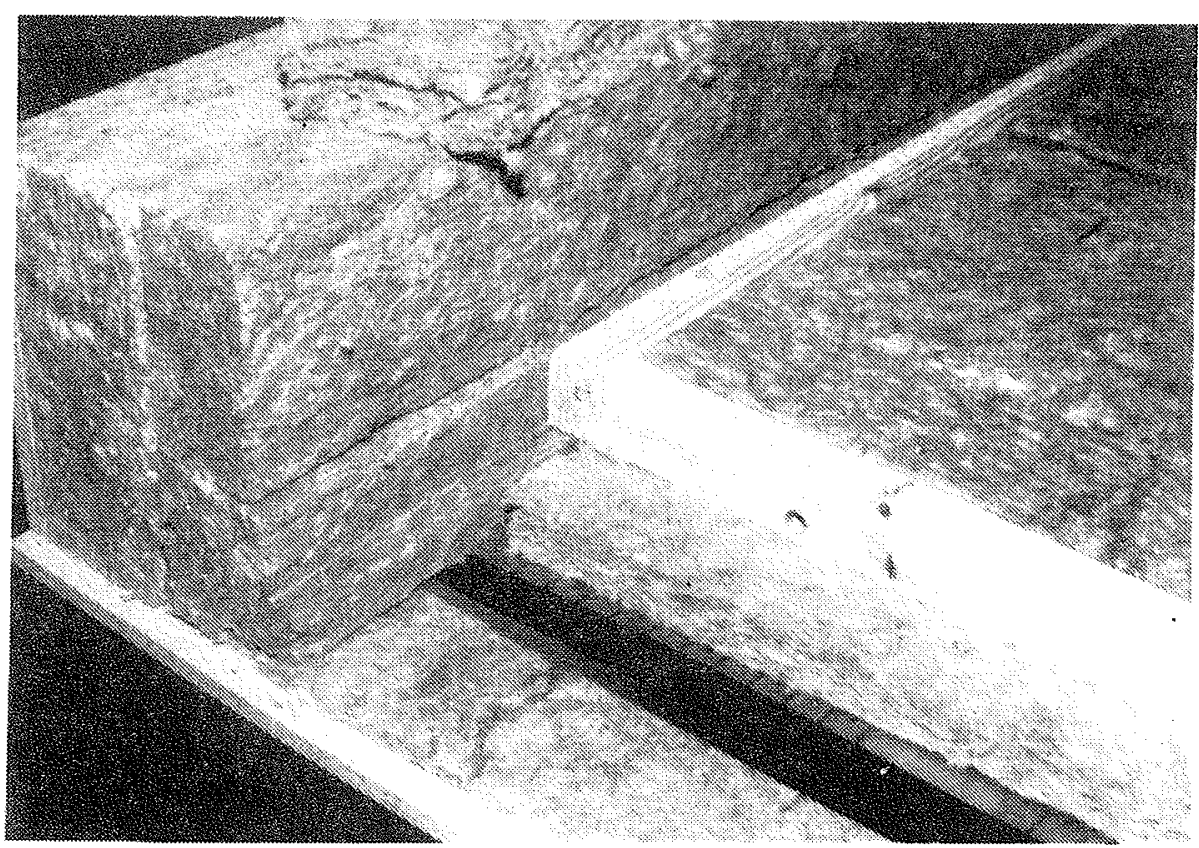

Fig. 2.7 The insulation of one of the solar collectors. A piece of the electric heat foil appears at the bottom. 


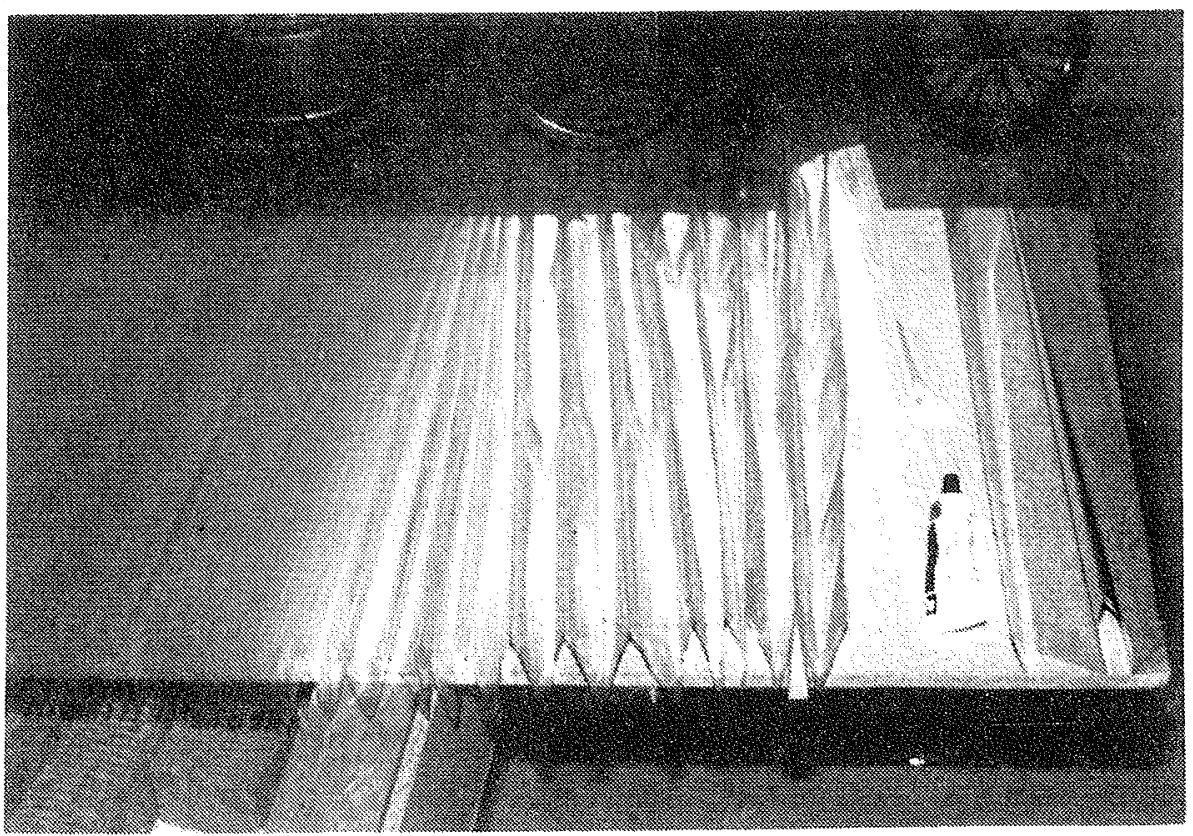

Fig. 2.8 Manufacturing of the honeycombs for TC-2. The bent plastic sheets are glued together.

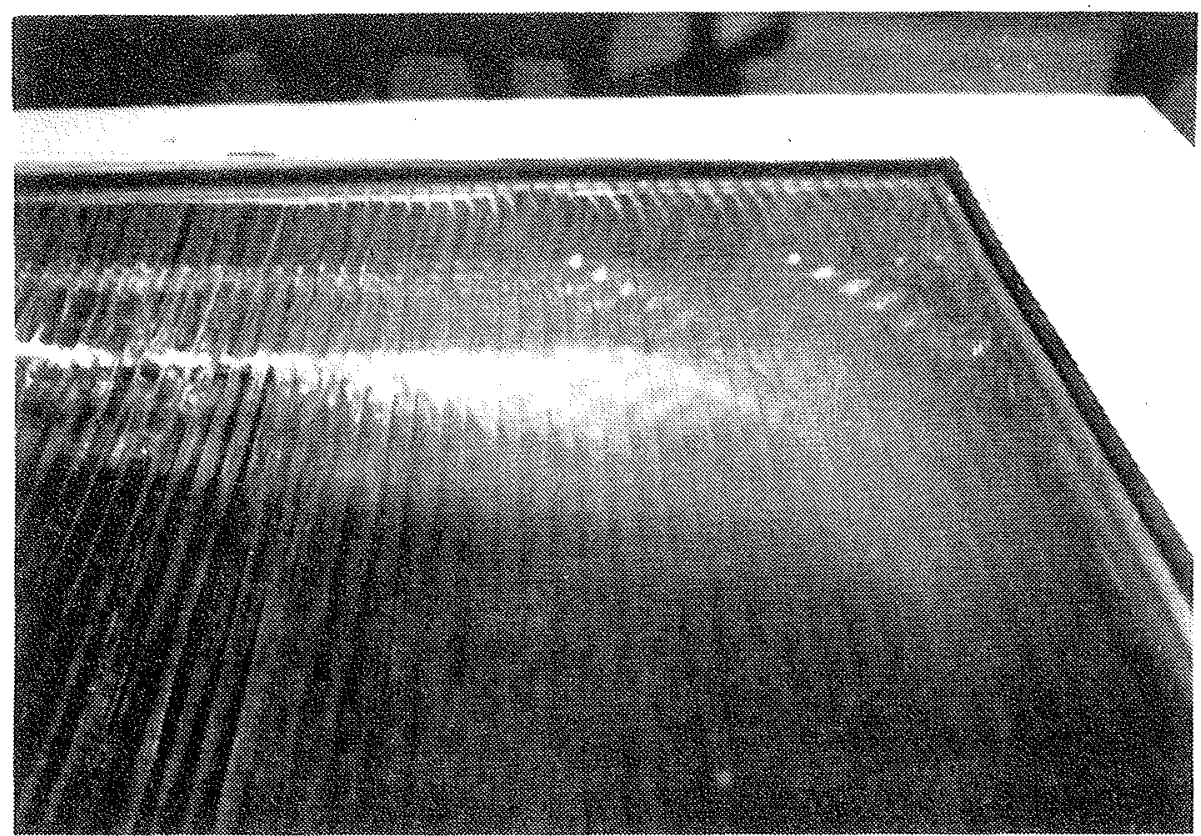

Fig. 2.9 The slatted honeycombs of $\mathrm{TC}-3$ have been fastened to the absorber. 


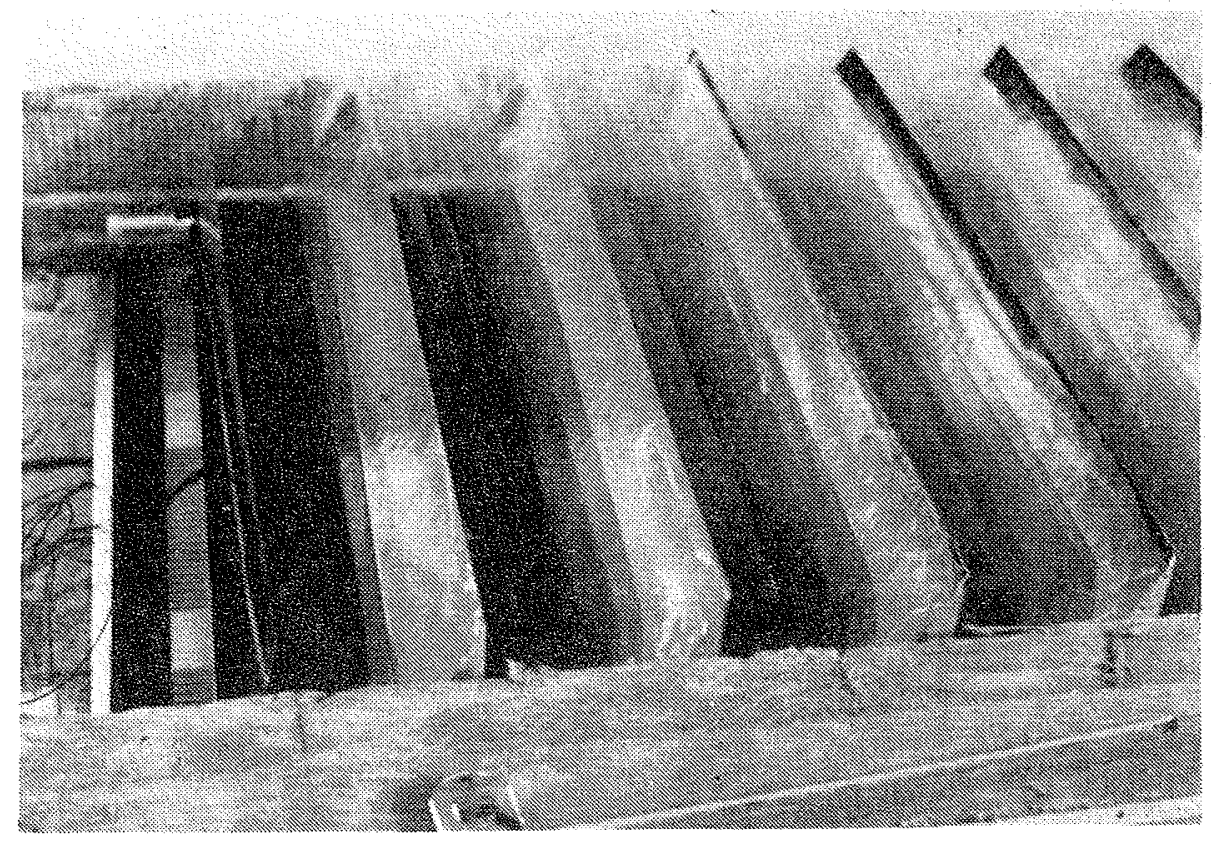

Fig. 2.10 From the construction of TC-4. The reflecting cylinders, the honeycombs, the edge insulation and the electric heat foil is noticed.

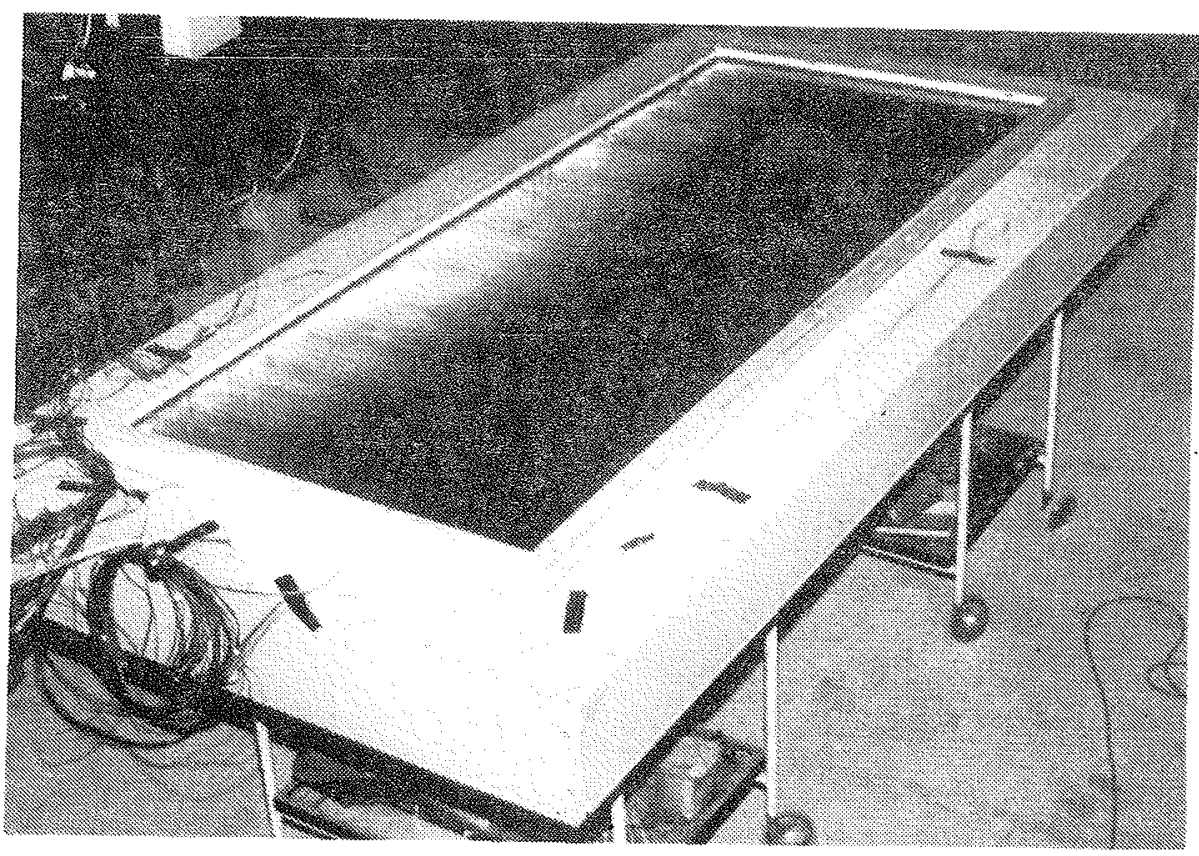

Fig. 2.11 One of the collectors $(\mathrm{TC}-2)$ is finished. 


\section{MEASUREMENTS OF THE SOLAR COLLECTORS}

The solar collectors described in the previous section were tested in order to determine the qualities of the honeycombs in relation to the transmission of solar radiation and the heat loss from the absorber through the honeycombs. For the 4 collectors the following measurements have generally been carried out.

a) The relation between the efficiency and the mean absorber temperature was investigated.

b) Determination of the solar transmittance at normal incidence and at an angle of incidence of $22.5^{\circ}$ from the normal. These angles represent the low angles of incidence during the winter.

c) The heat loss coefficient through the honeycombs under conditions with no sunshine was determined at different absorber temperatures.

\subsection{The Experiments}

The experimental set-up

The solar collectors were tested by use of an indoor solar simulator. The set-up is shown in fig. 3.1 and fig. 3.2 shows one of the collectors $(\mathrm{TC}-4)$ being tested.

The lamps of the solar simulator creates a radiant flux density of about $900 \mathrm{~W} / \mathrm{m}^{2}$ at the stand where the collector is mounted. Before the efficiency at a new absorber temperature is measured, the total irradiance on the plane of the collector is scanned by a pyranometer (EPPLEY PSP). A mean value of the radiation on different locations of the area is measured.

Aix with a velocity of about $5 \mathrm{~m} / \mathrm{s}$ was ventilated along the outer surface of the glass in order to include the effect of the wind. 


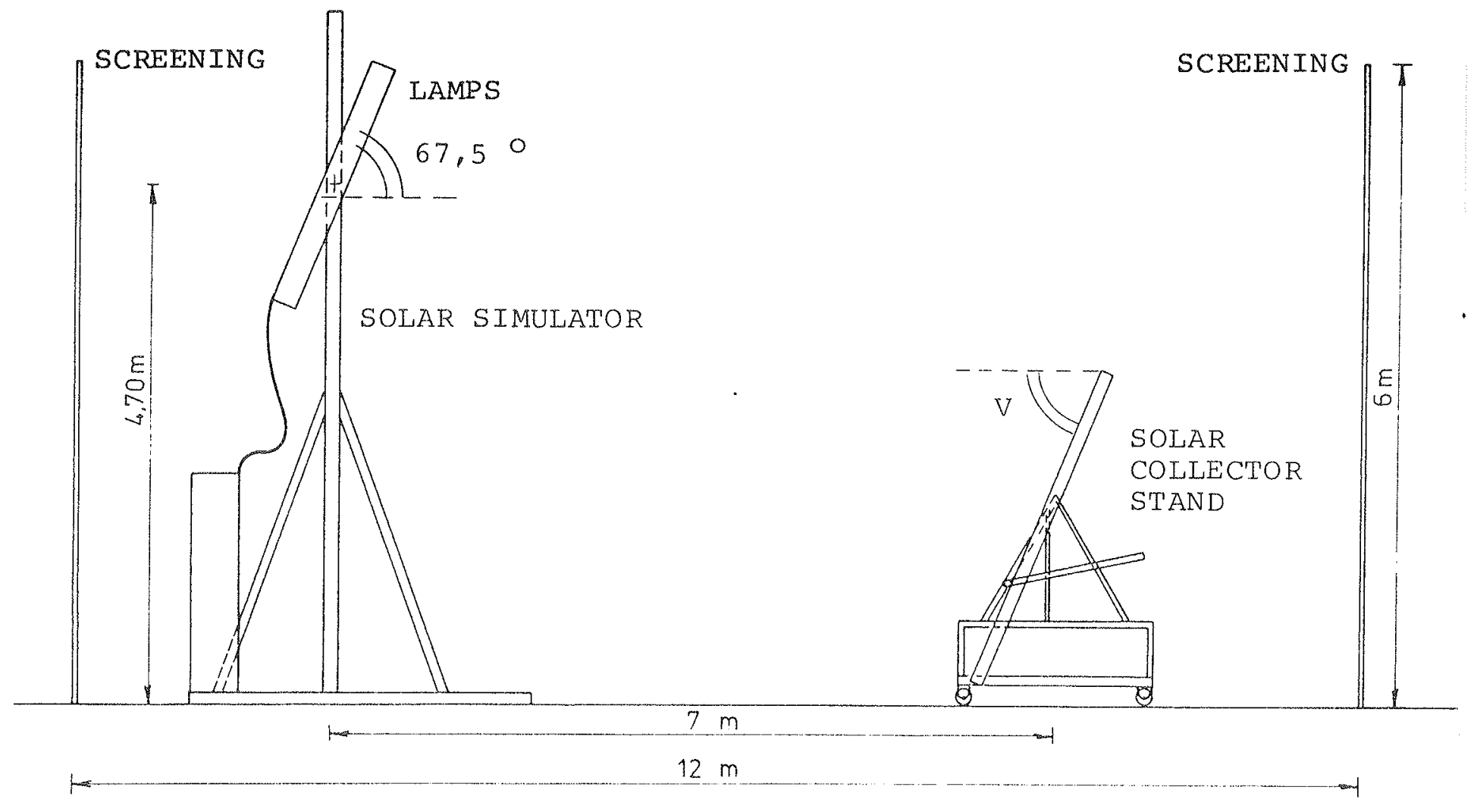

Fig. 3.1 Elevation of the setup.
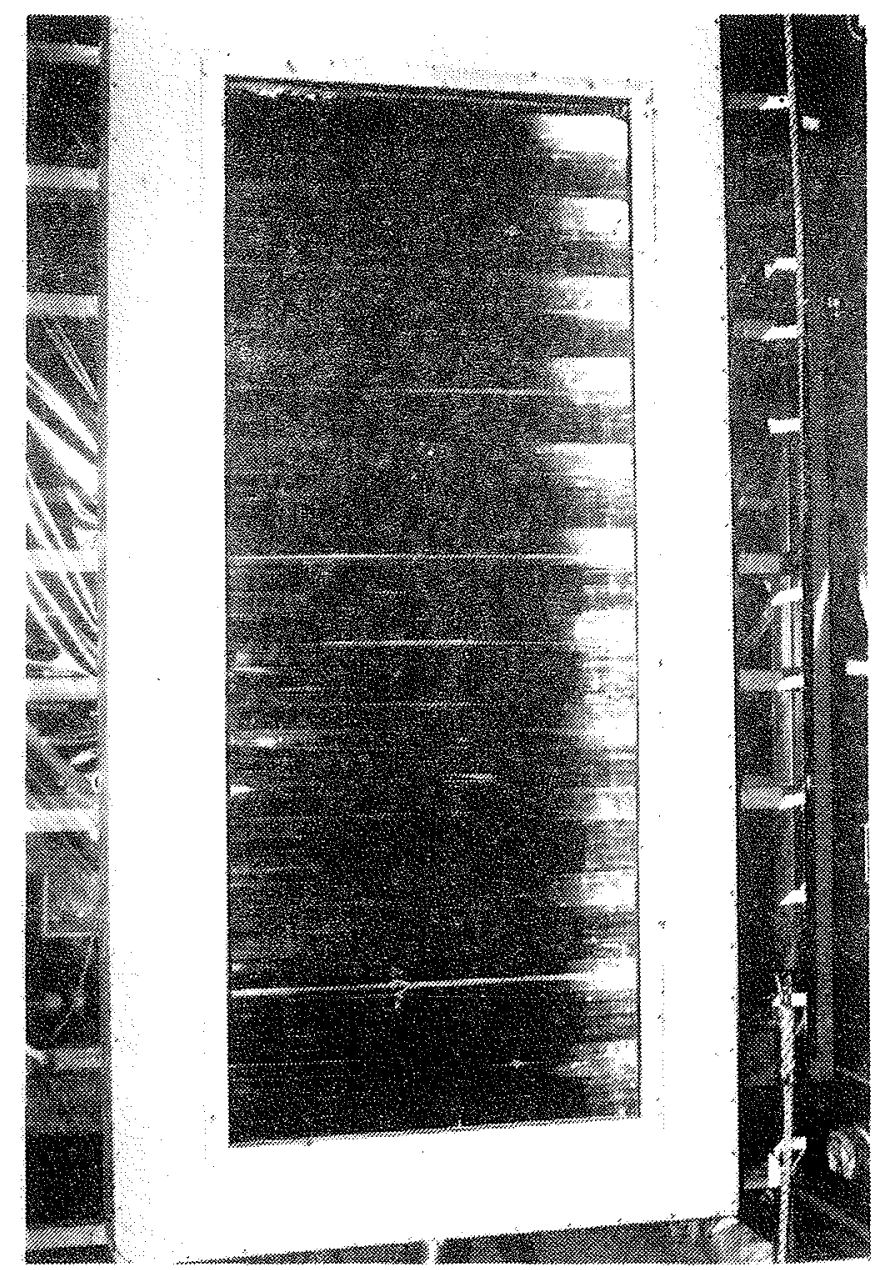

Fig. 3.2

The testing of one of the solar collectors. 
The absorber plate was cooled by a mixture of propyleneglycol and water. The flow of the collector fluid was registrated by a volume flow meter (AQUA METRO VZFM20) and the difference between the inlet and outlet temperature was measured by thermopiles (with 5 thermocouples in each thermopile).

The various temperatures were determined by thermocouples (Cu-const.) and the general position of the thermo elements on the absorber plate is shown in fig. 3.3 .

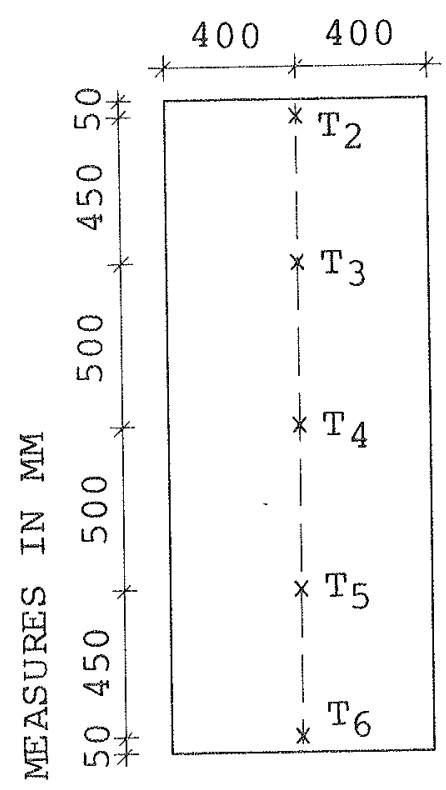

Fig. 3.3 The position of the thermoelements on the absorber plate.

Estimation of the efficiency, the solar transmittance and the heat loss coefficient

The values of temperatures and flow are registrated every minute by a scanner and they are printed out currently by use of a computer. A further description of the system (HEWLETT PACKARD) is given in (2).

The results are listed in tables in appendix $C$. At the different temperatures the results are taken as a series of 4 continuous scans from a period where the situation has become stationaxy. 
The efficiency is calculated from the expressions:

$$
n=\frac{q_{u}}{G_{m}}, \quad q_{u}=q+q_{s}+q_{b}
$$

The heat loss coefficient is calculated Erom:

$$
U=\frac{q_{t}}{\left(T_{p m}-T_{a}\right)}, \quad q_{t}=q-q_{s}-q_{b}
$$

where

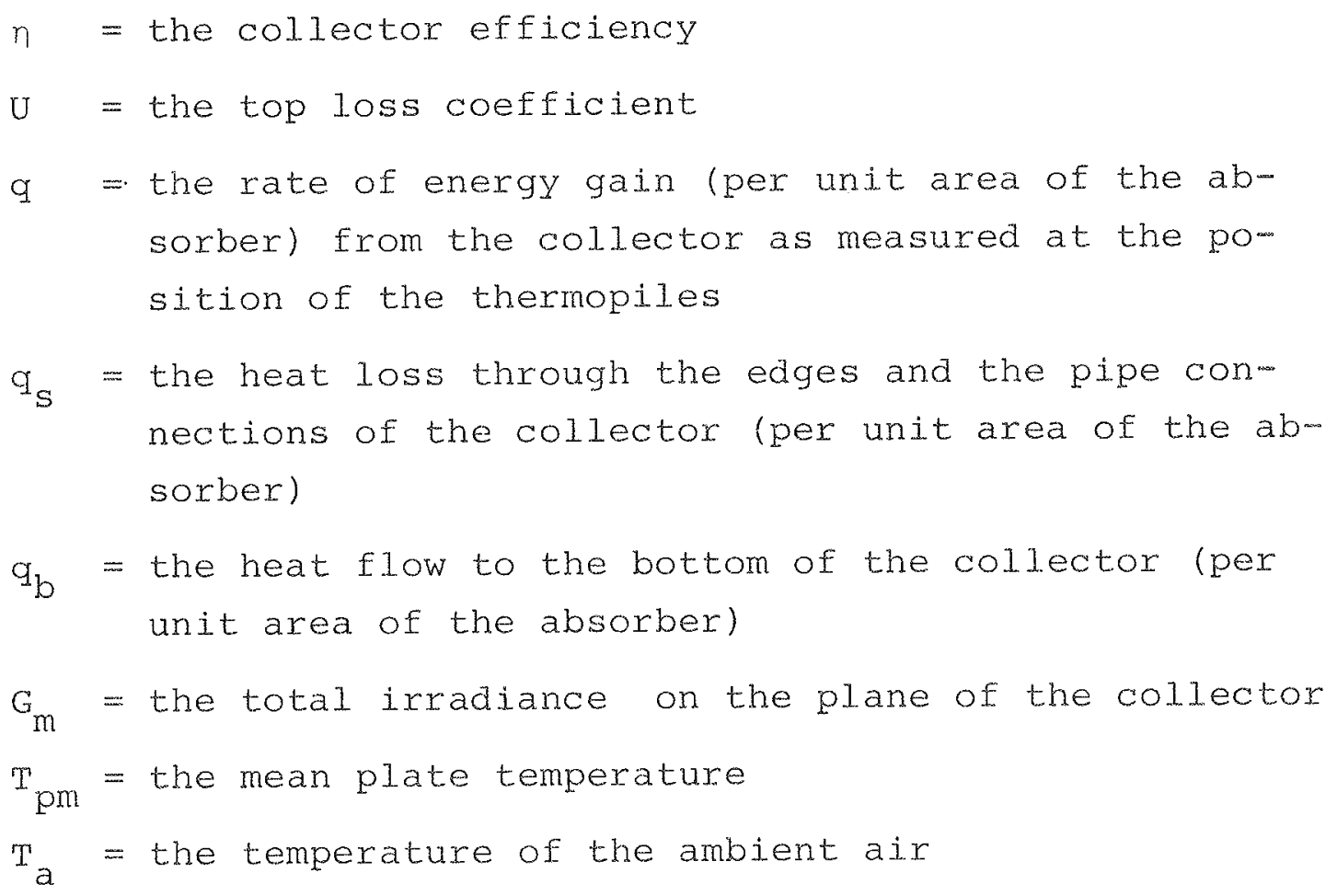

The rate of energy gain is found from the expression:

$$
q=\frac{\dot{m}}{\bar{A}} \cdot C_{p} \cdot \Delta T
$$

where

$\dot{m}=$ the mass flow rate through the collector

A = the absorber area

$\mathrm{C}_{\mathrm{p}}=$ the specific heat of the fluid

$\Delta \mathrm{T}=$ the temperature difference between the inlet and outlet 
The correction terms $q_{s}$ and $q_{b}$ are found from:

$$
\begin{aligned}
& q_{s}=K_{s} \cdot\left(T_{p m}-T_{a}\right) \\
& q_{b}=K_{b} \cdot\left(T_{p m}-T_{1}\right)
\end{aligned}
$$

where

the heat loss coefficients $K_{S}$ and $K_{b}$ are explained in appendix $\mathrm{C}$.

$\mathrm{T}_{I}=$ the temperature of the heat foil

The transmittance-absorptance product was determined from the efficiency test at $\mathrm{T}_{\mathrm{pm}}=\mathrm{T}_{\mathrm{a}}$. At this temperature the heat loss is only by reflection and absorptance in the glass and the honeycombs.

The progress of the measurements

The test programs for the different collectors are shown in the scheme on the following page.

The angle $V$ between the collector and the horizontal was $67,5^{\circ}$ (corresponding to normal incidence of solar radiation) at the efficiency tests of $\mathrm{TC}-1$ and $\mathrm{TC}-2$. Later, when testing $\mathrm{TC}-3$ and $\mathrm{TC}-4$, it was found more convenient to test the efficiency at $V=90^{\circ}$ as this position represents a more realistic situation regarding the heat loss through the glass.

Special circumstances for the collectors are mentioned in the following:

TC-1. (wihout honeycombs)

This collector was used as a reference and only a few tests were made for comparison.

TC-2 (with V-corrugated honeycombs)

After the ordinary program the glass was lifted $5 \mathrm{~mm}$ in order to investigate whether the untightness had influence on the heat loss coefficient. In this situation the heat 


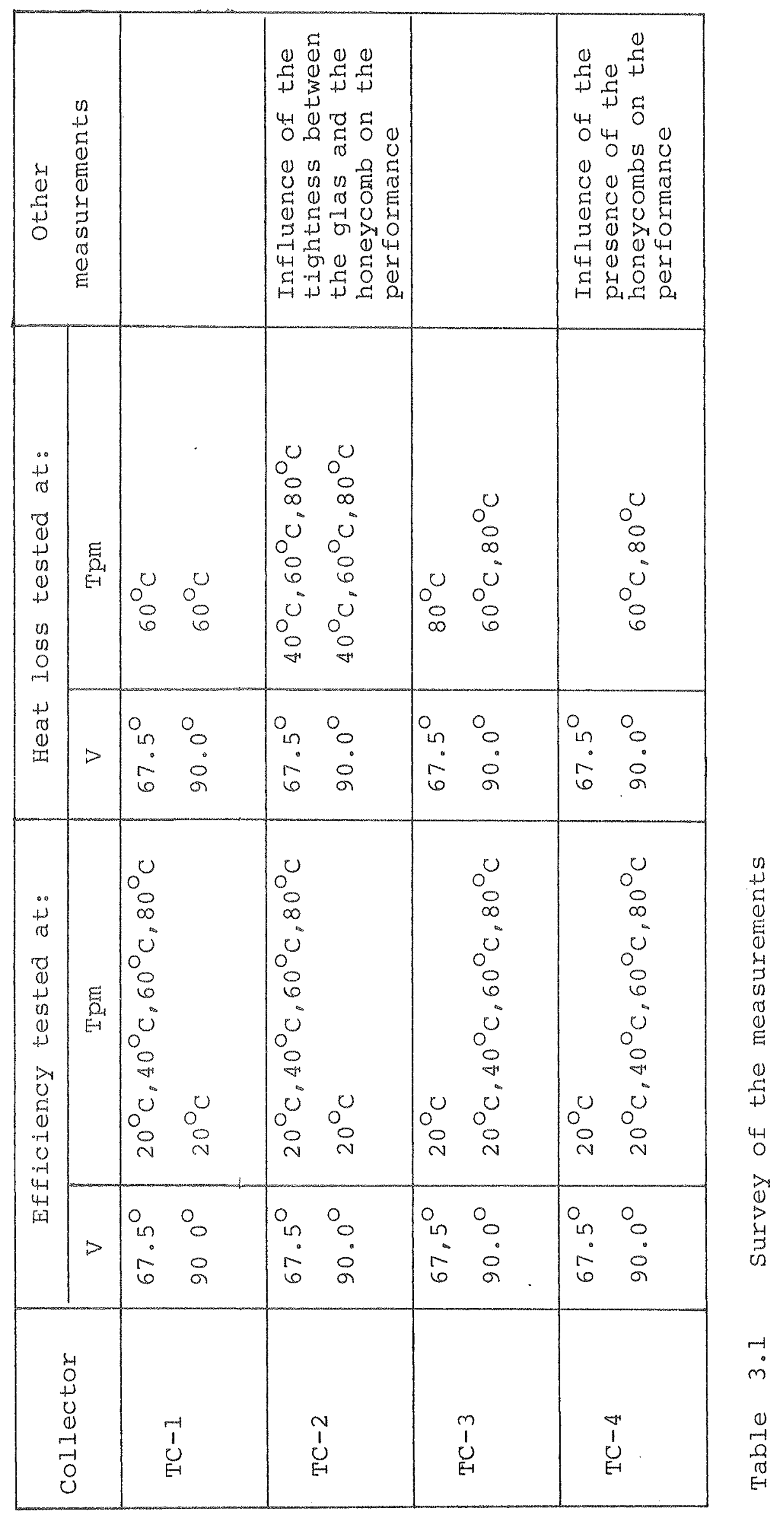


loss was measured at $\mathrm{V}=90^{\circ}$ and $\mathrm{T}_{\mathrm{pm}}=60^{\circ} \mathrm{C}, 80^{\circ} \mathrm{C}$.

At the end of the measurements (before the above mentioned test) it was discovered that the connection of the pipe to the absorber was not tight. It was necessary to remove the collector, disassemble it and replace the humid insulation. The collector was mounted again and the test was repeated. The results showed close agreement with the previous results.

TC-3 (with slatted honeycombs)

The test went according to the plan.

TC-4 (with reflecting cylinders)

In order to investigate how the principle with the reflectors were working without the honeycombs, these were removed and the heat loss coefficient was measured at $\mathrm{V}=90^{\circ}$ and $\mathrm{T}_{\mathrm{pm}}=60^{\circ} \mathrm{C}, 80^{\circ} \mathrm{C}$.

The uncertainty of the measurement of the heat loss coefficient was considered to be too large at a mean plate temperature of $\mathrm{T}_{\mathrm{pm}}=40^{\circ} \mathrm{C}$. This is the reason why this value is measured for only one of the collectors ( $\mathrm{TC}-2$ ). Considerations about the uncertainty are given in appendix D.

\subsection{Discussion of the Results from the Indoor Measurements} The collector efficiency

The measured values of the collector efficiency are plotted in figs. 3.4 and 3.5 . In the figures are also shown the distance between the honeycombs $a$ the distance between the glass and the absorber $l$, and the angle between collector and the horizontal $V$. The efficiency dependence on the difference between the absorber temperature and the ambient air temperature seems to be quite 1inear, and the curves are therefore drawn as straight lines. By that the 

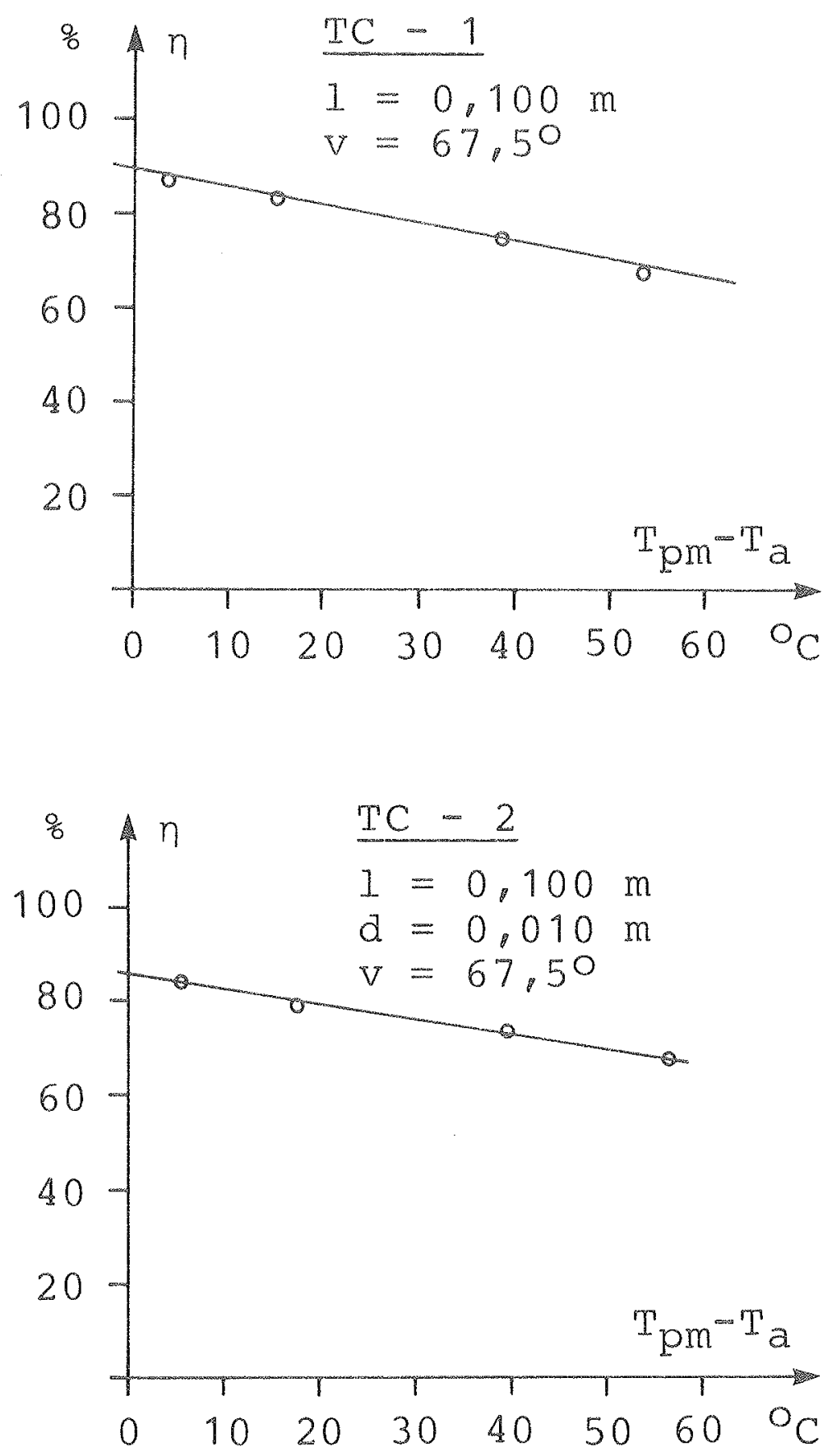

Fig. 3.4 The collector efficiency $n$ as a function of the difference between the absorber temperature and the ambient air temperature. TC-1 is the test collector without honeycombs. TC-2 is the collector with with the V-corrugated honeycomb. 

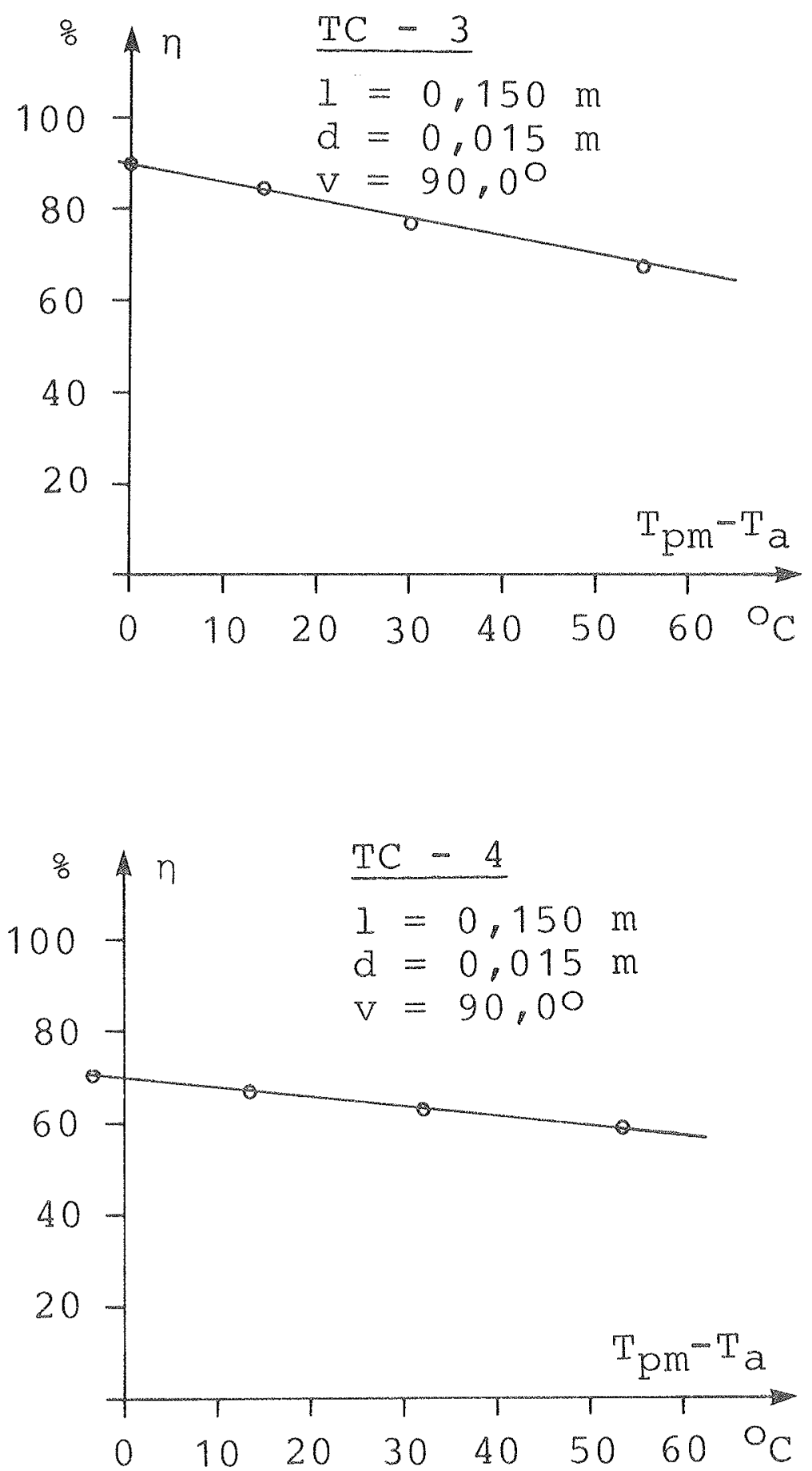

Fig. 3.5 The collector efficiency $n$ as a function of the difference between the absorber temperature and the ambient air temperature. $\mathrm{TC}-3$ is the test collector with the slatted honeycombs. TC -4 is the collector with the reflecting cylinders. 
heat loss coefficient is regarded as if it was constant, though it should increase with increasing temperature difference. The influence of this variation of the heat loss coefficient on the course of the curves is probably disguised due to the uncertainty of the measurements.

As mentioned earliex, the value of $V$ is $67.5^{\circ}$ for the collectors $\mathrm{TC}-1$ (without honeycombs) and $\mathrm{TC}-2$ (with $\mathrm{V}$ corrugated honeycombs), while it is $90.0^{\circ}$ for $\mathrm{TC}-3$ (with the slatted honeycombs) and $\mathrm{TC}-4$ (with the reflecting cylinders). In order to compare the four efficiency curves, the consequences of the deviation of $V$ was considered in relation to the theoretical equation of the curves:

$$
\eta=(\tau \alpha) e^{-\left(T_{p m}-T_{a}\right) \cdot U / G_{m}}
$$

where

$$
\begin{aligned}
& =\text { the efficiency } \\
(\tau \alpha) \mathrm{e}= & \text { the effective transmittance - arsorptance } \\
& \text { product } \\
\mathrm{T}_{\mathrm{pm}}= & \text { the mean absorber temperature } \\
\mathrm{T}_{\mathrm{a}}= & \text { the ambient temperature } \\
\mathrm{U}= & \text { the heat loss coefficient } \\
\mathrm{G}_{\mathrm{m}}= & \text { the total irradiance on the plane of the } \\
& \text { collector }
\end{aligned}
$$

It was found that the decrease of the slope of the curves. due to the lower value of $U$ when altering $V$ from $67.5^{\circ}$ to $90^{\circ}$, was to a high degree compensated by the influence of the smaller value of $\mathrm{G}_{\mathrm{m}}$. From theoretical consideration it is known that for $\mathrm{TC}-1 \quad(\tau \alpha)$ will be approximately the same at the two angles, and for $\mathrm{TC}-2$ the measurements show that $(\tau \alpha)_{e}$ is close in the two cases. By this it is concluded that with deviations which are minor than the uncertainty of the measurements $(3-4 \%)$ all of the curves practically represent the collector efficiency under the conditions 


\section{THE OUTDOOR MEASUREMENTS}

The outdoor measurements were carried out in a test house located at the Laboratory's test campus. A thermal storage wall with the V-corrugated, shaped honeycombs was compared with a thermal storage wall with only an airspace between the absorber and the glass. Both solar walls were equipped with one layer of glass and a selective absorbex. The measurements took place in the period from February 25 to May 1, 1983.

4. I Description of the Test House and the Thermal Storage Walls

The test house

The plan of the house is shown in fig. 4.1 and Eig. 4.2 shows a picture of the facade facing south.

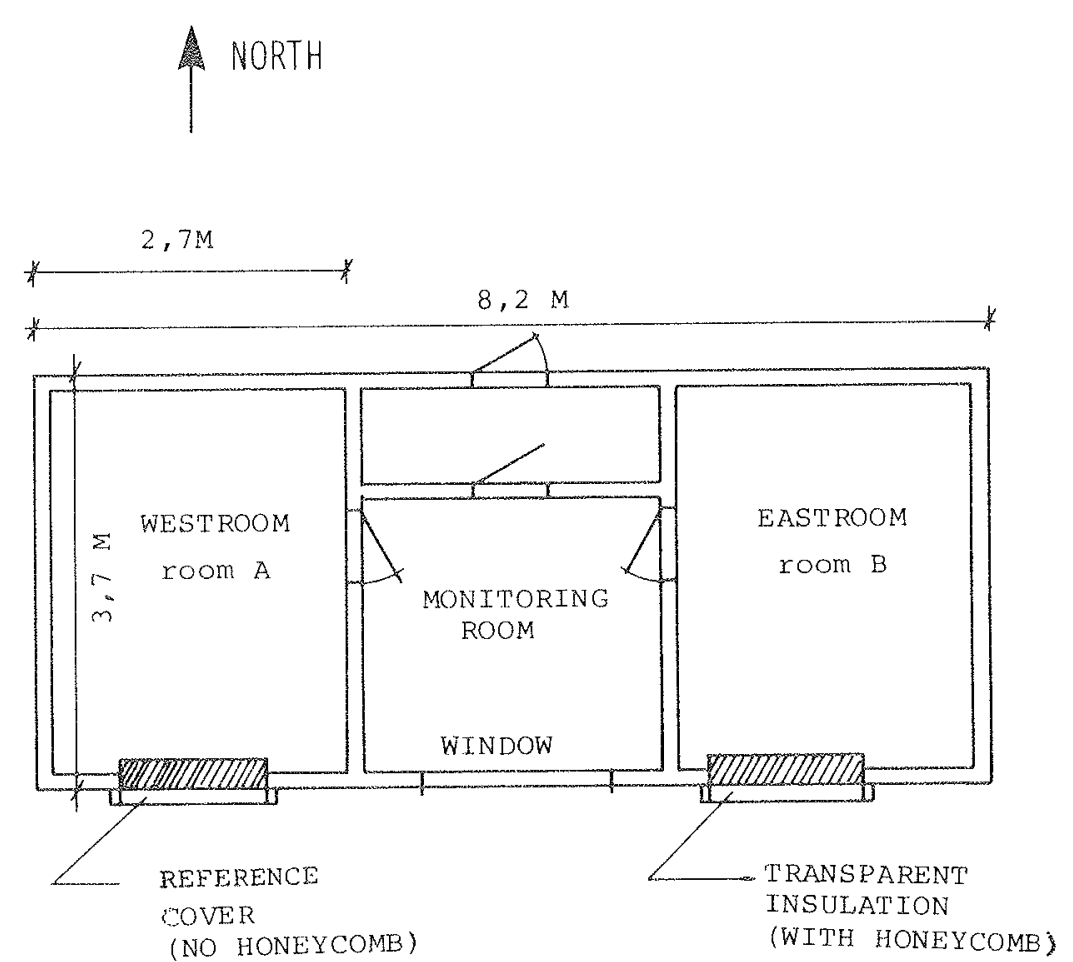

Fig. 4.1 plan of the testhouse. 


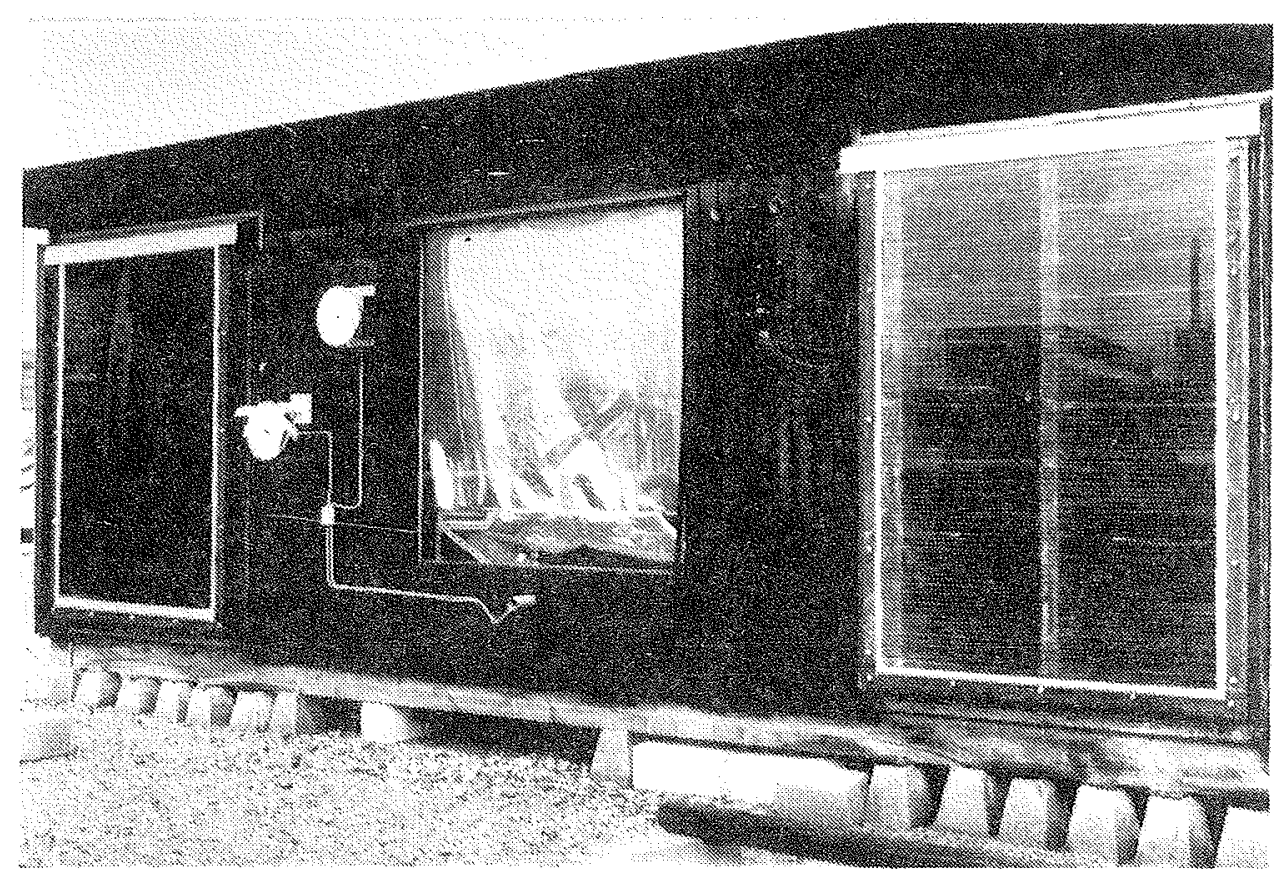

Figure 4.2 The southern front of the test house with the two thermal storage walls.

The house contains two identical test cells and between them is a room for measuring equipment and a porch. The house is constructed from wooden beams and laths. The outer walls, the floor and the ceilings of the rooms are insulated with $100 \mathrm{~mm}$ mineral wool. The inner surfaces (apart from the thermal storage walls) consist of plywood sheets on the walls, gypsum plates in the ceiling and chipboard on the floor. The floorspace of the two test cells is $10 \mathrm{~m}^{2}$. Auxiliary heat was supplied by thermostatic controlled electric panels ensuring that the room temperatures did not go below approx. $20^{\circ} \mathrm{C}$.

The construction of the thermal storage walls

A vertical section of the thermal storage walls is shown in fig. 4.3 .

The thermal mass of the solar walls has a thickness of $0.228 \mathrm{~m}$ and it consists of sand-lime bricks with the below mentioned characteristics: 


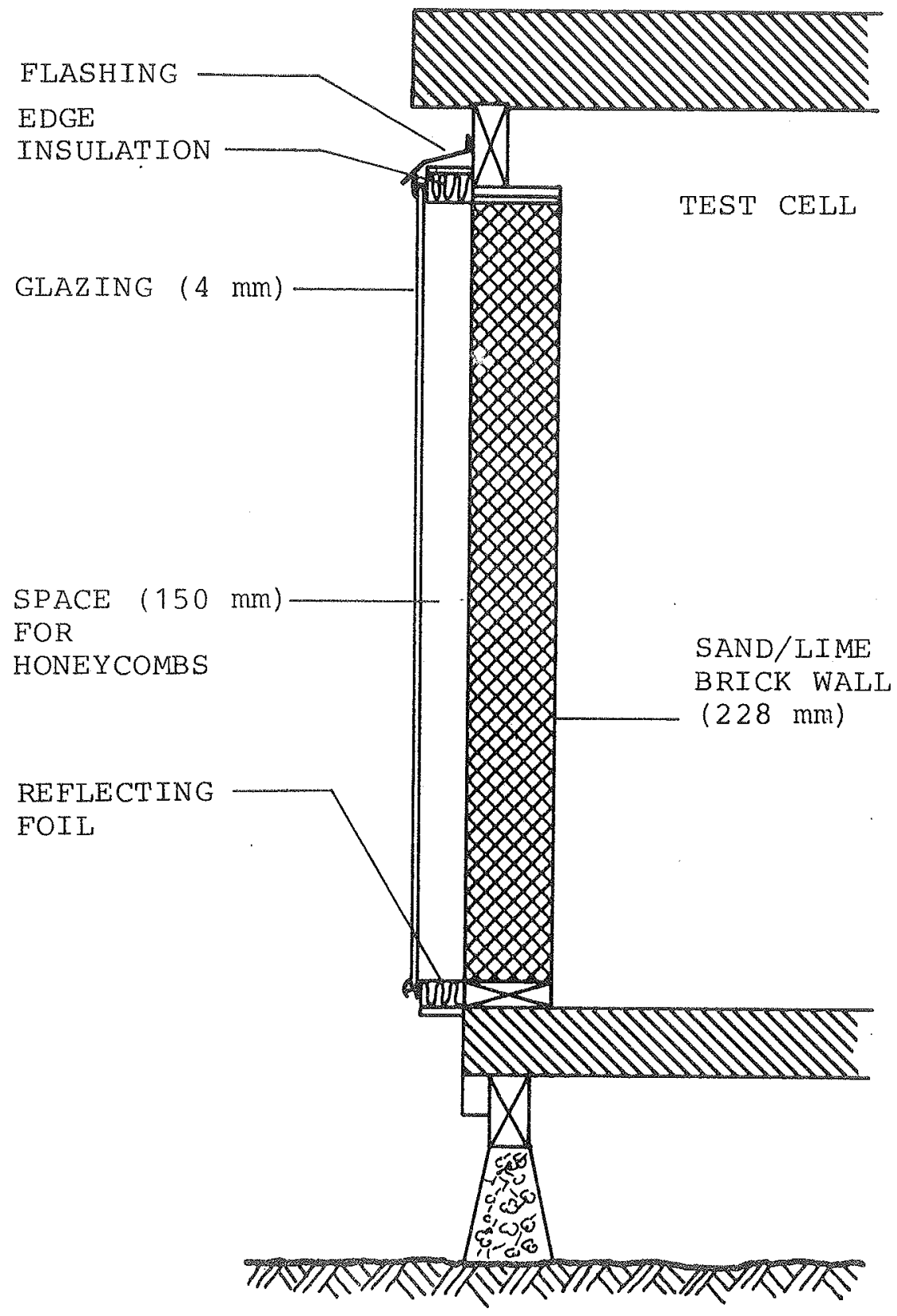

Fig. 4.3 Section of one of the thermal storage walls. 


$$
\begin{array}{ll}
\text { Thermal conductivity } & \mathrm{k}=0.95 \mathrm{~W} / \mathrm{m}^{\circ} \mathrm{C} \\
\text { Density } & \rho=1.8 \cdot 10^{3} \mathrm{~kg} / \mathrm{m}^{3} \\
\text { Specific heat } & \mathrm{C}_{\mathrm{p}}=0.8 \cdot 10^{3} \mathrm{~J} / \mathrm{kg}{ }^{\circ} \mathrm{C}
\end{array}
$$

The glazing area and the absorber area of each of the walls are $2.76 \mathrm{~m}^{2}$ and the walls are facing directly south.

Like in the testing of the solar collectors selective foil with an absorption coefficient of $\alpha_{s}=0.97$ and an emissivity for longwave radiation of $\varepsilon_{t}=0.10$, was used. Before the foil was placed, an adhesive was applied to the walls to ensure a good contact to the porous walls, as the existing adhesive on the back of the foil was found to be insufficient.

The edge insulation consisted of glass wool of a hard quality, covered with pieces of plywood, see fig. 4.4. Fig. 4.5 shows how the insulation is being fastened to the laths of the house by use of tap bolts.

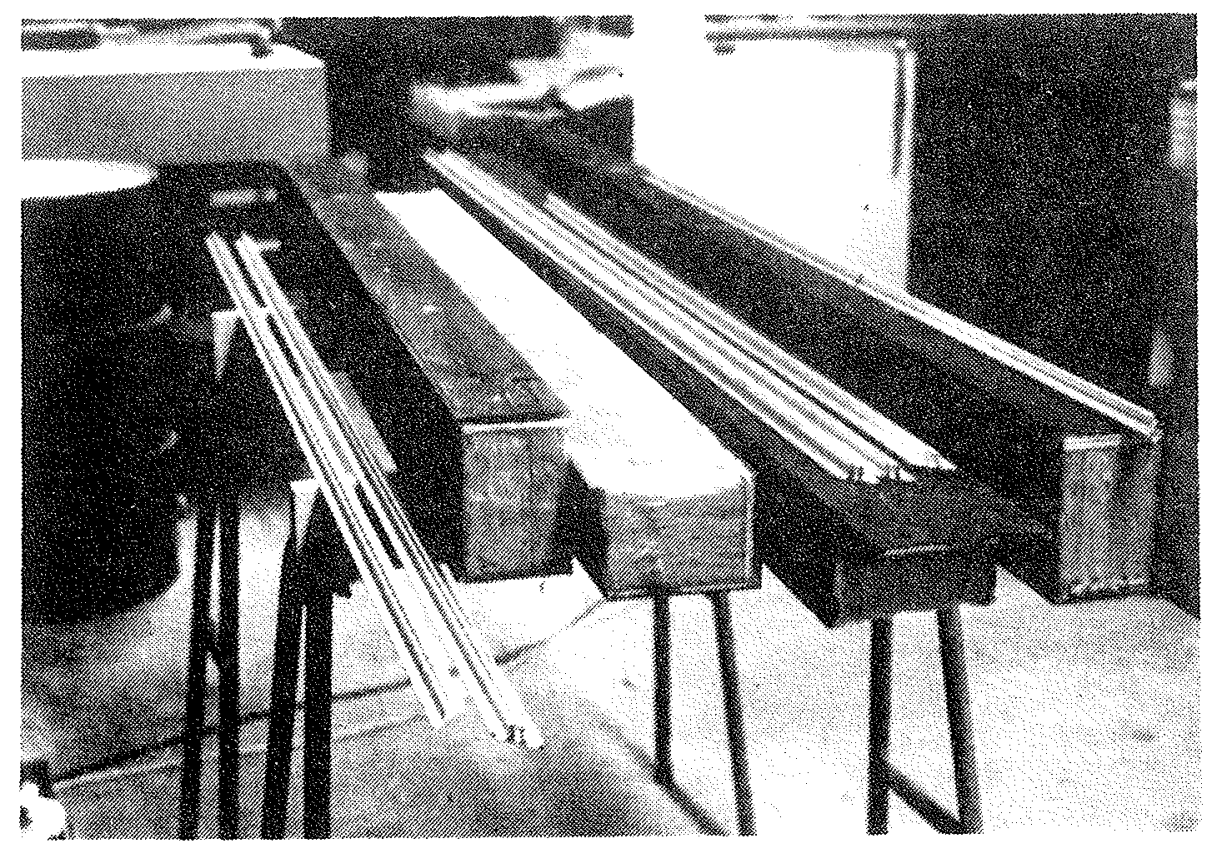

Figure 4.4 The edge insulation and aluminium lists for the glazing. 


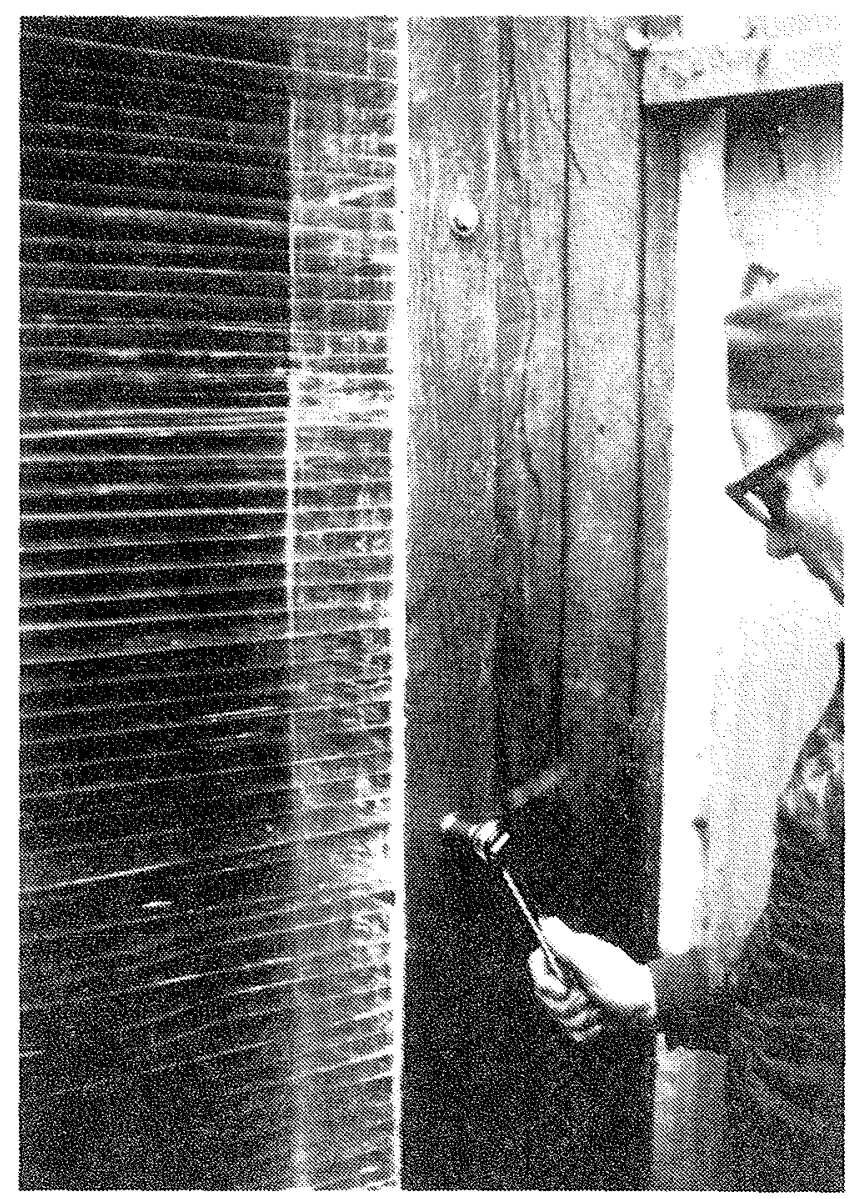

Figure 4.5

The edge insulation is mounted for the solar wall with the honeycombs.

Like in the solar collectors, soft glass wool and reflecting foil was used between the honeycombs and the edge insulation. (The glass wool can absorb temperature movements and the foil will reflect solar radiation in case of the angle of incidence being different from zero).

The manufacturing of the honeycombs for the outdoor experiments

The distance between the honeycombs (measured in the middle between the glass and the absorber) was $0.011 \mathrm{~m}$ and the distance between the glass and the absorber was $0.150 \mathrm{~m}$.

When forming the plastic into the V-corrugated honeycomb, a new technique was employed. Instead of bending and gluing together the complete sheets of polycarbonate, they were 
cut into pieces in the size of a single honeycomb wall and then glued together along the edges. By using this method, the consumption of time was somewhat shorter and the geometry of the finished honeycombs turned out to be slightly more regular.

In the process a special pattern was made from triangularshaped pieces of wood as shown in fig. 4.6 .

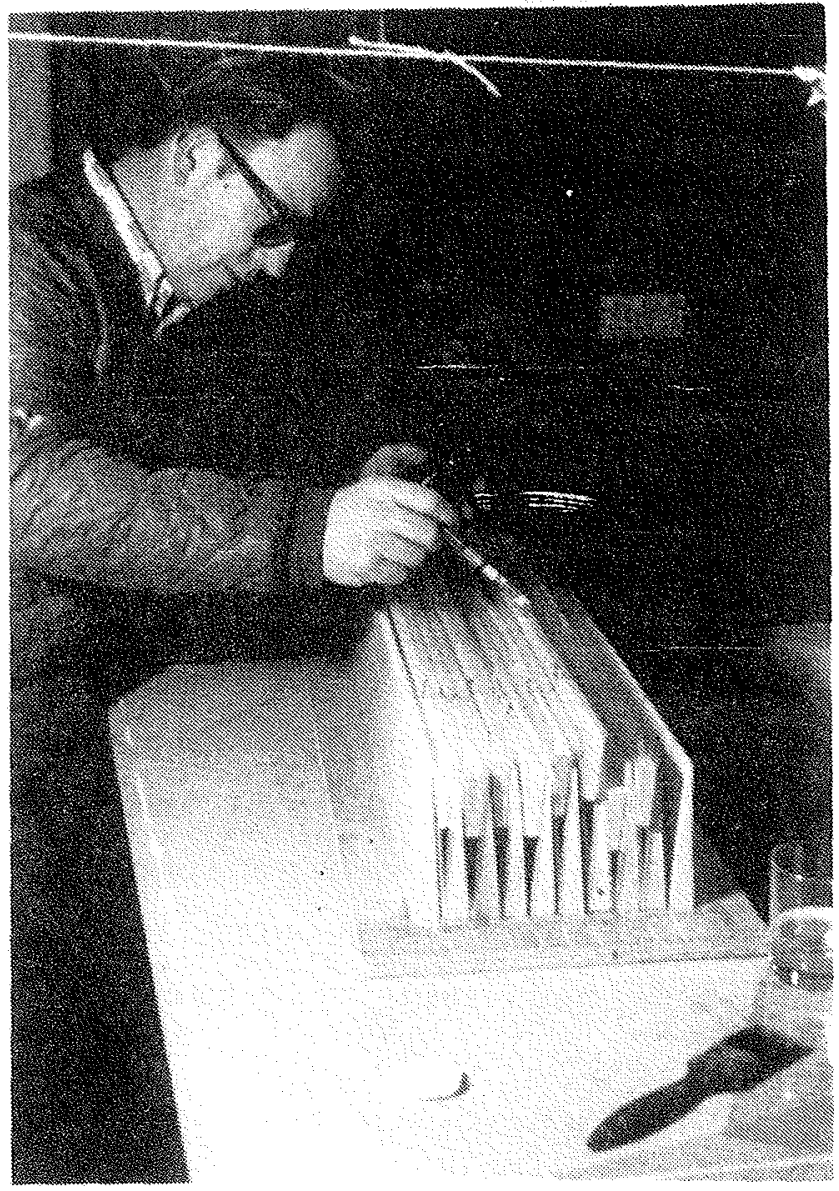

Fig. 4.6

Manufacturing of the honeycombs for the outdoor experiments.

After the pieces of plastic were placed in the pattern, they were glued together lengthwise and then fixed at the two ends by gluing pieces of polycarbonate perpendicular on to the honeycombs. The glue used for this pur pose contained a solvent to the polycarbonate, and the binding power was rather strong. Finally, two sections of honeycombs, $1970 \times 700 \times 150 \mathrm{~mm}$, were finished. They were fastened at the top to a piece of wood which could be 
screwed to the wall plate of the house. This way the weight of the honeycombs was absorbed as tension in the vertical pieces of plastic at the edges and transferred to the construction of the house. In fig. 4.7 is shown a part of one of the honeycomb sections.

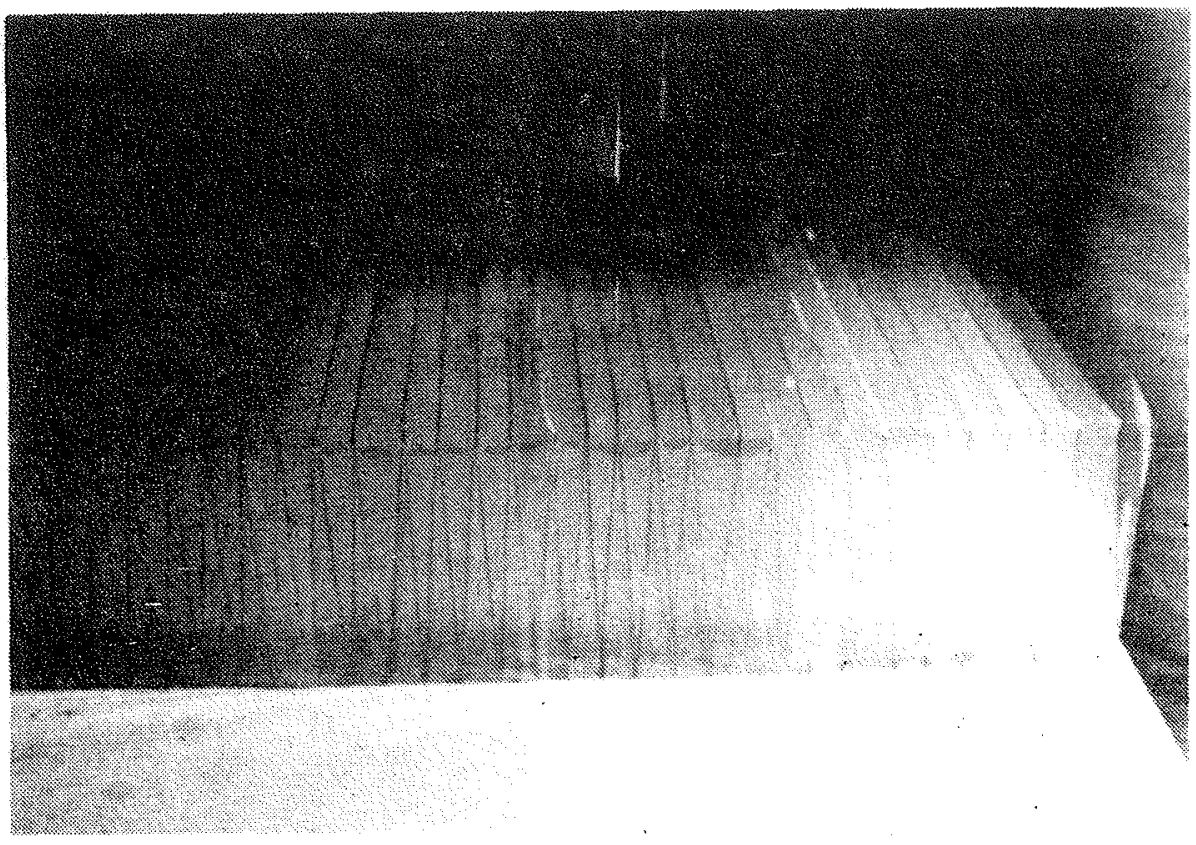

Figure 4.7 The honeycombs for the thermal storage wall.

In figs. 4.8 and 4.9 the finished thermal storage walls are shown.

The measuring equipment

The recording of the measurements was carried out by use of a datalogger (SOLARTRON COMPACT LOGGER 3430) and the channels were scanned every half hour. The different voltages were recorded on cassette tape which was changed every week for further treatment at the computer center at The Technical University.

The datalogger was supported by an instrument for counting pulses in connection with measurement of the consumption of electric heat, and an integrator (EASTER-LINE ANGUS) 
to integrate the signals from the pyranometers. Both the total and the diffuse solar radiation on the vertical plane was measured.

Some of the most important temperatures were also registered by a multipoint recorder (PHILIPS PM 8236). This was done in order to get an immediate picture of the progress of the measurements and to be informed in case of the datalogger being disarranged.

A further description of the measuring equipment and a list of placement of the sensors is given in appendix $E$.

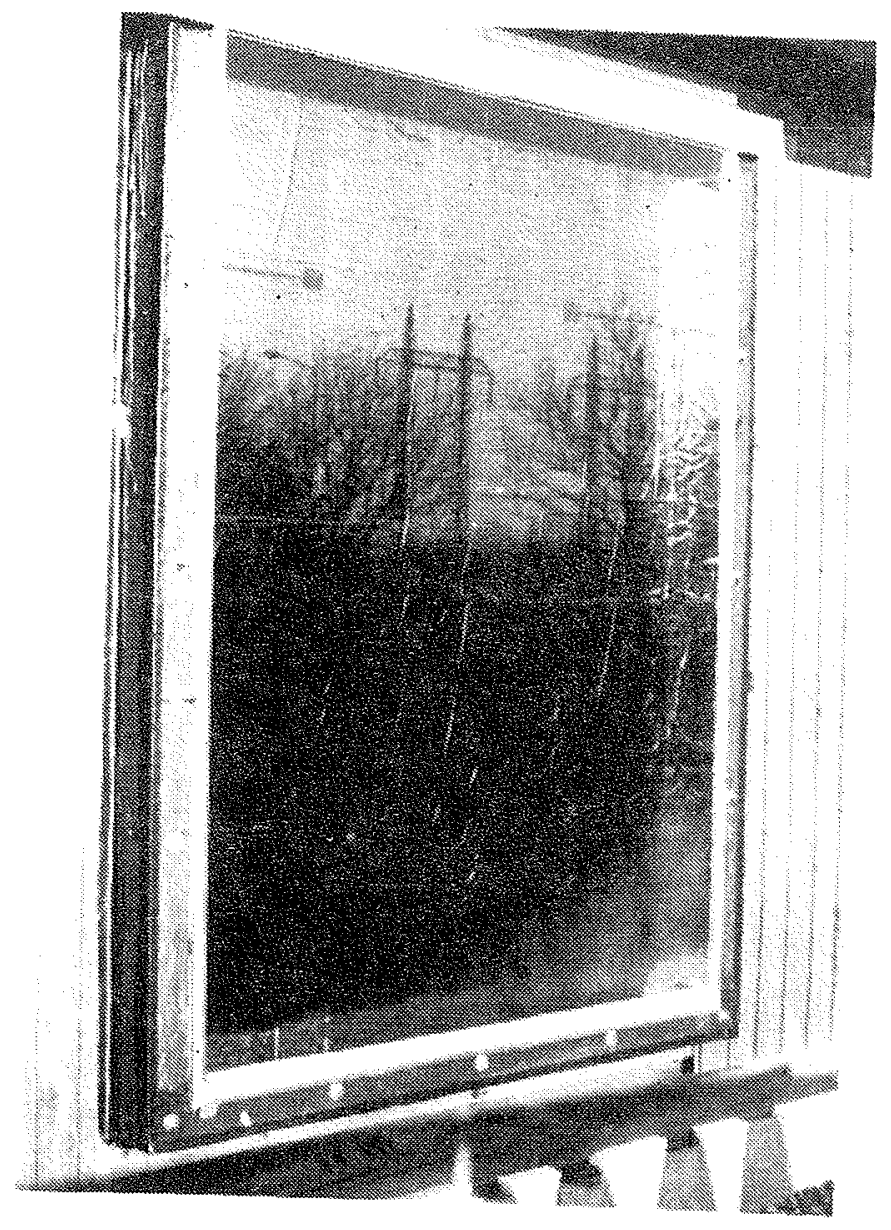

Fig. 4.8

The thermal. storage wall without honeycombs.

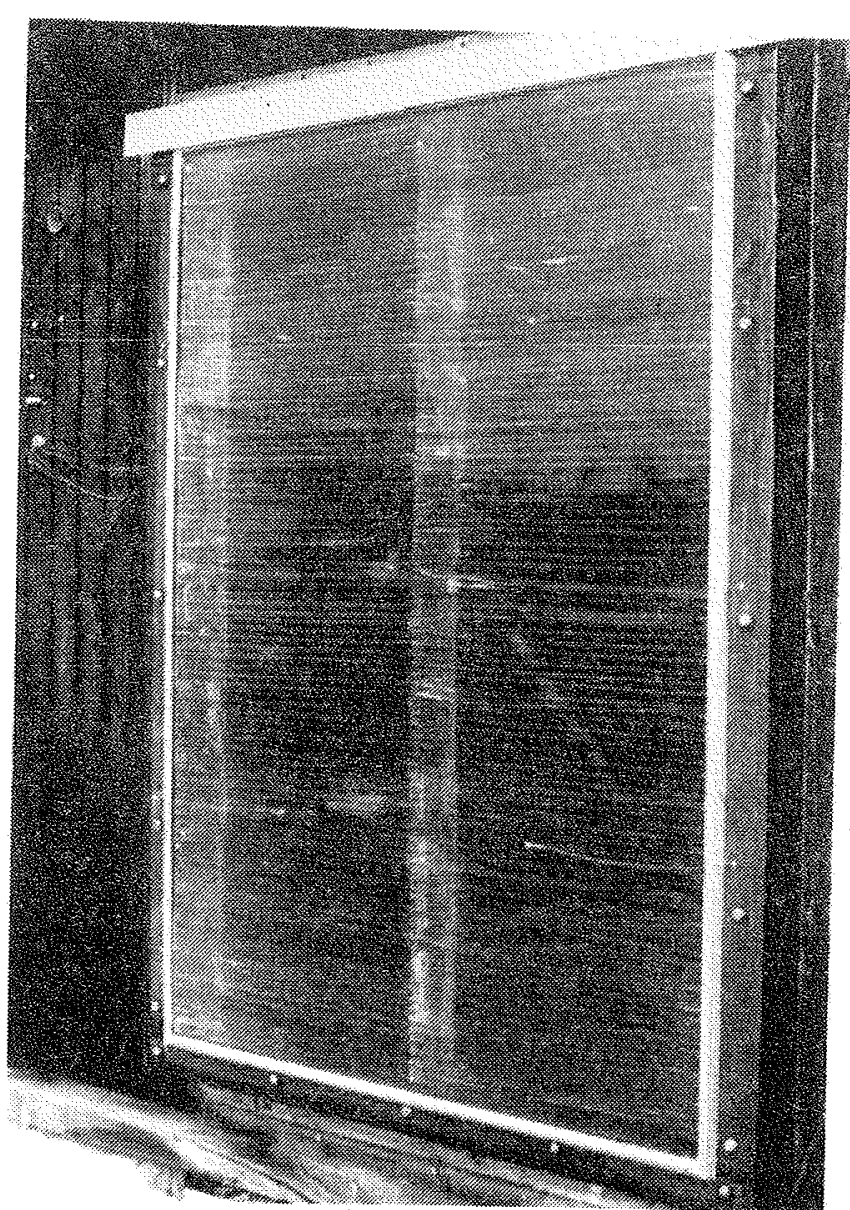

Fig. 4.9

The thermal storage wall with V-corrugated honeycombs. 


\subsection{Results from the Outdoor Experiments}

\section{Preparation of the data}

The cassette tapes with the recorded voltages from the measurements were translated to accessible data at the computer center at the technical university. A special computer programme was written in order to calculate the temperatures and the heat flows from the data, and to find mean values, sums, etc. from these values. Further, the programme was able to sort out data that were evidently wrong due to incorrect registrations by the data logger. By means of a similar programme it was possible to prepare the data for an arbitrary period.

The following results are represented:

a) The heat loss coefficients from the absorber to the ambient air was measured during a period where stationary heat flow through the walls was obtained.

b) The general function of the thermal storage walls is illustrated by the variations of some important temperatures and by the net heat supplies to the test rooms through the solar walls and by auxiliary energy.

In the following the superscript $A$ is used for symbols when referring to the case where the solar wall has no honeycombs, and superscript $B$ is used in case of the solar wall with the V-corrugated honeycombs. Correspondingly the test cells are designated room $A$ and room B.

\section{(a) Measurement of the heat Ioss coefficient}

The heat loss coefficient from the absorber to the ambient air, U. "was measured after a period of three days, where stationary heat flow through the thermal storage walls was obtained by protecting the walls against solar radiation 
by means of an exterior screening. For ten successive scans the coefficients were calculated from

$$
\begin{aligned}
& u=\left(m+m_{w}\right)^{-1} \\
& m=\frac{T_{w, O}-T_{g}}{q} \\
& m_{a}=0.04 \mathrm{~m}^{2}{ }^{\circ} \mathrm{C} / w
\end{aligned}
$$

where

$$
\begin{aligned}
& m= \\
& \text { and the thermal resistance between the absorber } \\
m_{a}= & \text { the thermal resistance corresponding to a } \\
& \text { "standard" wind velocity of } 5 \mathrm{~m} / \mathrm{s} \\
\mathrm{T}_{\text {wo }}= & \text { the absorber temperature } \\
\mathrm{T}_{\mathrm{g}}= & \text { the temperature of the } 9 \text { lass } \\
\mathrm{q}= & \text { the heat flow (measured by heat flow meters). }
\end{aligned}
$$

These results were obtained:

$$
\begin{aligned}
& \underline{\mathrm{U}}^{\mathrm{A}}=1.38 \mathrm{~W} / \mathrm{m}^{2} \text { at } \mathrm{T}_{\mathrm{w}_{\circ} \mathrm{O}}^{\mathrm{A}}=14^{\circ} \mathrm{C} \text { and } \mathrm{T}_{\mathrm{a}}=5^{\circ} \mathrm{C} \\
& \underline{\mathrm{U}}^{\mathrm{B}}=0.83 \mathrm{~W} / \mathrm{m}^{2} \text { at } \mathrm{T}_{\mathrm{w}_{\diamond} \mathrm{O}}^{\mathrm{B}}=17^{\circ} \mathrm{C} \text { and } \mathrm{T}_{\mathrm{a}}=5^{\circ} \mathrm{C}
\end{aligned}
$$

where $\mathrm{T}_{\mathrm{a}}$ is the temperature of the ambient air.

The values are seen to be considerably less than what was measured for the test solar collectors. From the calculations in chapter 5 it appears that this is partly due to the ratio of the length of the honeycombs to the distance between the honeycombs being bigger in case of the outdoor experiments. A contributory cause is that the values of the absorber temperature, the ambient temperature and the difference between them are lower in case of the outdoor experiments. 
(b) The general function of the thermal_storage walls In order to give an impression of the function of the two thermal storage walls some major results are mentioned in the following.

Most of the measuring results that were used for the comparison of the function of the two thermal storage walls were taken from three periods of 14 days in which there was no interruption of the data registration. For a period of this length the net energy stored in the thermal storage walls shows to be small compared to the net gain from the walls.

In table 4.1 the mean, the minimum and the maximum values of the absorber temperature, $\mathrm{T}_{\mathrm{W}, \mathrm{O}}$ " the room air temperature, $\mathrm{T}_{\mathrm{R}}$, and the ambient air temperature, $\mathrm{T}_{\mathrm{a}}$, are shown for the three periods.

\begin{tabular}{|c|c|c|c|c|c|c|c|c|c|c|}
\hline \multirow{4}{*}{$\frac{\text { Period }}{1}$} & \multirow{4}{*}{$\begin{array}{l}\text { Room } \\
\text { A } \\
\text { B }\end{array}$} & \multicolumn{3}{|c|}{$T_{W, \circ}\left({ }^{\circ} \mathrm{C}\right)$} & \multicolumn{3}{|c|}{$\mathrm{T}_{\mathrm{R}}\left({ }^{\circ} \mathrm{C}\right)$} & \multicolumn{3}{|c|}{$\mathrm{T}_{\mathrm{a}}\left({ }^{\circ} \mathrm{C}\right)$} \\
\hline & & \multicolumn{3}{|c|}{$\operatorname{mean} / \min / \max$} & \multicolumn{3}{|c|}{ mean $/ \min / \max$} & \multicolumn{3}{|c|}{$\operatorname{mean} / \min / \max$} \\
\hline & & 21.1 & 12.3 & 67.3 & 19.5 & 18.6 & 20.6 & \multirow{2}{*}{2.2} & \multirow{2}{*}{-5.0} & \multirow{2}{*}{7.5} \\
\hline & & 24.4 & 15.0 & 68.4 & 20.7 & 19.4 & 21.8 & & & \\
\hline \multirow[t]{2}{*}{2} & A & 22.2 & 12.6 & 55.2 & 19.2 & 18.2 & 22.9 & \multirow{2}{*}{2.3} & \multirow{2}{*}{-1.6} & \multirow{2}{*}{11.3} \\
\hline & B & 25.3 & 16.1 & 54.6 & 20.6 & 19.6 & 22.2 & & & \\
\hline \multirow[t]{2}{*}{3} & A & 25.7 & 16.7 & 58.4 & 19.7 & 18.4 & 23.9 & \multirow{2}{*}{7.8} & \multirow{2}{*}{0.3} & \multirow{2}{*}{16.8} \\
\hline & B & 27.9 & 19.8 & 56.4 & 21.2 & 20.3 & 24.0 & & & \\
\hline
\end{tabular}

Table 4.1 Mean, minimum and maximum temperatures of the absorber $\left(\mathrm{T}_{\mathrm{W}, \mathrm{O}}\right)$, the room $\operatorname{air}\left(\mathrm{T}_{\mathrm{R}}\right)$ and the ambient air $\left(\mathrm{T}_{\mathrm{a}}\right)$ in three 14 days periods. (Period 1: Feb.26 - March 11, period 2: March 22 - April 4, period 3: April 18 - May 1).

It is remarkable that the mean value of the absorber is $2.2^{\circ} \mathrm{C}-3.3^{\circ} \mathrm{C}$ higher for the solar wall with honeycombs than for the one without, whereas the mean room temperature 
is only $1.2^{\circ} \mathrm{C}-1.5^{\circ} \mathrm{C}$ higher. About the same tendency applies for the minimum values of the temperatures, and it indicates the lower losses from the wall with the honeycombs.

During the whole period of measuring (from Feb. 25 to May 1) the minimum temperatures of the inner side of the solar walls $\left(\mathrm{T}_{W}, i\right)$ was found to be (March 3$)$ :

Room A: $T_{W_{2} \underline{1}}=16.2^{\circ} \mathrm{C} \quad$ Room B: $T_{W_{2}}=17.5^{\circ} \mathrm{C}$

During the 3 hours before, the average room temperatures were about $19.3^{\circ} \mathrm{C}$ and $20.5^{\circ} \mathrm{C}$, while the ambient aix temperature was about $-2^{\circ} \mathrm{C}$.

The maximum temperatures showed to be (March 12):

Room $A: T_{W, i}=34.5^{\circ} \mathrm{C} \quad$ RoOm B: $T_{W, i}=36.4^{\circ} \mathrm{C}$

In this situation the room temperatures were about $19.5^{\circ} \mathrm{C}$ and $20.30^{\circ}$, while the ambient air temperature was about $0^{\circ} \mathrm{C}$.

The measurements show that the inner surface temperature is maximum $3-4^{\circ} \mathrm{C}$ lower and maximum $15-20^{\circ} \mathrm{C}$ higher than the room air temperature. These variations will not be critical to the themal comfort level under winter conditions. under summer condjtions it will be necessary to shade the thermal storage wall.

In figures 4.10-4.11 are shown some typical courses of ' ${ }^{W}, O^{\prime}$ $\mathrm{T}_{\mathrm{R}}$ and the heat flow through the inside of the solar walls, $q_{i n}$. They are compared with Ta and the total solar irradiation on the vertical south facing plane, $H_{t}$ for a three day period with rather much sunshine (fig.4.10) and for a three day period with only a small amount of irradiation, (fig. 4.11).

From the curves it is seen that during most of the time after a period with sunshine, the gain $q_{\text {in }} B$ is bigger than $g_{\text {in }}^{A}$. For the curves corresponding to the days without 


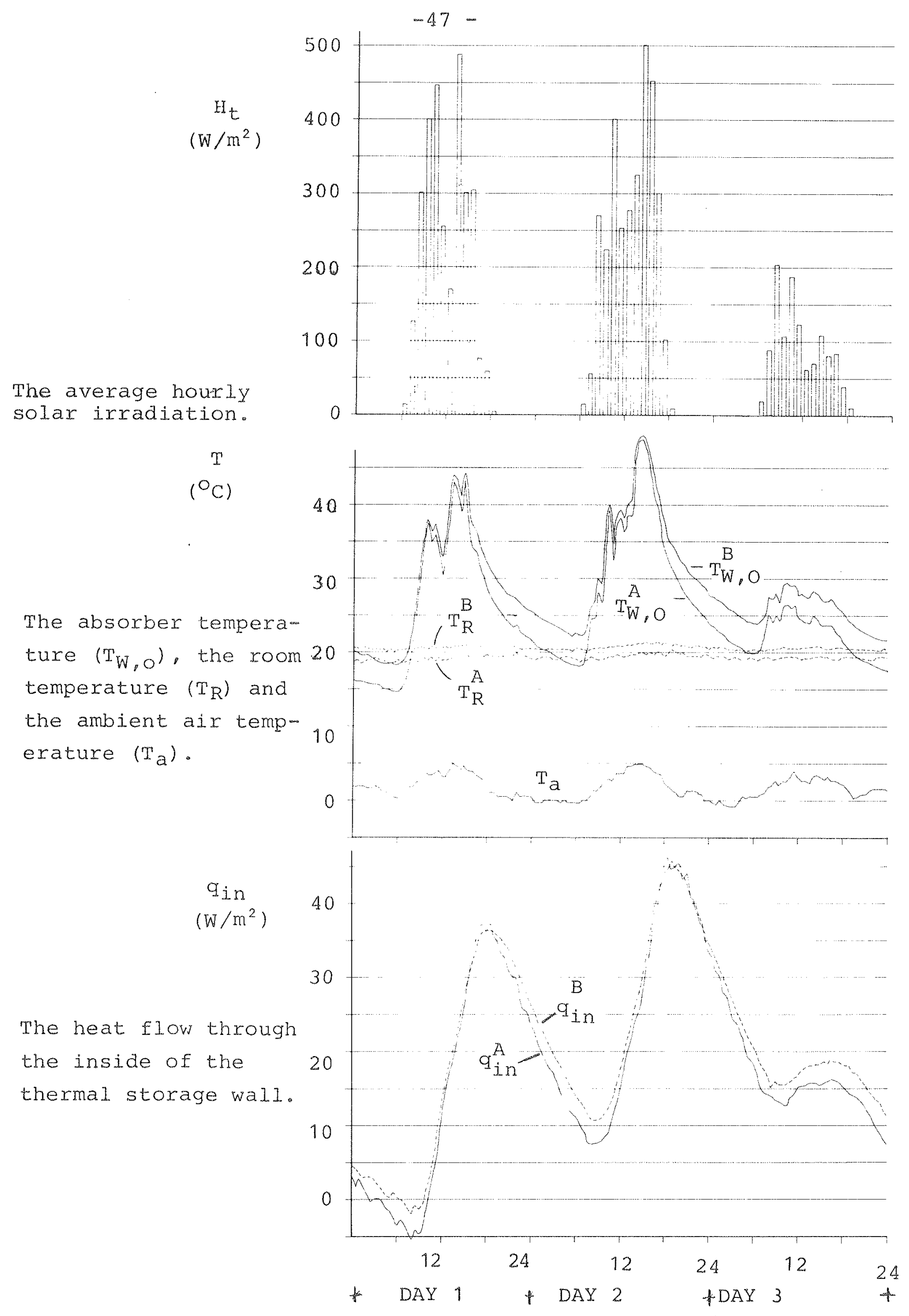

Fig.4.10 The function of the solar walls during a period of three days with rather much sunshine. The symbols $A$ and $B$ refer to the walls without and with honeycombs respectively. 
The average houxly solax irradiation.

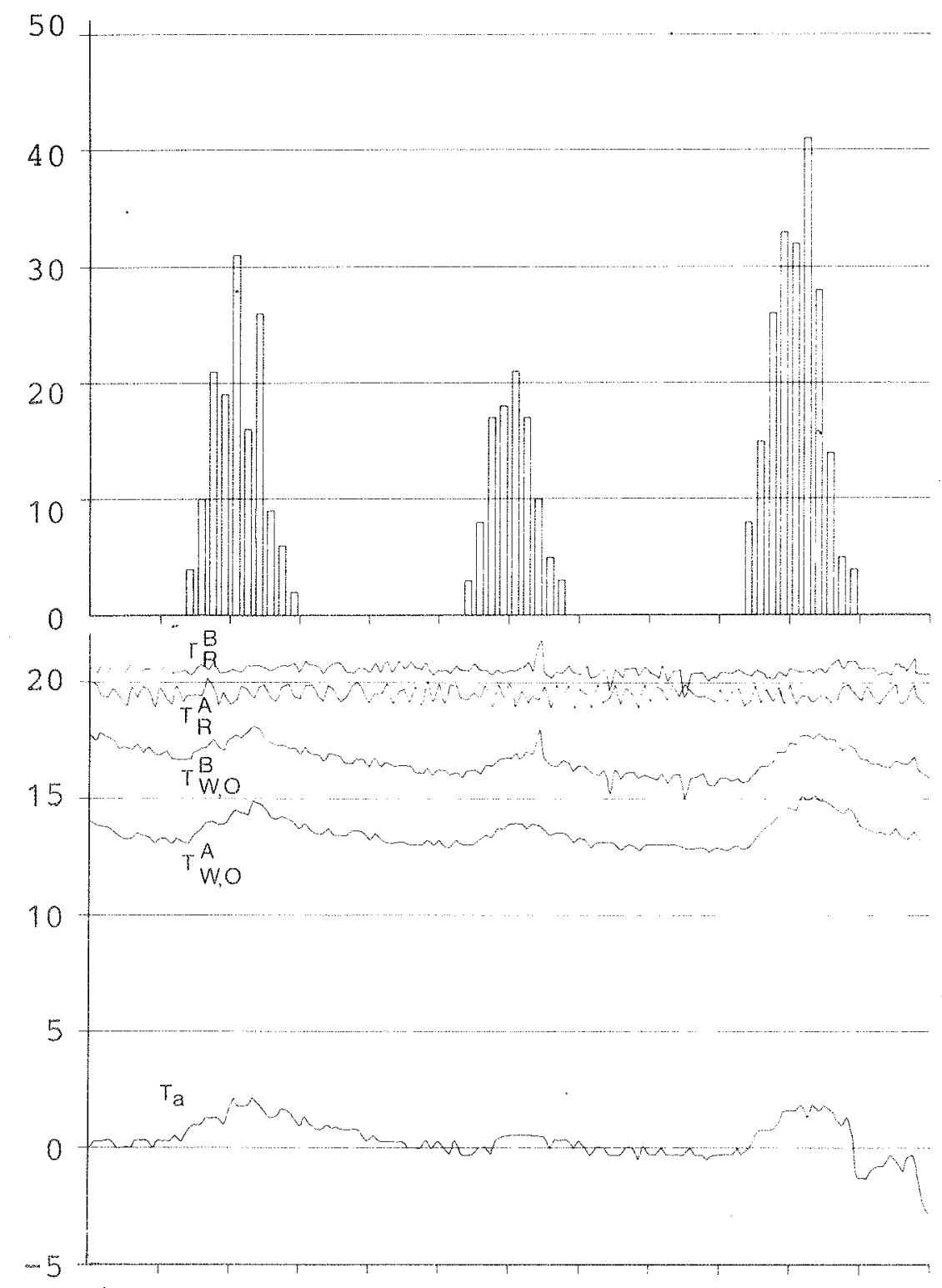

The absorber temperature $\left(T_{W}, 0\right)$, the room temperature $\left(T_{R}\right)$ and the ambient air temperature $\left(T_{a}\right)$.

$$
\frac{q_{\ln }}{\left(w / m^{2}\right)}
$$

The heat flow through the inside of the thermal storage wall.

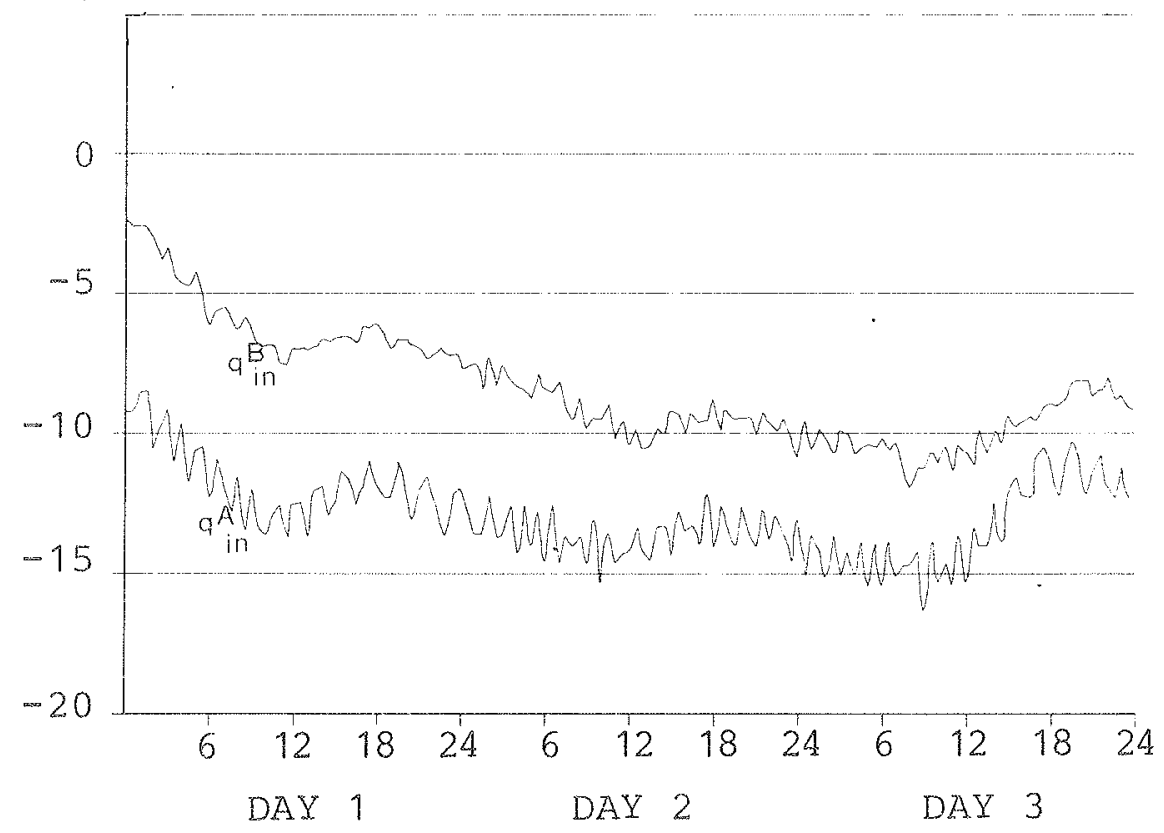

Fig.4.11 The function of the solar walls during a period of three days with cloudy weather. The symbols $A$ and $B$ refer to the walls without and with honeycombs respectively. 
any considerable irradiation (the absolute value of) $q_{\text {in }}{ }^{B}$ is clearly less than $q_{\text {in }} A$, and this is in good agreement with the before mentioned measurement of the heat loss coefficients.

In table 4.2 are 1 isted for the three 14 day periods: the net flows of energy through the thermal storage walls, $Q_{\text {in }}$ the net increase of the heat content of the walls, $\Delta \mathrm{Q}_{\mathrm{W}^{\prime}}$ the total incident solar radiation, $\mathrm{H}_{t}$, the incident diffuse radiation, $\mathrm{H}_{\mathrm{d}}$, and the supply of auxiliary energy, $Q_{\text {aux }}$ All the quantities are per $\mathrm{m}^{2}$ of the thermal storage walls.

Due to the adjustment of the thermostats, $\mathrm{T}_{\mathrm{R}}^{\mathrm{B}}$ generally was about $1^{\circ} \mathrm{C}$ higher than $T_{R}{ }^{A}$. By theoretical considerations (given in appendix $F$ ) it was found that if $T_{R}{ }^{A}$ was raised with $1{ }^{\circ} \mathrm{C}$, the mean value of $T_{w, O} A$ would rise about $0.6^{\circ} \mathrm{C}$, and $\Omega_{\text {in }} A$ would drop about $0.4 \mathrm{kWh} /\left({ }^{\circ} \mathrm{C} \mathrm{m}{ }^{2}\right)$ for the 14 day periods. Correcting $Q_{\text {in }} A$ by subtracting this value gives $Q_{\text {in, }} A$, also listed in table 4.2 . When looking at $Q_{i n, C} A$ and $Q_{i n} B$ it is noticed that for both solar walls the net heat gain is positive. The gain $Q_{\text {in }}{ }^{B}$ is between $12 \%$ and $83 \%$ higher than $Q_{\text {in }}{ }^{A}$, and the biggest difference occurs in periods with low ambient temperature.

The diffuse solar radiation is seen to give a rather big contribution to the total irradiation. For the three periods the share is between $31 . \%$ and $51 \%$

The values of $\Delta \mathrm{Q}_{\mathrm{w}}$ (heat contents of the walls) are noticed to be small, which legitimates that they have not been taken into account.

When the energy savings due to the thermal storage walls are estimated, the net heat gain has to be compared with the heat losses from a normal insulated wall. In table 4.2 is shown, for the 14 day periods, the demand for auxiliary energy in case of the test rooms with the thermal 


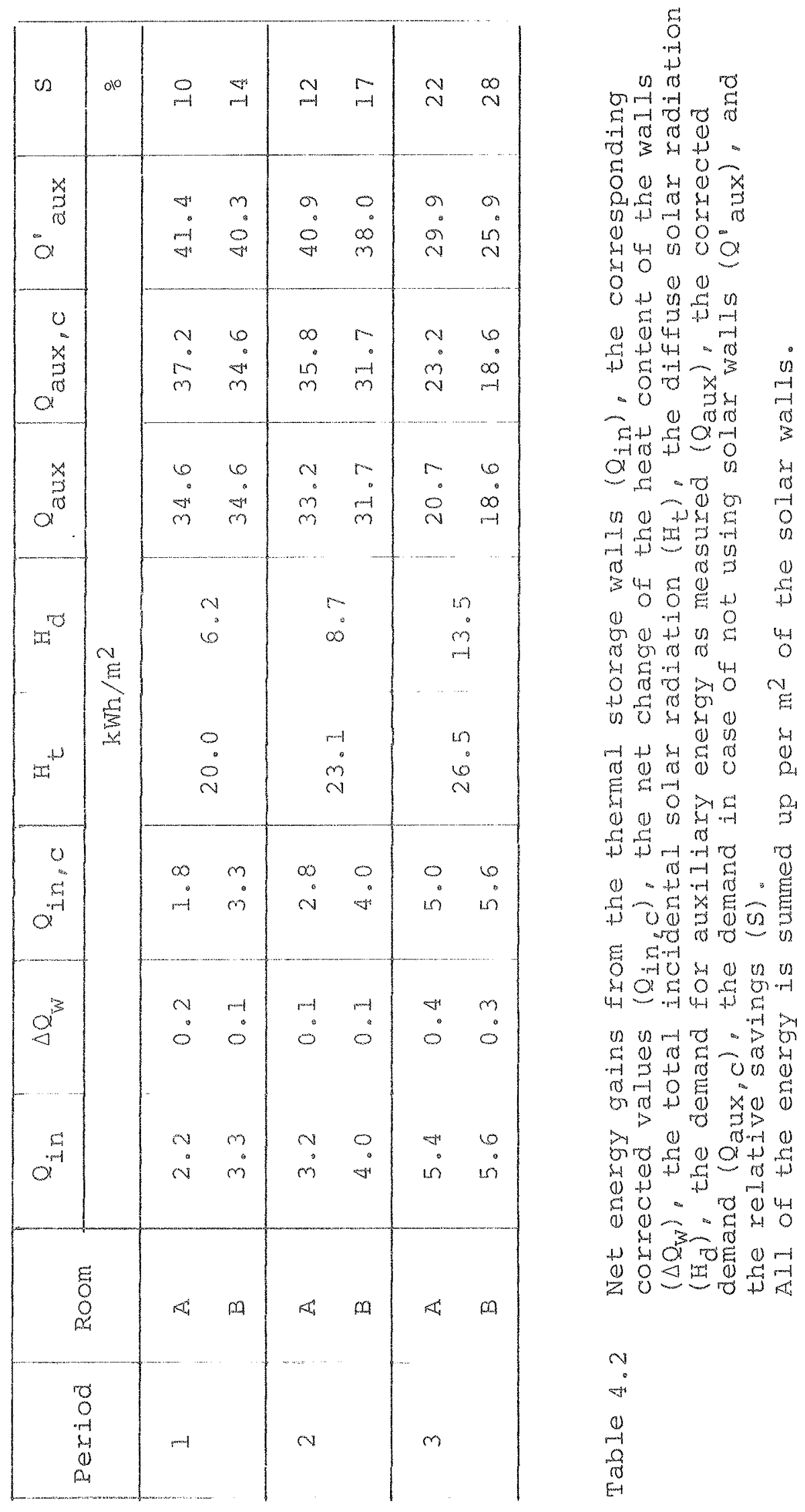


storage walls, $Q_{\text {aux,c }}$ and for the corresponding rooms where the thermal storage walls have been replaced by walls with the same heat loss coefficient as the other room suxfaces, Q'aux . (The values have been corrected with regard to the room temperature).

The following equations were used:

$$
\begin{aligned}
& \mathrm{UA}=\frac{Q_{\text {in }}+Q_{\text {aux }}}{\left(\overline{\mathrm{T}}_{\mathrm{R}}-\overline{\mathrm{T}}_{\mathrm{a}}\right) \Delta \tau} \\
& \mathrm{Q}_{\text {aux, }}=Q_{\text {aux }}+\overline{\mathrm{UA}}\left(\overline{\mathrm{T}}_{\mathrm{R}, \mathrm{C}}-\overline{\mathrm{T}}_{\mathrm{R}}\right) \Delta \tau+\left(\mathrm{Q}_{\text {in }}-\mathrm{Q}_{\text {in, }}\right) \\
& \mathrm{Q}_{\text {aux }}=Q_{\text {aux, }}+Q_{\text {in, }}+\mathrm{U}^{\prime}\left(\mathrm{T}_{\mathrm{R}, \mathrm{C}}-\mathrm{T}_{\mathrm{a}}\right) \Delta \tau
\end{aligned}
$$

with the symbols:

$\mathrm{UA}=$ the heat loss through the room surfaces (excl. the solar walls) per ${ }^{\circ} \mathrm{C}$ and per $\mathrm{m}^{2}$ of the solar walls. (The heat flow to the central rooms was not considered since these rooms were heated to about the same temperature as the test cells).

$\overline{\mathrm{UA}}=$ the mean value of UA for the three periods.

$\overline{\mathrm{T}}_{\mathrm{R}}=$ the mean room temperatuxe.

$\overline{\mathrm{T}}_{\mathrm{R}, \mathrm{C}}=$ the corrected mean room temperature, that is in case of room $A$ the room temperature is raised with $1^{\circ} \mathrm{C}$.

$Q_{\text {aux }}=$ the measured values of the supply of electric energy.

$\Delta \tau=$ the length of the period.

$U^{\prime}=$ the heat loss per ${ }^{{ }^{\circ}} \mathrm{C}$ and per $\mathrm{m}^{2}$ through the insulated wall, $U^{\prime}=0.4 \mathrm{~W} / \mathrm{m}^{2}{ }^{\circ} \mathrm{C}$.

For the two rooms the following mean values were found:

$$
\overline{\mathrm{UA}}^{\mathrm{A}}=6.4 \mathrm{~W} /\left({ }^{\circ} \mathrm{C} \mathrm{m}^{2}\right) \quad \overline{\mathrm{UA}}^{\mathrm{B}}=5.8 \mathrm{~W} /\left({ }^{\circ} \mathrm{C} \mathrm{m}^{2}\right)
$$


Finally listed in table 4.2 are the relative savings of energy due to the presence of the solar walls, $s$, calculated from

$$
S=\frac{Q^{\prime a u x}-Q_{\text {aux, }}}{Q_{\text {aux,c }}}
$$

The savings are seen to be considerable - between $10 \%$ and $22 \%$ for the solar wall without honeycombs, and between $14 \%$ and $28 \%$ for the solar wall with honeycombs. It must be added that the insolation on the solax walls is less (about 20\%) than what is usual for the Danish climate in the springtime. 


\section{THE SIMULATION MODELS}

In this section the simulation models for the calculation of the solar transmission and the heat loss through the transparent insulation are presented, and they are compared with the results of the measurements. Some parameter variations are done in order to find the most suitable design of the honeycombs. Finally, the energy savings due to the use of transparent insulation is calculated.

\subsection{Solar Transmission}

The solar transmission through the V-corrugated honeycomb is calculated by a raytracking simulation model (fig. 5.1). For the honeycomb material used, the reflections are assumed to be specular and the absorption in the honeycomb occurs only within the material. The extinction coefficient is $8 \mathrm{~m}^{-1}$. The calculated transmission and absorption is shown in fig. 5.2. The transmission shows to be very large even at large angles of incidence. At normal incidence, the transmission is 0.98 corresponding to the results obtained when testing in the solar simulator.

The maximum angle of refraction in the honeycomb is $39^{\circ}$ and therefore the solar rays will travel only quite a short distance across the honeycomb walls. This is one of the reasons why the amount of solar radiation absorbed in the walls is small.

If the honeycomb is placed in horizontal rows in vertical thermal storage walls facing south, the solar transmission will be quite large during winter because of the low solar altitudes. The variation of azimuth angle has only a quite small effect on the transmission through the honeycomb due to the above mentioned small angle of refraction in the honeycomb wall.

It must be remarked that this theoretical transmittance will be reduced by effects as diffuse reflection and absorption at the honeycomb wall surfaces due to for example 


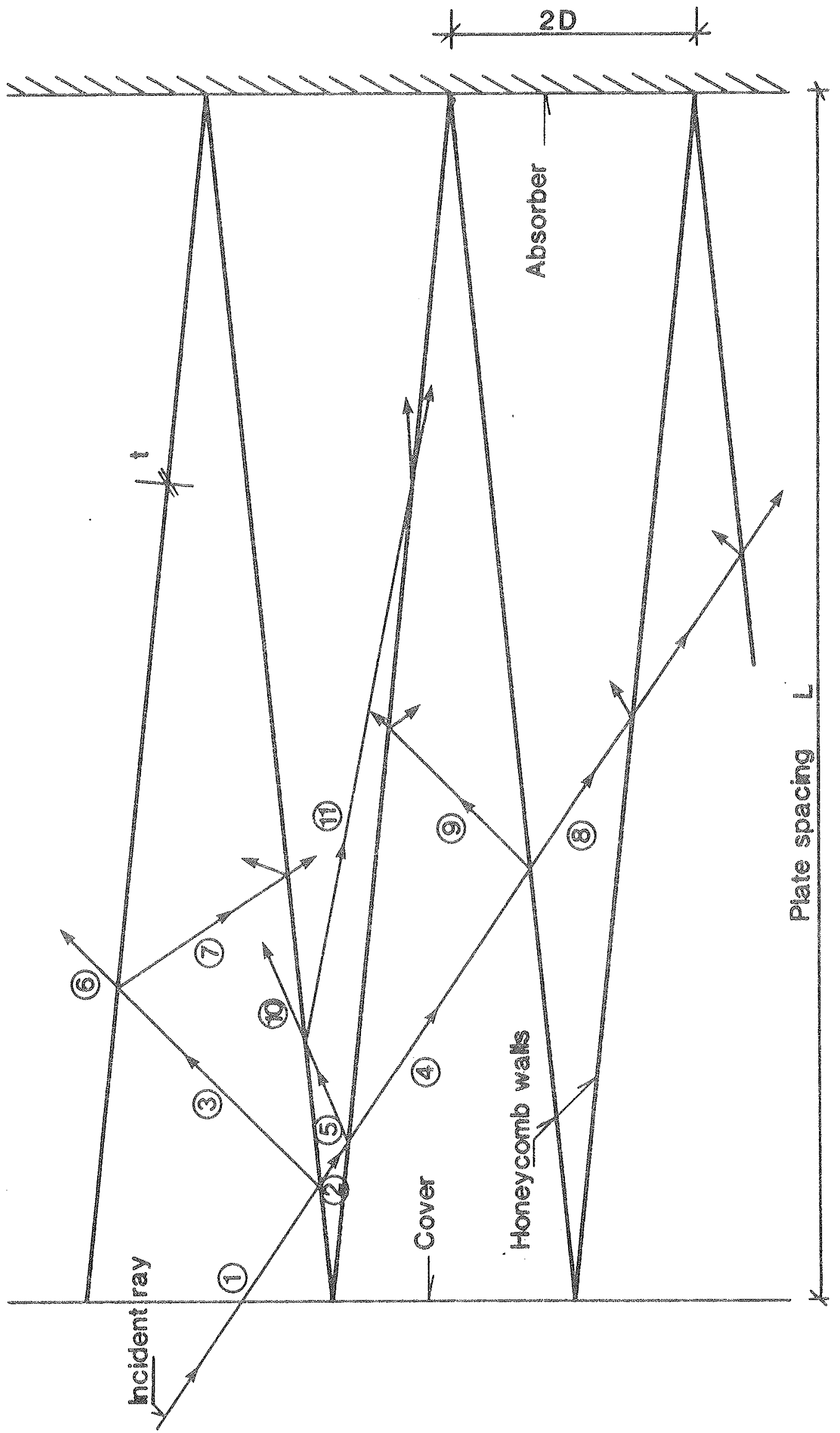

Fig. 5.1 Cross-section of a V-corrugated honeycomb. An example of raytracks are shown. 
dust or agening effects. These reductions will have the greatest importance at large angles of incidence.

For vertical thermal storage walls facing south, the total transmitted radiation will not be so sensitive to variations of the transmittance at large angles of incidence. This is because the radiation from large angles of incidence contains only a minor part of the total daily incident radiation and because the outer glazing will reflect quite a large part of the incident radiation.

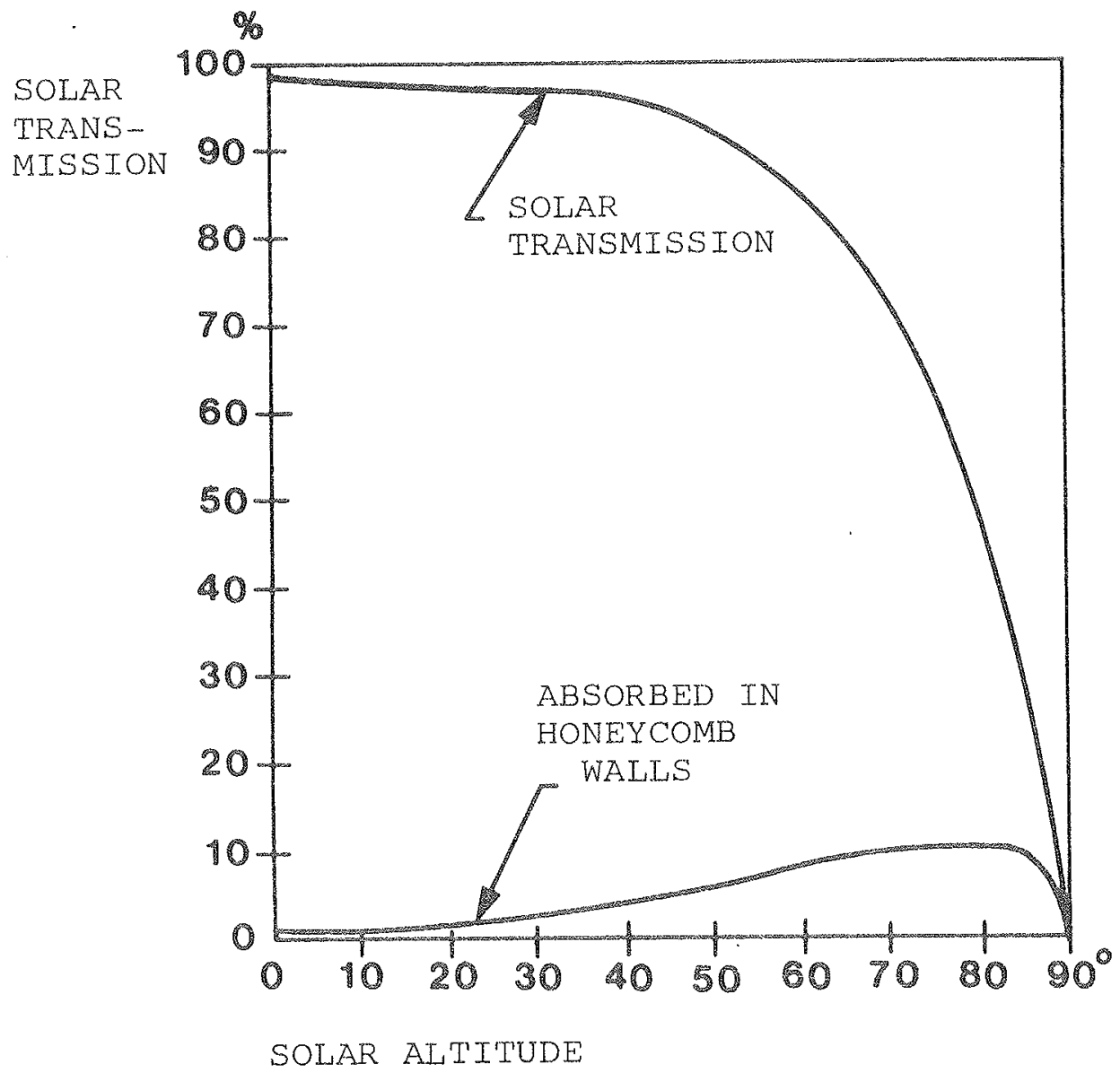

Fig. 5.2 Calculated solar Transmission of V-corrugated honeycomb. Distance between outer glazing and absorber: $0,15 \mathrm{~m}$. Aspect ratio: $\mathrm{L} / \mathrm{d}=15$. Honeycomb wall thickness $0,38 \mathrm{~mm}$. Extinction coefficient: $8 \mathrm{~m}^{-1}$. Index of refraction: 1,586 . Solar radiation incident from a vertical plane perpendicular to the outer glazing. 


\subsection{Calculation Model for the Thermal Heat Loss through the Honeycombs}

\section{General}

A computer program has been prepared in order to calculate the combined heat flow through the honeycombs in the form of thermal radiation, convection and conduction in the air, and conduction in the honeycomb material. The calculations are based upon a division of the honeycombs into a number of small elements, as shown in fig. 5.3. For given temperatures of the absorber and the glazing, the temperatures of the different elements are assumed, whereas the net heat supply to each element is calculated. By using an iteration process, new temperatures of the elements are fissed until the net heat supply to the elements generally shows to be almost equal to zero. In this situation we have steady state conditions, and the heat loss coefficient bew tween the absober and the glazing can be determined.

The heat flow by thermal radiation

The exchange of thermal radiation is decided by regarding the surfaces surrounding the elements as a grey enclosure. According to (3) page $211-219$, the heat radiation ex.change between the elements can be found from the equations (I) $\sum_{j=1}^{N} E_{i j} \cdot B_{j}-\frac{1}{\rho_{i}} \cdot B_{i}=\frac{\varepsilon_{i}}{\rho_{i}} \cdot \sigma \cdot T_{i}{ }^{4}$

$$
Q_{i}=A_{i} \cdot \frac{\varepsilon_{i}}{\rho_{i}}\left(\sigma \cdot T_{i}^{4}-B_{i}\right)
$$

where

$$
\begin{aligned}
N_{i}= & \text { the numner of elements } \\
F_{i j}= & \text { the configuration factor from elements } i \text { to } \\
& \text { element } j \\
B_{j}= & \text { the sum of the radiation emitted and reflected from } \\
& \text { element } i \\
\rho_{i}= & \text { the reflectance of element } i
\end{aligned}
$$



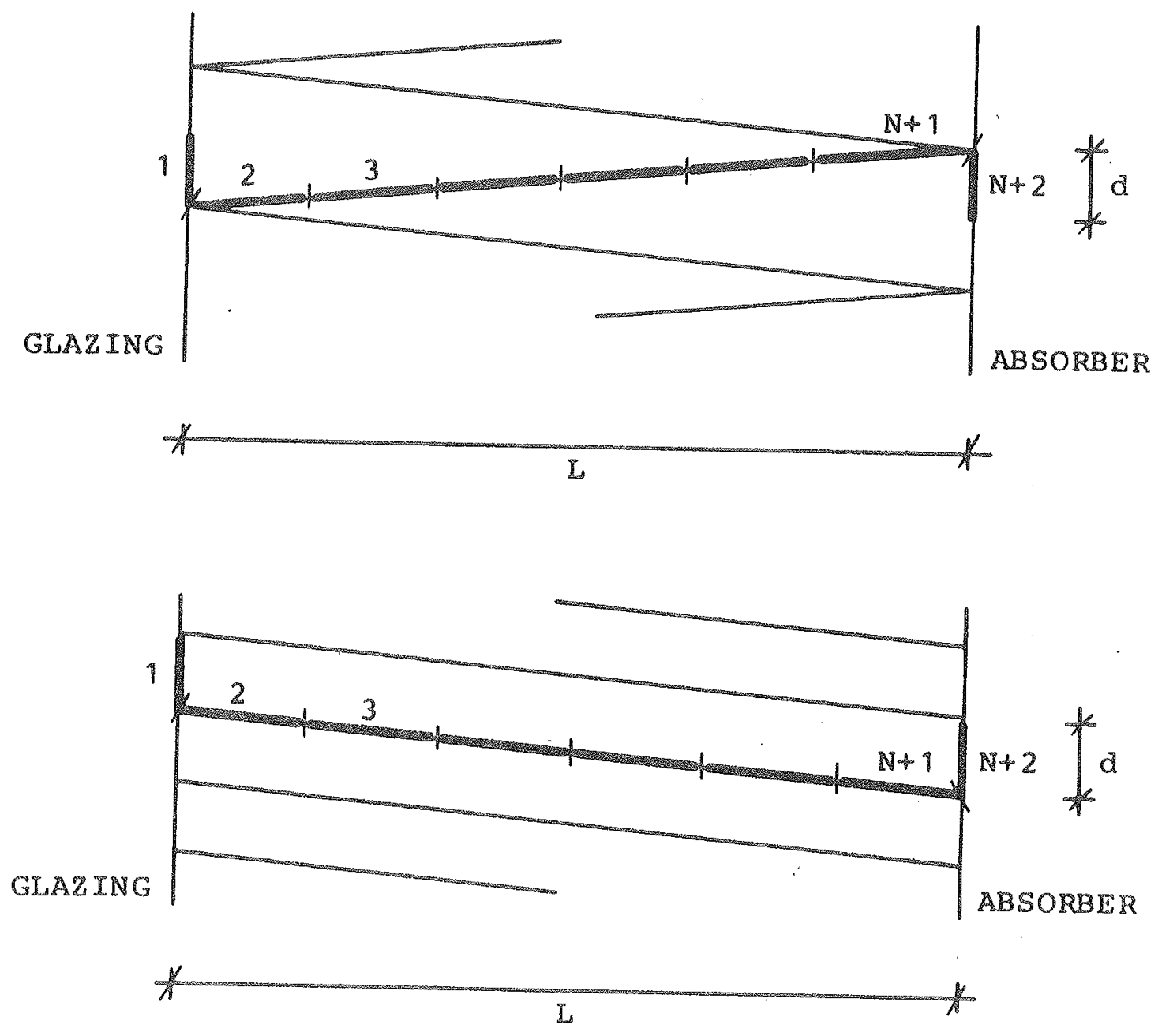

Figure 5.3 The division of the V-corrugated and the slatted honeycombs into $\mathrm{N}$ elements. The glazing and the absorber are also represented by elements. 


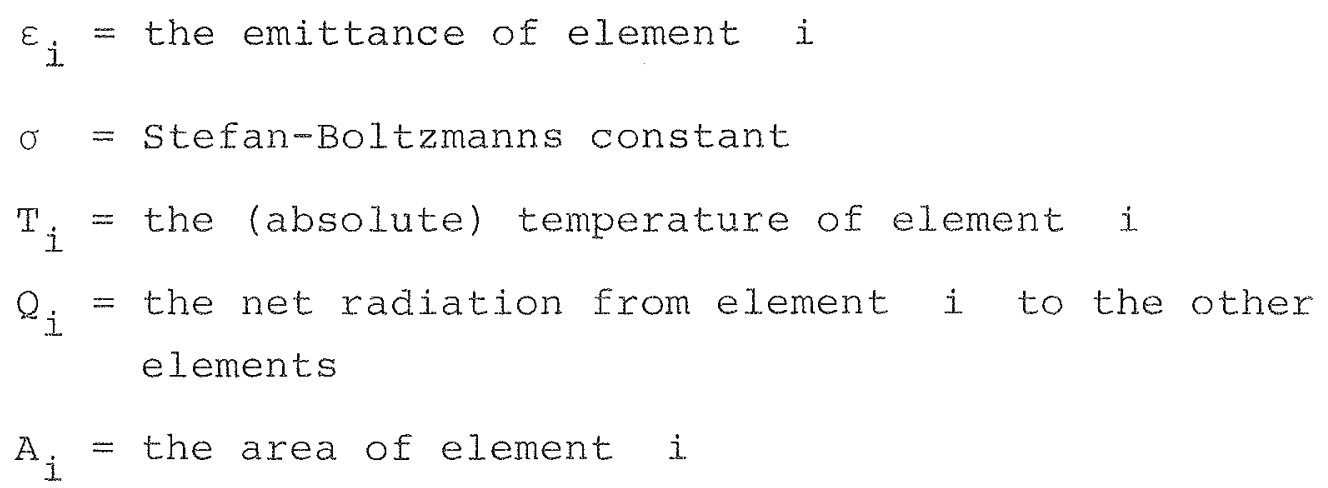

The expression (I) forms a system of linear equations Erom which $B_{i}$ can be found when the values of $I_{i}$ are fixed. Next $Q_{i}$ is calculated from (II).

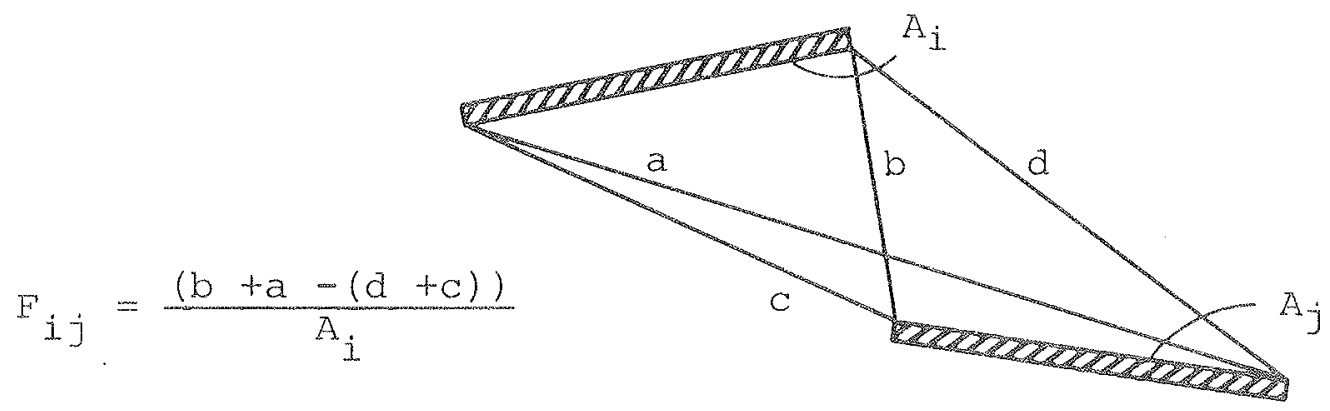

Figure 5.4 Determination of the configuration factor $F_{i j}$ from the element with area $A_{i}$ to the element with area $\mathrm{A}_{j}$.

The heat flow by convection and conduction in the air A literature study was made in order to find a suitable way to proportion the honeycombs and to find the most appropriate expression for calculating the convective heat transfer inside the honeycomb. Especially the informations given in $(4),(5)$ and $(6)$ were of interest. 
Mainly two types of honeycombs have been investigated, the squaremcelled honeycomb with vertical and horizontal walls and the slatted honeycomb where only horizontal walls are used. The air movements causing the convective heat transfer will form longitudinal rolls (i.e. rolls with axes perpendicular to the plane of the honeycombs) and transverse rolls (i.e. rolls with horizontal axes parallel to the plane of the absorber). When dimensioned correctly, the vertical walls of the cell will restrain the formation of the longitudinal rolls, and the horizontal walls will restrain the transverse rolls.

Amorig other things the investigation dealt with the influence of the inclination angle of the air layers $\phi$ (shown in fig. 5.5). The theoretical comparison of the two types of honeycombs led to the following conclusion: with the same quantity of material for the walls, the square-celled honeycomb is superior for $\phi<70^{\circ}$, and at $\phi>75^{\circ}$ the slatted honeycomb is superior. The reason is that when $\phi$ approaches $90^{\circ}$, the longitudinal rolls will have little or no tendency to form. For the present purpose it is of interest to choose $\phi>75^{\circ}$. This is to avoid too big optical losses of solar radiation due to the presence of honeycombs in the case of small angles of incidence during winter. Moreover, the vertical honeycomb walls will increase the optical losses for big values of the azimuth angle. It was therefore decided to further investigate only the slatted honeycombs.

A method for calculating the convection in a honeycomb with a V-corrugated shape was not found in the literature studied. Instead some "equivalent rectangular dimensions" of the triangular honeycomb were defined. These dimensions $l_{e}$ and $d_{e}$ are shown in fig. 5.6, and an expression valid for slatted honeycombs was used. Another approximation concerning the geometry was done. In the literature, the inclination angle of the honeycombs 
corresponds to the tilt of a solar collector as shown on the left side of fig. 5.5. In the present calculation the solar wall is vertical, while the angle between the honeycombs and the vertical plane, as shown on the right side of fig. 5.5, is used for $\phi$ in the formulas.

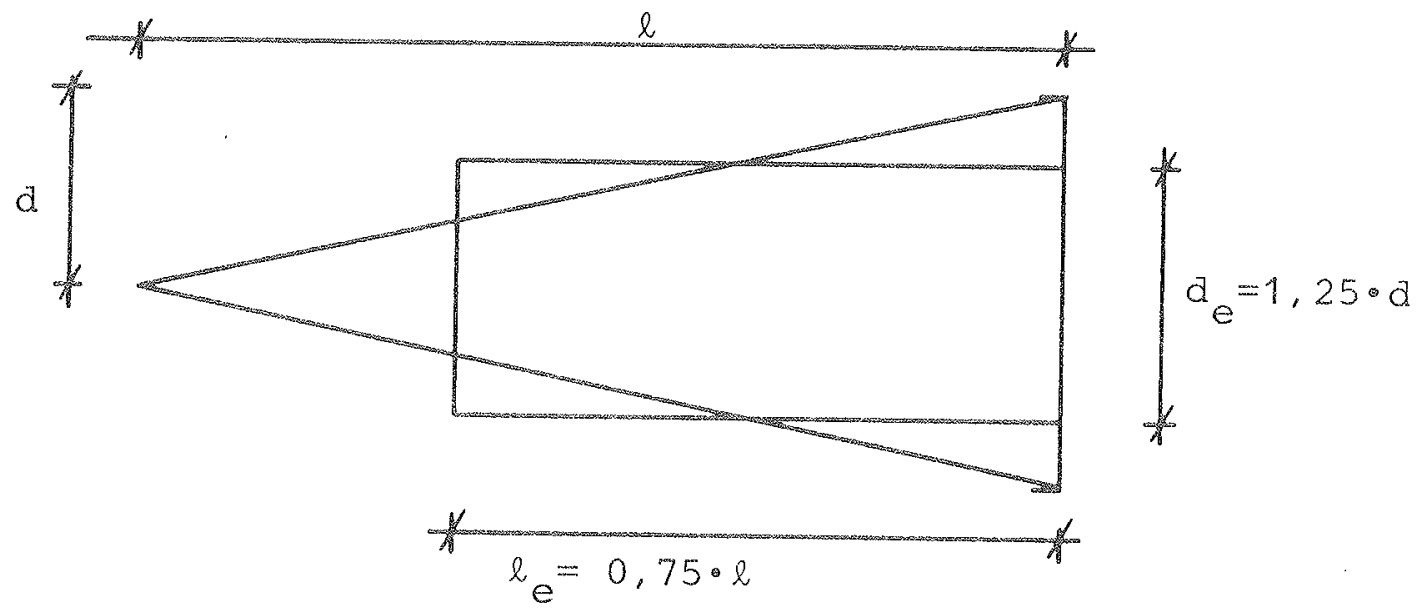

Figure 5.5 The equivalent length ( $\left.\ell_{e}\right)$ and width $\left(d_{e}\right)$ of the $V$-corrugated honeycomb.
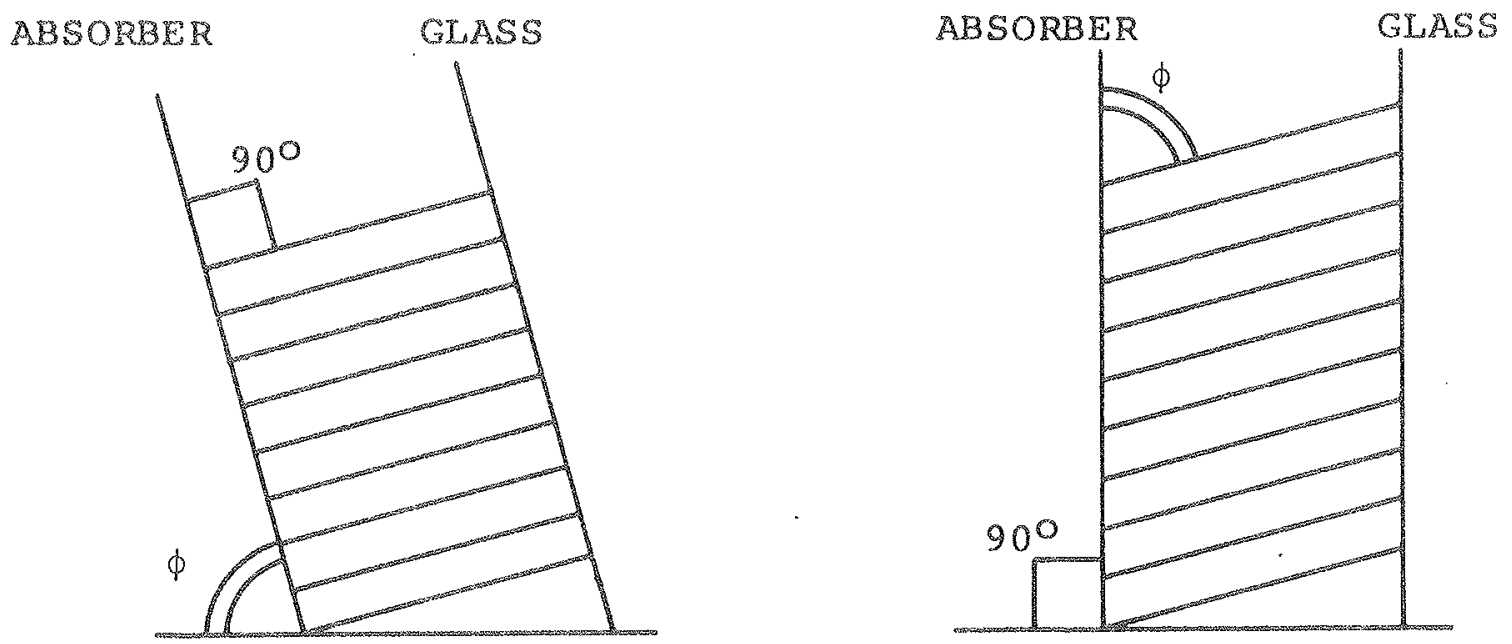

Figure 5.6 Vertical section through the honeycombs. The inclination angle, $\phi$, as defined in the litterature (left) and as used in the present calculations (right). 
The heat transfer is characterized by the Nusselt number, $\mathrm{Nu}$, which is dependent on several parameters. The most important parameters are $\phi$ (the inclination angle), the aspect ratio $A$ (the ratio of the distance between the absorber and the outer glazing to the distance between the honeycomb walls) and the Rayleigh number, defined as:

$$
R a=\frac{g \cdot \beta \cdot \Delta T \cdot L^{3}}{\nu \cdot \alpha}
$$

where

$$
\begin{aligned}
g= & \text { the accelaration due to gravity } \\
\beta= & \text { volumetxic expansion coefficient of air at the } \\
& \text { mean air temperature } \\
\Delta T= & \text { the temperature difference between the absorber } \\
& \text { and the outer glazing } \\
L= & \text { the distance between the absorber and the glazing } \\
\nu= & \text { the kinematic viscosity of air at the mean air } \\
& \text { temperature } \\
\alpha= & \text { thermal diffusivity of air at the mean tempexature }
\end{aligned}
$$

When $\mathrm{Ra}$ is increased, Nu will rise in a way that is determined by $\phi$. At $\phi<75^{\circ} \mathrm{Nu}$ will be equal to 1 (which means that the heat transfer is by pure conduction in the air) until Ra reaches the critical Rayleigh number Ra. At this value the air starts to circulate resulting in an abrupt rise of $\mathrm{Nu}$. At $\phi=90^{\circ}$ the gravity will always drive a "base flow" of air, so in this situation $\mathrm{Nu}$ will rise gradually with $\mathrm{Ra}$ and the above mentioned critical Rayleigh number is not introduced. In the range $75^{\circ}<\phi<90^{\circ}$ informations concerning the rectangular honeycombs are lacking.

In the present calculations of the heat flow through the slatted honeycombs by convection and conduction in the air, the following expressions (both appearing in ( 4 )) have been used. 
FOr $\Phi \leq$.

$\mathrm{Nu}=1$, when $\mathrm{Ra}<\mathrm{Ra}_{\mathrm{C}}$

$\mathrm{Nu}=1+\mathrm{C} \cdot(\mathrm{Ra} \cdot \operatorname{Cos} \phi)^{1 / 3}\left[1-\exp \left\{-(a+b \cdot \phi) \cdot\left[\left(\frac{\mathrm{Ra}}{\mathrm{Ra}}\right)^{\mathrm{n}}-1\right]\right\}\right]$

when $\mathrm{Ra} \geq \mathrm{Ra}_{\mathrm{C}}$

with the constants

$a=0.18$

$\mathrm{b}=1.2 \cdot 10^{-3} \mathrm{deg}^{-1}$

$c=0.131$

$\mathrm{n}=0.513$

The critical Rayleigh number $\left(\mathrm{Ra}_{\mathrm{C}}\right)$ is found from the equations:

$$
\left(R a_{C}\right)_{0}=A^{2}\left[768+\frac{1536 A}{C}+48 \varepsilon_{W} N \cdot A \cdot \frac{(I-S)}{I-S\left(1-\varepsilon_{W}\right)}\right]
$$

$R a_{C}=\left(R_{C}\right)_{O} / \cos \phi$

where $\mathrm{C}, \mathrm{N}$ and $\mathrm{s}$ are defined as

$C=\frac{K_{E} \cdot L}{K_{W} \cdot e} \quad N=\frac{4 \cdot \sigma \cdot T_{m}^{3}}{L \cdot K_{E}}$

$S=1.0102-\frac{1.4388}{A}-\frac{9.4653}{A^{2}}+\frac{31.440}{A^{3}}-\frac{27.515}{A^{4}}$

The below mentioned new symbols are used:

$\mathrm{T}_{\mathrm{m}}=$ the mean air temperature

$K_{f}=$ the thermal conductivity of the air at the $\mathrm{T}_{\mathrm{m}}$

$\mathrm{K}_{\mathrm{W}}=$ the thermal conductivity of the honeycomb material

$\mathrm{e}=$ semi-thickness of the honeycomb walls

$\varepsilon_{\mathrm{w}}=$ the emissivity of the honeycomb walls 
$\operatorname{For} \Phi=-90^{\circ}$

$\mathrm{Nu}=1+\left\{\left[\gamma_{1}\left(\frac{\mathrm{Ra}}{\mathrm{A}}\right)^{2}\right]^{\mathrm{m}}+\left[\gamma_{2} \mathrm{Ra}^{1 / 5} \cdot \mathrm{A}^{2 / 5}\right]^{\mathrm{In}}\right\}^{1 / \mathrm{m}}$

with the constants

$\gamma_{1}=2.756 \cdot 10^{-6}$

$\gamma_{2}=0.623$

In accordance with the formulas the heat transfer by convection and conduction in the air was calculated for the slatted honeycombs. Fig. 5.7 shows the convective heat transfer in relation to the plate spacing (i.e. the distance between the absorber and the glazing). The two sets of curves are based on a temperature difference of respectively $25^{\circ} \mathrm{C}$ and $50^{\circ} \mathrm{C}$ and an average temperature of $70^{\circ} \mathrm{C}$. It can be seen that each of the curves has a minimum heat transfer. This minimum heat transfer is very dependent on the aspect ratio and the slope. The larger the aspect ratio is, the more it is possible to suppress the convective flow. The dependence on the slope is also indicated. For large plate spacings there is a large increase in the heat flow with an absorber slope of $75^{\circ}$ instead of $90^{\circ}$ (vertical).

The convective heat loss of a flat plate collector is shown. It can be seen that the convective losses can be reduced to one fourth for slatted honecombs compared. with the flat plate case. From the curves it can be seen that an aspect ratio of $A=10$, and a plate spacing between 50 and $100 \mathrm{~mm}$ seems to be an appropriate optimum as far as the convection heat flow is concerned.

In the computer program, the convective heat transfer between two adjacent elements was calculated by defining the equivalent conductivity of the air $\mathbb{K}_{f, e^{\circ}}$

$$
K_{f, e}=K_{f} \cdot \mathrm{Nu}
$$

By this the heat transfer was regarded as if it was pure conduction through the air space between the honeycombs when using a modified conductivity of the air. 

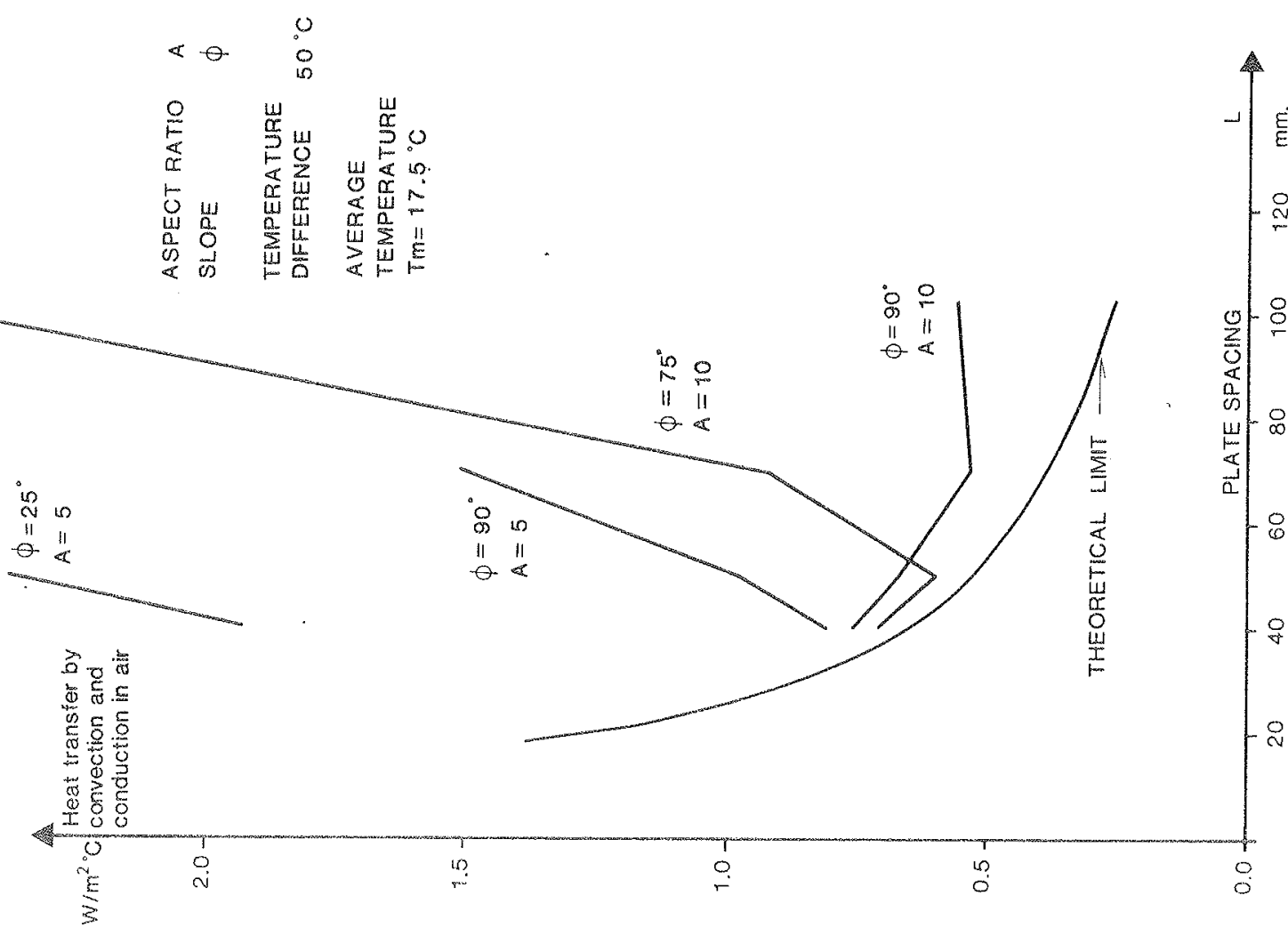

-1
.4
4
4
40
0
0
0
4
4

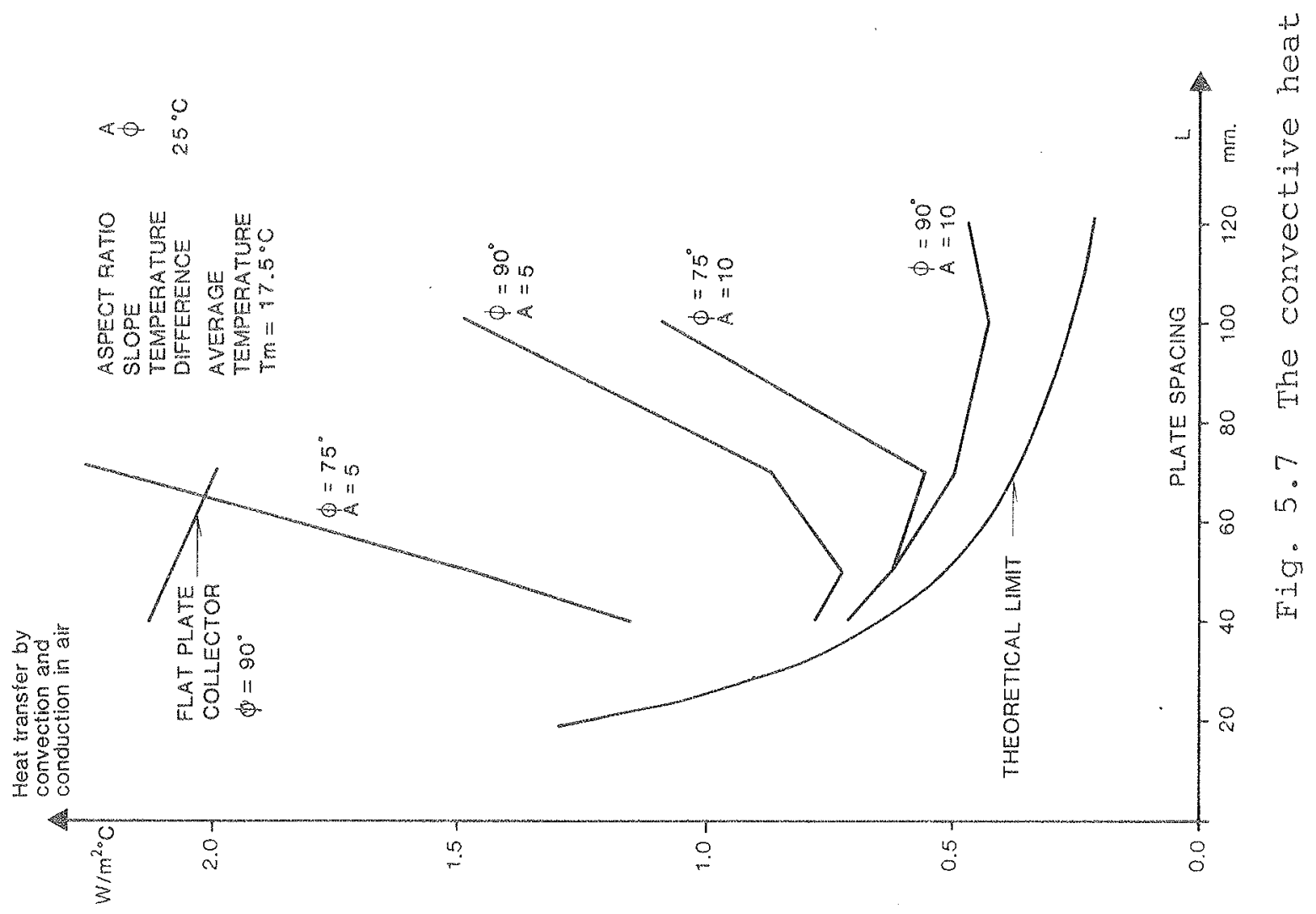


The conduction in the honeycomb material

The conduction in the honeycomb walls is calculated as simple one-dimensional heat flow between two adjacent elements.

The influence of some parameter variations on the convective_heat_loss coefficient

By using the computer program, the heat loss coefficient $U_{1}$ from the absorber to the glazing could be found at different temperatures, geometries, etc. From the experiments and the initial calculations it showed, that the $V$-corrugated honeycombs were preferable to the slatted honeycombs, and therefore these calculations involve only the $\mathrm{V}$-corrugated type of honeycomb. The inclination angle was set to $\phi=90^{\circ}$.

The results are presented graphically on the following pages. The general conditions are:

- The thickness of the honeycomb walls is $0.25 \mathrm{~mm}$ and the conductivity is $0.2 .0 \mathrm{~W} / \mathrm{m}^{\circ} \mathrm{C}$

- The emittance of the honeycomb walls and the glazing is 0.90 and the reflectance is 0.10 .

The variations of $U_{1}$ was investigated in the below mentioned cases.

The distance between the absorbex and the glazing was varied for different values of the absorber temperature and the absorber emittance. This was done for aspect ratios $A=I / d=10$ and 15 , where $\mathrm{I}$ is the distance between the absorber and the glazing, and $d$ is the mean aistance between the honeycomb walls.

The absorber emittance was varied for a given geometry and fixed temperatures of the absorber and the glazing.

The difference between the absorber temperature and the glazing temperature was varied for different values of the glazing temperature. 


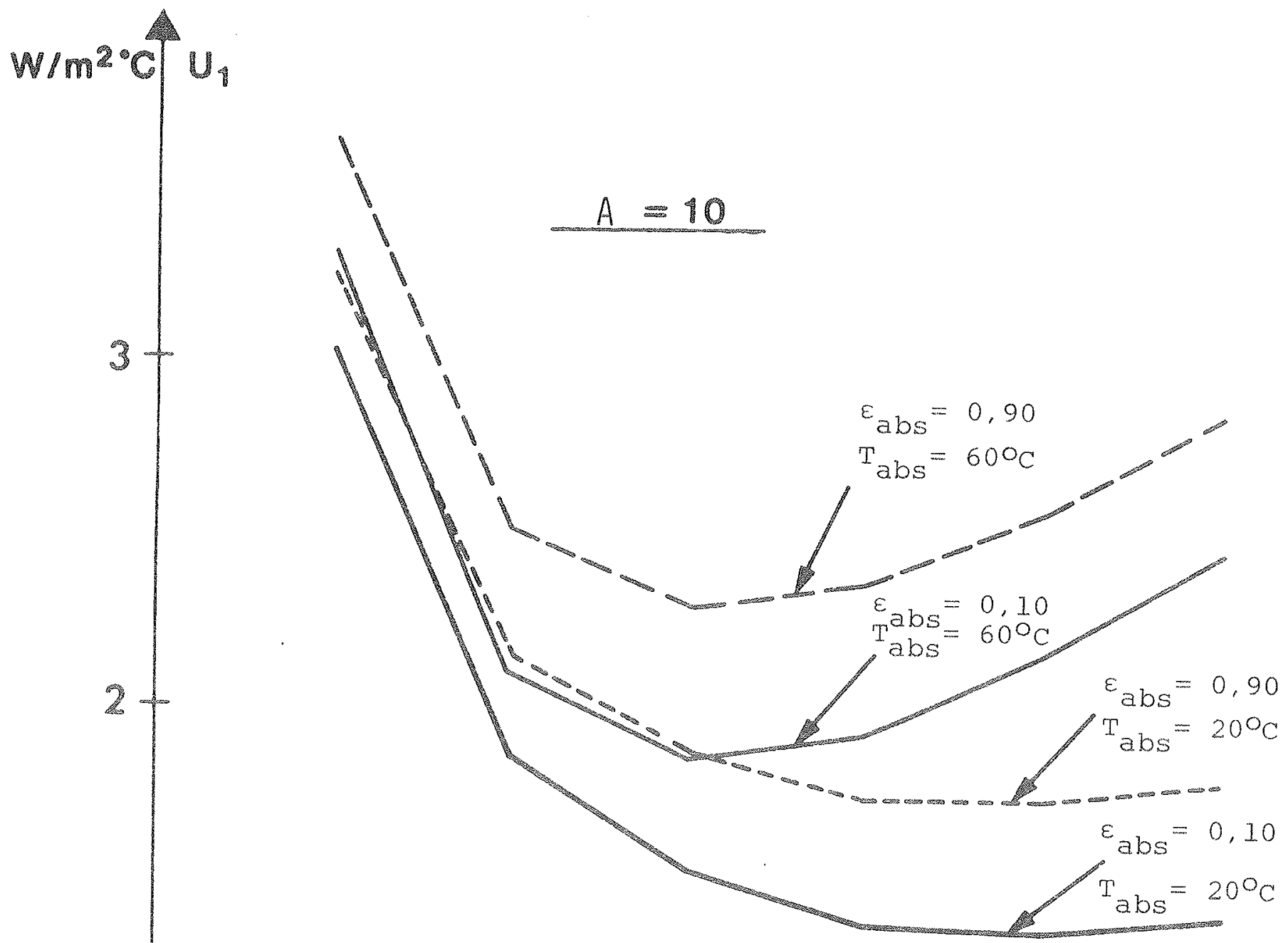

Figure 5.8 The heat loss coefficient between the absorber and the glazing $\left(U_{1}\right)$ as a function of the distance between the two surfaces (L) for different values of the absorber emissjvity $\left(\varepsilon_{\mathrm{abs}}\right)$ and the absorber temperature ( $\mathrm{T}_{\mathrm{abs}}$ ). The glass temperature is $10^{\circ} \mathrm{C}$ and the aspect ratio is $A=10$. 


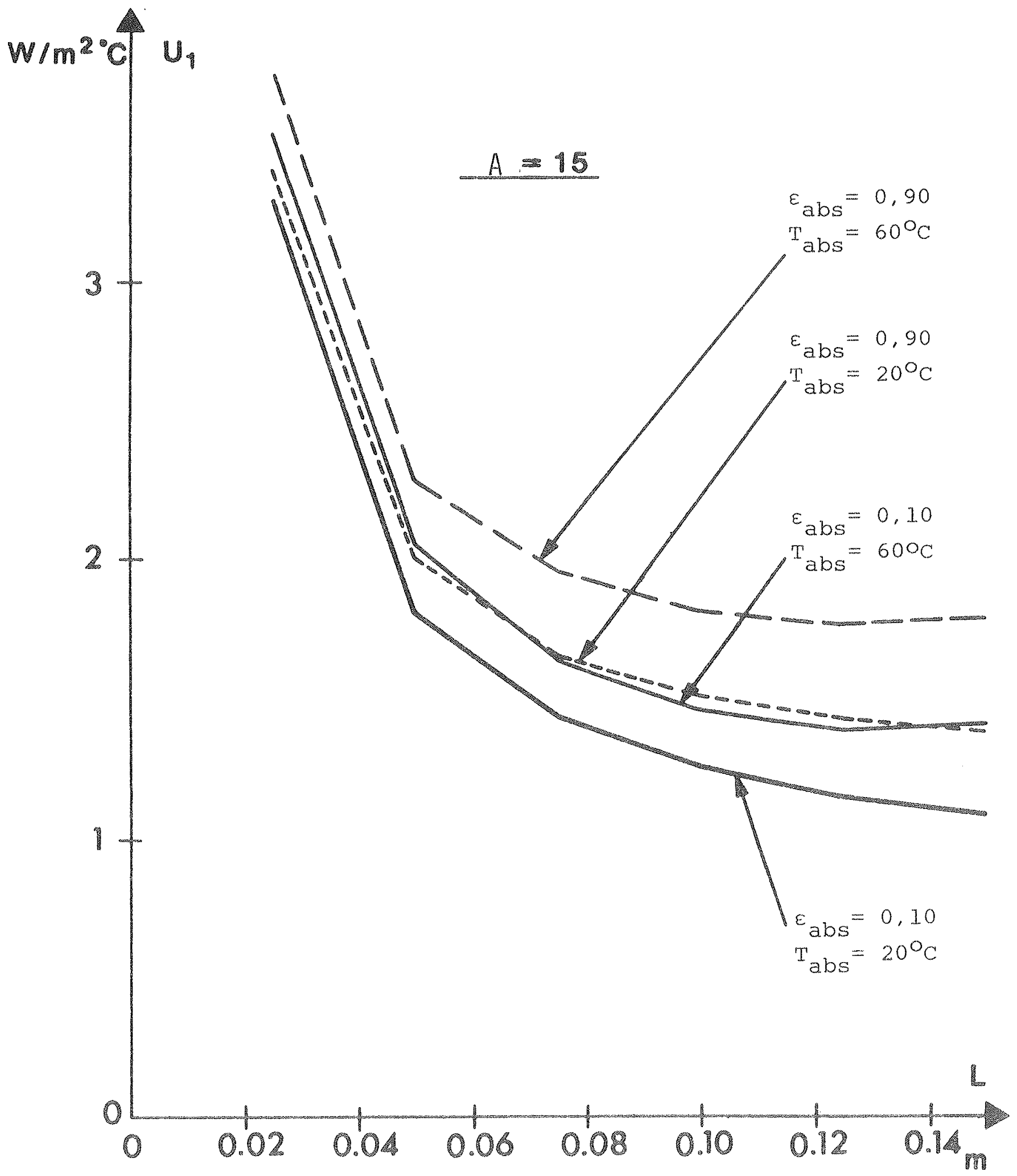

Figure 5.9 The heat loss coefficient between the absorber and the glazing $\left(U_{1}\right)$ as a function of the distance between the two surfaces (I) for different values of the absorber emissivity $\left(\varepsilon_{\mathrm{abs}}\right)$ and the absorber temperature ( $\mathrm{T}_{\mathrm{abs}}$ ). The glass temperature is $10^{\circ} \mathrm{C}$ and the aspect ratio is $A=15$. 


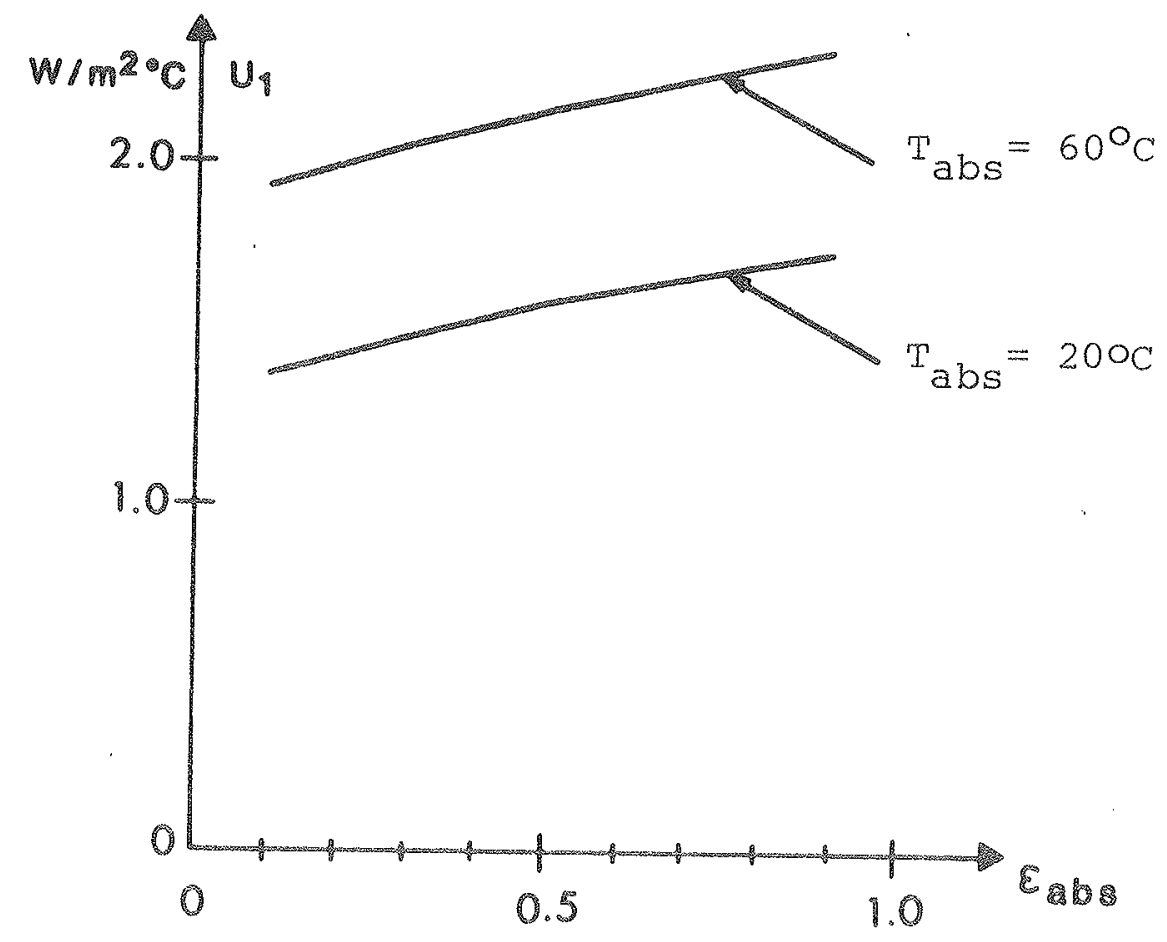

Fig. 5.10 The heat loss coefficient between the absorber and the glazing $\left(U_{1}\right)$ as a function of the absorber plate emissivity (eabs). The distance between the absorber and the outer glazing is $L=0,10 \mathrm{~m}$ and the mean distance be-. tween the honeycomb walls is $0,01 \mathrm{~m}$.

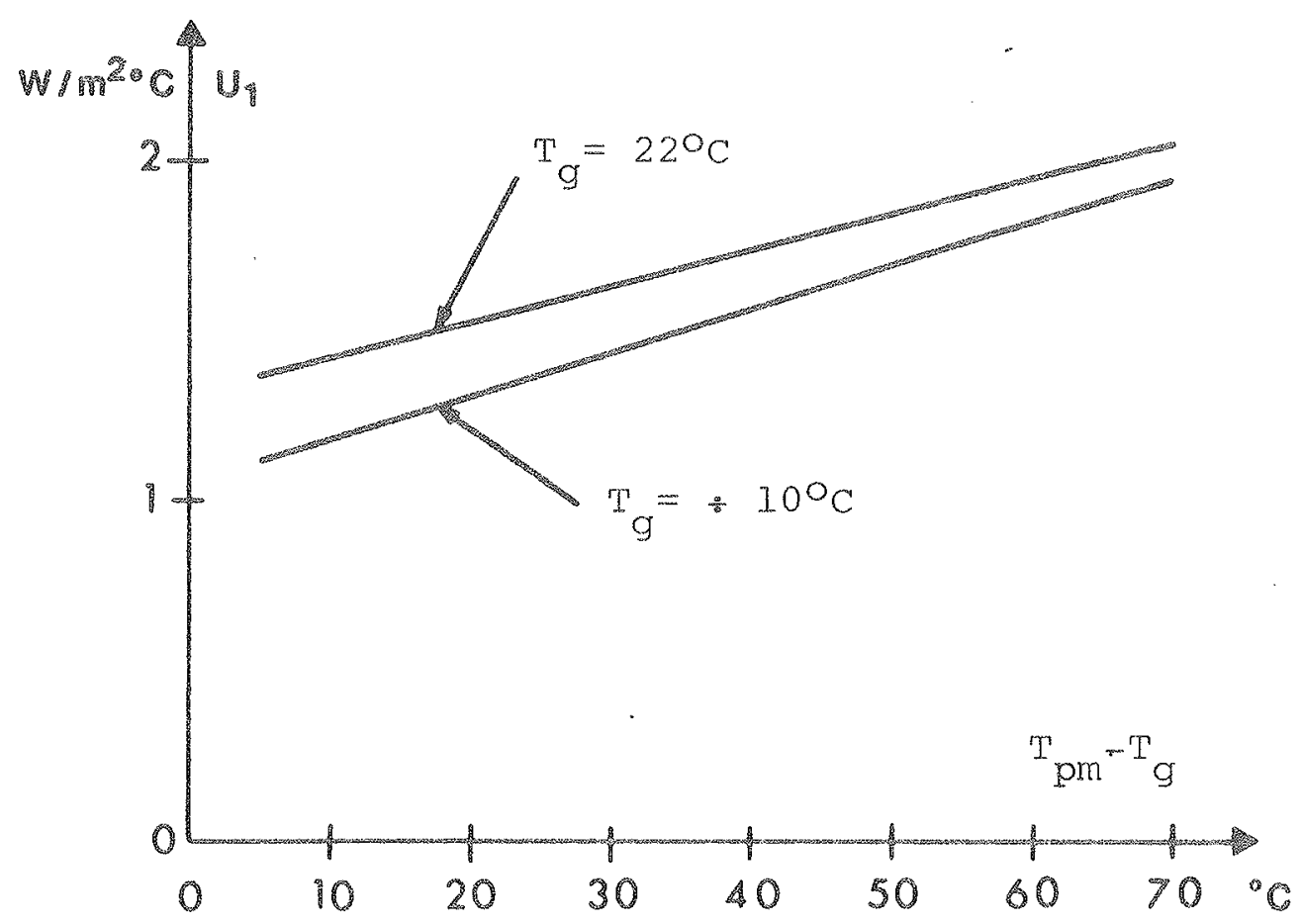

Fig. 5.11 The heat loss coefficient $\left(U_{1}\right)$ between the absorber and the glazing for two different values of the glass temperature. The distance between the absorber and the outer glazing is $L=0,10 \mathrm{~m}$ and the mean distance between the honeycomb walls is $0,01 \mathrm{~m}$. 
From figs. 5.8 and 5.9 it appears that if the aspect ratio $A=10$. is chosen, a plate distance of about $I_{1}=0.10 \mathrm{~m}$ will be favourable for both high and low values of the absorber temperature and the absorber emissivity. For $A=15, L$ should be about $0.15 \mathrm{~m}$. This corresponds to the dimensions chosen for the indoor and outdoor experiments. It is noticed that for these values of $L_{\text {, the }}$ value of $U_{1}$ drops about $25 \%$ when the absorber emittance is lowered from 0.90 to 0.10. From fig. 5.10 it appears that $U_{1}$ rises gradually when the absorber emittance is rised.

The dependence of $U_{1}$ on the difference between the absorber temperature and the glass temperature shows to be quite linear (fig.5.11). A rise of the temperature of the glass, and with this the mean temperature of the aix in the honeycombs, shows to cause a significant rise of $\mathrm{U}_{1}$. In fig. 5.12 an example of the temperature distribution between the absorber and the glazing is shown. The decreased radiation from the absorber in case of a low emittance will be compensated partly by an increased heat flow by convection and conduction in the air at the absorber due to an increased temperature gradient.

Comparison of the calculation model with the results of the measurements

A correction was made in order to include the outside thermal resistance $\left(m_{a}=0.04 \mathrm{~m}^{2}{ }^{\circ} \mathrm{C} / \mathrm{W}\right.$ corresponding to a wind velocity of $5 \mathrm{~m} / \mathrm{s}$ ) when calculating the theoretical heat loss coefficient (U).

In fig. 5.13 the results from the measurements of. TC-2 (the solar collector with the V-corrugated honeycombs) and TC-3 (the solar collector with the slatted honeycombs) are shown.

The calculations for the V-corrugated honeycomb seem to be in good agreement with the measured values. The theoreti- 


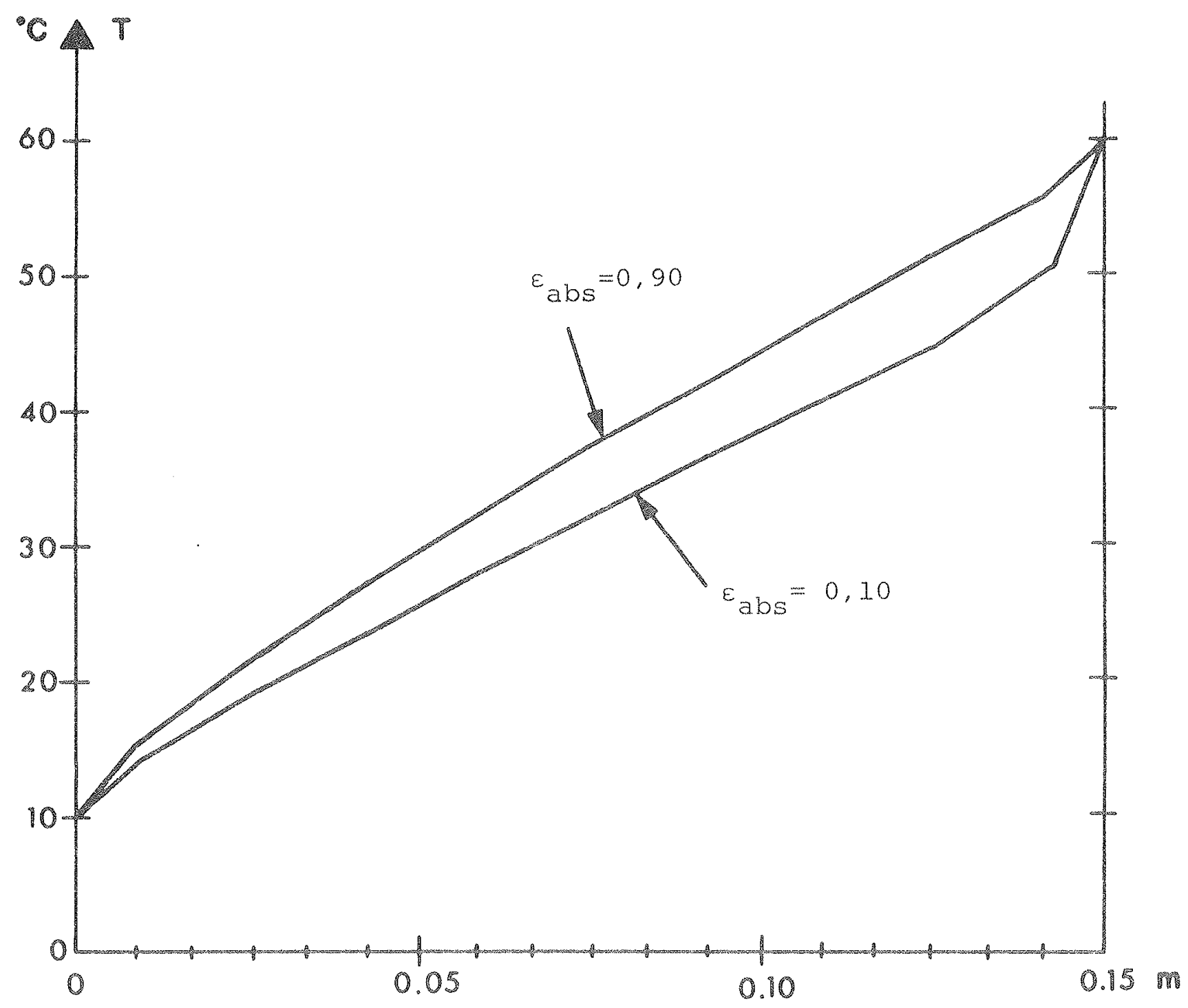

Fig. 5.12 The temperature distribution in the space between the absorber (right) and the glazing (left) for different absorber emissivities $\left(\varepsilon_{\text {abs }}\right)$ with an absorber temperature of $60^{\circ} \mathrm{C}$ and a glass temperature of $100 \mathrm{C}$. The distance between the glass and the absorber is $0,15 \mathrm{~m}$ and the mean distance between the honeycomb walls is $0,01 \mathrm{~m}$. 

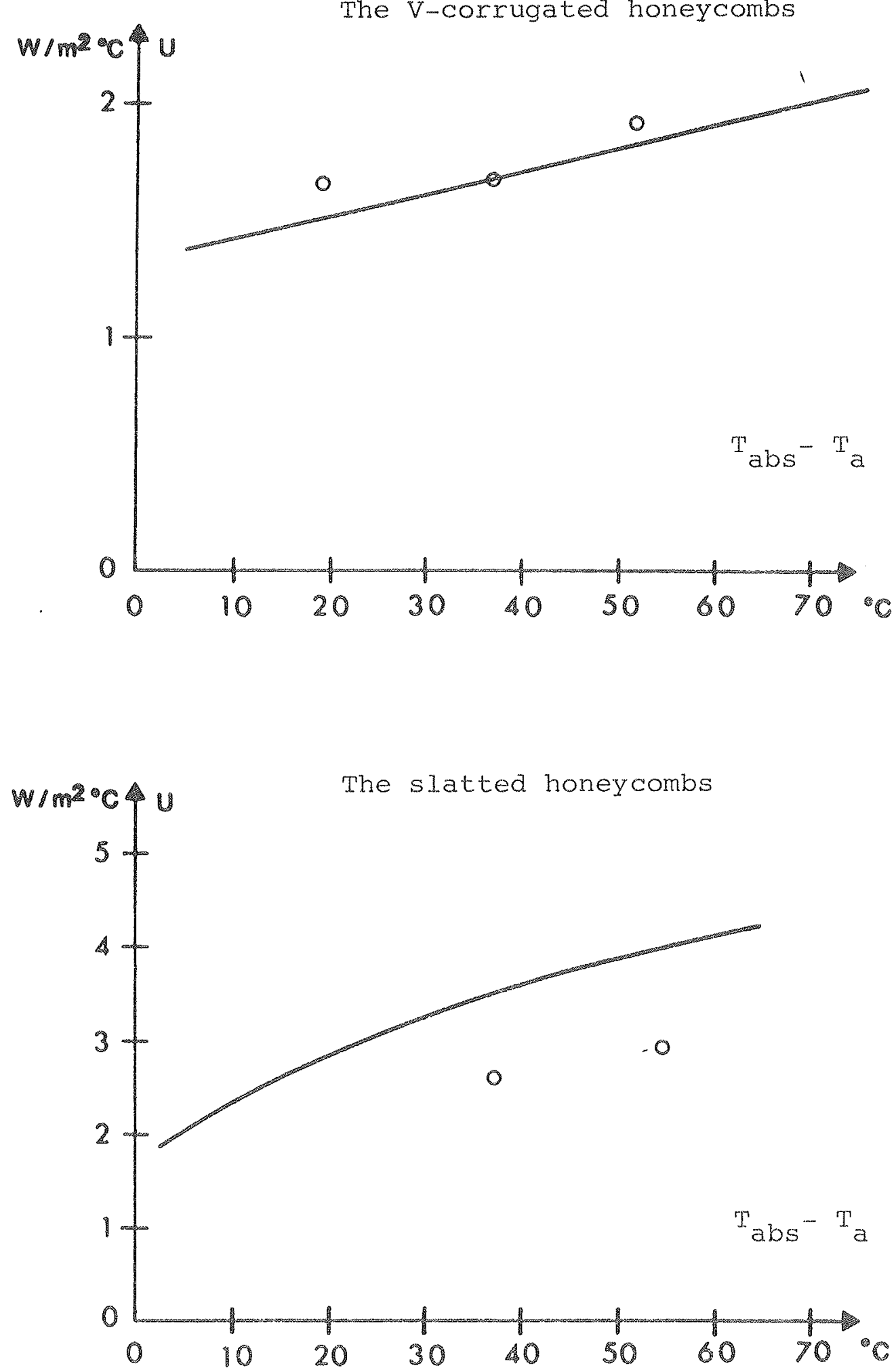

Figure 5.13 Comparison of the theoretical values (the curve) with the measured values (the points) of the heat loss coefficient (U) as a function of the difference between the absorber temperature ( $\mathrm{T}_{\mathrm{abs}}$ ) and the ambient air temperature $\left(\mathrm{T}_{\mathrm{a}}=20^{\circ} \mathrm{C}\right)$. 
cal prediction is within 10\%. For the slatted honeycombs the calculated values are $35 \%-37 \%$ bigger than the measured values.

A calculation with data corresponding to the outdoor measurement (as described in chapter 4.2) led to.

$$
\mathrm{U}=1.08 \mathrm{~W} / \mathrm{m}^{2}{ }^{\circ} \mathrm{C}
$$

which is $26 \%$ more than the measured value $\left(U=0.86 \mathrm{~W} / \mathrm{m}^{2}{ }^{\circ} \mathrm{C}\right)$. It is concluded that the calculations for the V-corrugated honeycombs give results that are fairly close to what is measured, but the calculations overestimates the heat loss coefficient in case of the slatted honeycombs. A reason for this could be that the equations used do not predict the convective heat transfer well enough in case of a selective absorber or in case of the rather big distance between the absorber and the glass $(0.15 \mathrm{~m})$.

Calculation of the convective heat transfer in a vee trough concentrator

For a vee trough (i.e. the air space between the triangular reflection cylinders which were proposed as a means of decreasing the heat loss) "the convective heat transfer has been studied. By using the theory in ( 7 ) the curves in fig. 5.14 were made. They illustrate the variation of the heat loss coefficient between the absorber and the outer glazing per $\mathrm{m}^{2}$ of the glazing for different plate spacings and different slopes. The reduction of the convective heat transfer for this solution compared with the flat plate collector is up to 25\%. The radiation heat exchange is also reduced because of the reduction of the absorber area.

The problem in this solution is that the temperature at the absorber is larger than in the flat plate case due to the concentration of the rays. If the storage is of water or a good conductor, this problem will be of minor importance. 


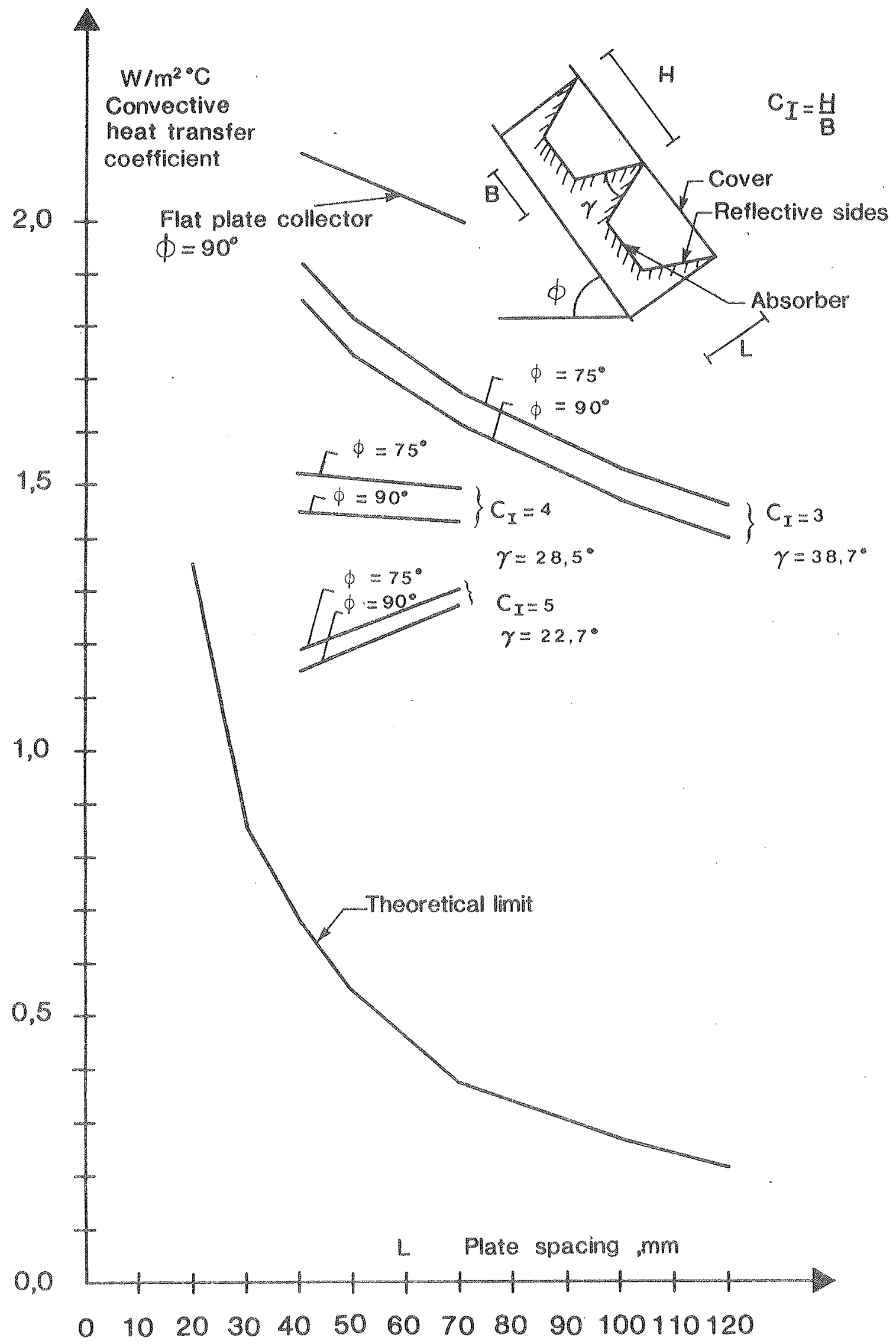

Fig. 5.14 convective heat transfer in a vee trough concentrator. Temperature difference $\Delta t=25^{\circ} \mathrm{C}$. 
Nevertheless, the suppresion of the convection does not seem to be as effective as with properly dimensioned honeycombs (fig. 5.7).

When constructing the solar collector with the reflecting cylinders, it was proposed to improve the heat loss coefficient by supplying honeycombs in the vee troughs. As mentioned in section 3.2. this turned out to be successful. 


\subsection{Modelling of Yearly Performance}

The solar transmission and the heat loss data have been used to model the performance of the thermal storage wall in a single-family dwelling.

The dwelling is assumed to have a total floor area of $150 \mathrm{~m}^{2}$. The building is insulated in accordance with the Danish Building Regulations. The areas, U-values and ventilation rates are shown in table 5.1. The windows have two layers of glass. The insulation in the outer walls has a thickness of $125 \mathrm{~mm}$. The ventilation air change rate is 0.50 per hour. With an assumed inside temperature of $20^{\circ} \mathrm{C}$, an outside temperature of $-12^{\circ} \mathrm{C}$ and a ground temperature of $8^{\circ} \mathrm{C}$, the design heat loss is $8.2 \mathrm{~kW}$. This value includes the stationary heat loss by transmission and ventilation. The rooms are assumed to be fitted with walls of bricks, ceilings of lightweight gipsum boards and wooden floors on concrete slab.

The rooms are supplied with incidential gains from electric appliances and inhabitants. The diurnal size of these gains is $18.2 \mathrm{~kW}$. The main part of these gains are supplied to the building in the evening.

The air temperature in the building is kept within the limits of $20-24^{\circ} \mathrm{C}$. If the air temperature exceeds $24^{\circ} \mathrm{C}$, the room is ventilated with outside air with a maximum air-change rate of 4 air-changes per hour.

The building is simulated exposed to a typical Danish climate called the Danish Test Reference Year (8).

The thermal storage wall is assumed to be constructed of $0.23 \mathrm{~m}$ concrete. The absorber area is assumed to be $18 \mathrm{~m}^{2}$ exclusive frame area which is assumed to be $20 \%$ of the area. It is constructed the same way as in the outdoor experiments. The thermal storage wall is assumed to be non-vented. 


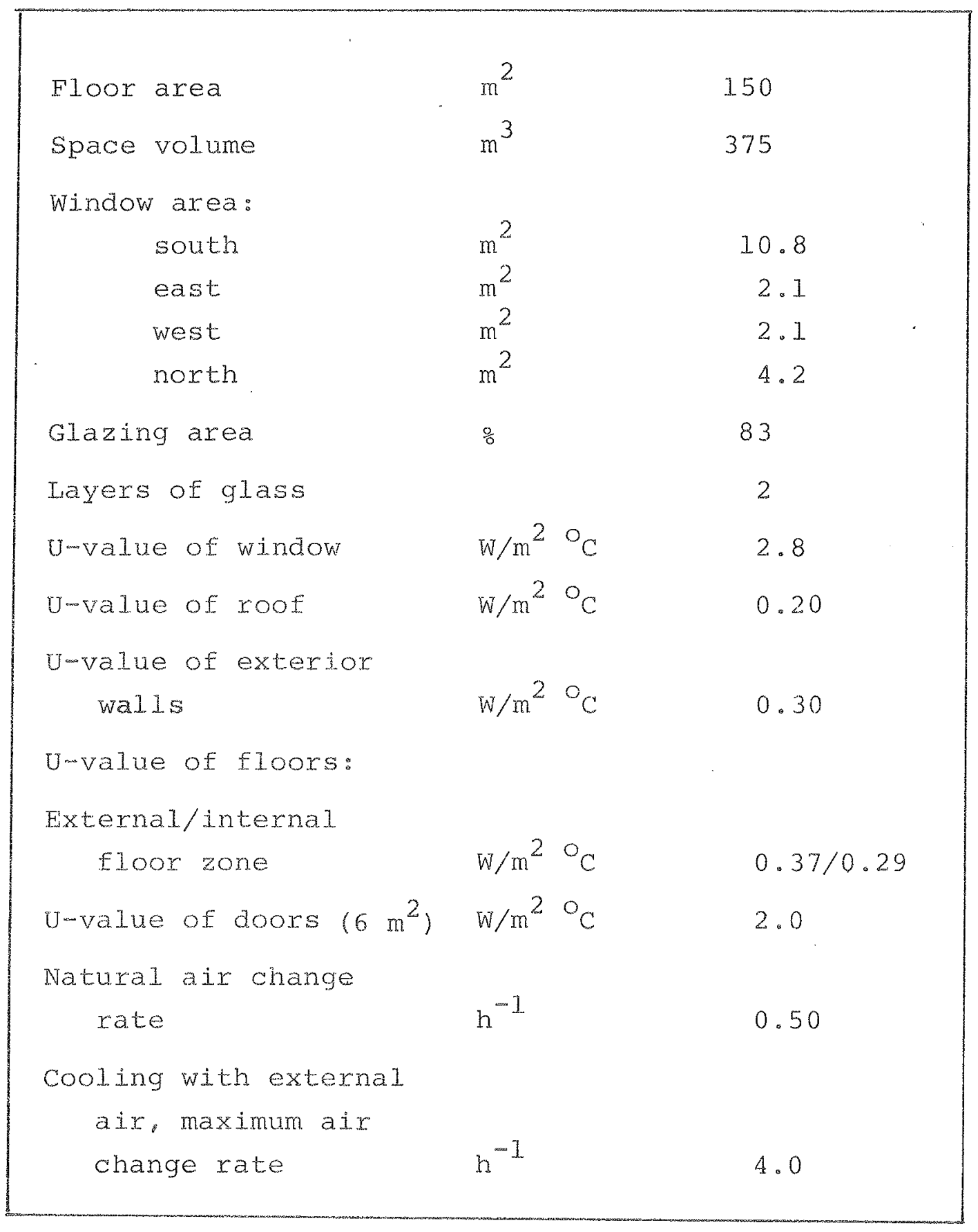

Table 5.1 Builaing data 
The solar transmission and heat loss data for the honeycomb have been integrated in a simulation model which calculates the performance of thermal storage walls in a building. The simulation is based on half-hourly steps through the Test Reference Year. The model is using an explicit solution method.

The model is used for calculating the performance in the below mentioned cases:

0) No thermal storage wall.

1) Thermal storage wall without honeycomb but with a selective absorber.

2) Thermal storage wall with V-corrugated honeycomb. Average distance between the honeycomb walls, $a=0.01 \mathrm{~m}$.

Absorber - outer glazing distance, $\mathrm{I}=0.150 \mathrm{~m}$. Emmisivity of absorber, $\varepsilon=0.10$.

3) As 2), but $L=0.10 \mathrm{~m}$

4) As 3) but $\varepsilon=0.90$

In the base case 1) is only used a single layer of glass. If the thermal storage wall has 2 layers of glass the thermal resistance will be increased due to the additional airspace but the solar transmission will be decreased. Totally will the additional layer of glass only increase the performance slightly.

The results are shown in table 5.2 .

The results show that the performance of the thermal storage wall can be remarkably improved by adding a honeycomb structure in the space between the absorber and the outer glazing. Even if honeycomb is used with a non-selective absorber, the performance is better than in cases where the honeycomb is not used, but where the absorber is selective. The results also show that an 
increase of the aspect ratio L/d from 10 to $15 \mathrm{in-}$ creases the savings with $15 \%$. The savings, listed in the tabel, is the difference in the annual energy consumption between case 0 ) and the actual case.

\begin{tabular}{|c|c|c|c|}
\hline & $\begin{array}{l}\text { Annual } \\
\text { energy } \\
\text { consump } \\
\text { tion }\end{array}$ & Savings & $\begin{array}{l}\text { Saving } \\
\text { per } \mathrm{m}^{2} \\
\text { absorber }\end{array}$ \\
\hline & k.wh/year & kWh/year & $\mathrm{m}^{\mathrm{k}} \mathrm{kh} /$ year \\
\hline o. Reference house & 11250 & - & - \\
\hline $\begin{array}{l}\text { 1. Thermal storage wall } \\
\text { without honeycomb. } \\
\text { selective absorber. } \\
L=0.03 \mathrm{~m}, \varepsilon=0.10\end{array}$ & 9570 & 1680 & 94 \\
\hline $\begin{array}{l}\text { 2. Thermal storage wall } \\
\text { with honeycomb. } \\
L=0.15 \mathrm{~m}, \varepsilon=0.10\end{array}$ & 8590 & 2660 & 148 \\
\hline $\begin{array}{l}\text { 3. Thermal storage wall } \\
\text { with honeycomb. } \\
I=0.10 \mathrm{~m}, \varepsilon=0.10\end{array}$ & 8930 & 2320 & 129 \\
\hline $\begin{array}{l}\text { 4. Thermal storage wall } \\
\text { with honeycomb. } \\
I=0.10^{\circ} \quad \varepsilon=0.90\end{array}$ & 9190 & 2060 & 114 \\
\hline
\end{tabular}

Table 5.2 Results of computer simulation 


\subsection{The Economic Savings}

The private economic savings are estimated in cases where the different types of thermal storage walls, which have been considered in the calculations, replace a part of the ordinary insulated southern wall. The area of the thermal storage walls is $18 \mathrm{~m}^{2}$ as used in the calculations. The economy is estimated by means of the simple pay back time, and it must be pointed out that several parameters are connected with considerable uncertainty, for example the development of the oil prices and the costs of manufacturing the honeycombs. The simple pay back time (in years) are calculated from:

$$
\eta=\frac{H \cdot \eta_{1} \cdot P}{P_{0} \cdot S}
$$

where

$$
\begin{aligned}
H= & \text { the heating value of the oil }(=9.84 \mathrm{kWh} / \mathrm{l}) \\
n_{1}= & \text { the efficiency of the boiler (it is typically } 0.81 \text { ) } \\
P= & \text { the extra expenses to be paid if a thermal storage } \\
& \text { wall is chosen instead of the insulated wall } \\
\mathrm{S}= & \text { the energy savings due to the thermal storage wall } \\
P_{0}= & \text { the oil price, the actual value is } 3.24 \mathrm{kr} / \ell
\end{aligned}
$$

For the V-corrugated honeycombs, it is possible to choose a rather small thickness of polycarbonate. When using foil, $0.1 \mathrm{~mm}$ thick, the price of the material and manufacturing is expected to be $35 \mathrm{kr}$. per $\mathrm{m}^{2}$ of plastic.

The total cost for the honeycombs per $\mathrm{m}^{2}$ of the thermal storage wall will then be $L \cdot / d \cdot 35 \mathrm{kr}$ ( $\mathrm{L}$ is the distance between the glazing and the absorber and $d$ is the mean distance between the honeycombs). The price of the selective foil. is about $200 \mathrm{kr} / \mathrm{m}^{2}$. Glazing, edge insulation and labour for mounting the materials are assumed to cost 
$300 \mathrm{kr}$ per $\mathrm{m}^{2}$ of the absorber. The price is quite low because the glazing replaces part of the normal building envelope.

In table 5.3 are shown the values of $n$ in the four cases:

1) no honeycombs, selective absorber

2) honeycombs with $\mathrm{L} / \mathrm{d}=15$, selective absorber

3) honeycombs with $\mathrm{L} / \mathrm{d}=10$, selective absorber

4) honeycombs with $\mathrm{L} / \mathrm{d}=10$, ordinary black absorber

\begin{tabular}{|l|c|c|c|}
\hline & $\mathrm{P}$ & $\mathrm{S}$ & $\mathrm{n}$ \\
\hline & $\frac{\mathrm{kr}}{\mathrm{m}}$ & $\frac{\mathrm{kWh}}{2}$ & years \\
\hline case 1 & 500 & 94 & 13 \\
case 2 & 1025 & 148 & 17 \\
case 3 & 850 & 129 & 16 \\
case 4 & 650 & 114 & 14 \\
\hline
\end{tabular}

Table 5.3 The expenses per $\mathrm{m}^{2}$ of the wall by using a thermal storage wall instead of an ordinary insulated wall (P) " the energy savings per $\mathrm{m}^{2}$ of the wall (S) and the simple pay back time ( $\mathrm{n})$.

It seems that only the pay back time for the thermal storage wall with honeycomb and a non-selective absorber is comparable to the thermal storage wall without honeycomb and a selective absorber. However, it is expected that it is possible to lower the price of the honeycomb for example by using vacuum forming. With this procedure it will be possible to reduce the material consumption and the manufacturing cost. 


\section{CONCLUSION}

Honeycomb structures offer several advantages in passive solar heating systems. It is possible to construct honeycomb structures which have a low heat loss coefficient and a high solar transmission. The durability can be large and the maintenance expenses low because there are no moving parts.

The tests in the solar simulator show that the V-corrugated honeycomb for normal incidence has a reduction of solar transmittance which is less than 3\%.

The reduction of the heat loss is approximately $30 \%$ when this type of honeycomb is placed in the test collector with a selective absorber.

The slatted honeycomb does not reduce the solar transmission for solar radiation parallel with the honeycomb walls, but the heat loss coefficient is not reduced in the experiments due to the slope of the honeycomb and the higher emissivity of the absorber.

The collector with reflecting triangular shaped cylinders and $V$ corrugated honeycomb shows a reduction of transmit-ted solar energy of about $20 \%$ compared to the reference collector. However, the reduction of the heat loss coefficient is about 50\% compared with the reference collector. The reduction of the transmission is due to the relatively low reflectivity at large angles of incidence at the reflecting surface.

The V-corrugated honeycomb has been selected for the outdoor experiments because of its performance. Also, it is easy to manufacture and support structural1y.

The tests show that the thermal storage wall with V-corrugated honeycomb has a better performance than the reference thermal storage wall without honeycomb. The savings of auxiliary energy show to be between 25 and $40 \%$ higher for the wall with honeycomb than for the wall without. 
The simulation of the thermal storage walls used in a single-family dwelling shows that the savings on a thermal storage wall with a selective absorber, but with out honeycomb, can be $94 \mathrm{kWh} / \mathrm{m}^{2}$. If the cavity between the absorber and the glazing is filled with V-corrugated honeycomb, the savings will be increased with 35 to $60 \%$ depending on the type of honeycomb. The largest savings are obtained by the honeycomb with an aspect ratio ( $\mathrm{L} / \mathrm{d}$ ) of 15. The results also show that the savings will only be reduced with approx. 12\% if the honeycomb is used with a non-selective instead of a selective absorber.

The economic estimates indicates that it can be economical feasible to use honeycomb for the thermal storage walls.

The results from this study show that there is a large potential for application of honeycomb structures, not only for solar walls but also in other passive solar systems, for example in direct gain systems. 


\section{REFERENCES}

(1) Long-term glazing performance.

G. Jorgensen, SERI, Prensented at "Solar Glazing: 1979, Topical conference", Stockton state college, Pomona, New Jersey, June 22-23 1979.

(2) S. Svendsen. Solfangeres effektivitet, målt og beregnet. Meddelelse nr. 109, Laboratoriet for Varmeisolering, $\mathrm{DTH}, 1980$.

(3) S. Hadvig. Termisk stråling for ingeniører. Danmarks tekniske Hojskole, Laboratoriet for varme- og klimateknik, 1980.

(4) D.R. Smart, K.G.T. Hollands and G.D. Raithby. Free convection heat transfer across Rectangular-Celled Diathermanous Honeycombs, Journal of heat transfer vol 102 , Feb. 1980, pp 75-80.

(5) R.L.D. Cane, K.G.T. Hollands, G.D. Raithby and T.E. Unny. Free convection heat transfer across inclined honeycomb panels. Journal of heat transfer, vol 99 pp 86-91, 1977.

(6) A. Bejan and C.L. Tiens. Laminax natural convection heat transfer in a horizontal cavity with different end temperatures. Asme Journal of heat transfer, vol 100 no 4 pp $640-647,1978$.

(7) B.A. Meyer, J.W. Mitchell and M.M. El-Wakil. Convective Heat Transfer in Vee-Trough Linear Concentrators. Solar Energy, vol 28 no 1 pp $33-40,1982$.

(8) Vejrdata for VVS og energi, Dansk referenceår TRY, SBIrapport 135, Statens Byggeforskningsinstitut, 1982. 
(9) S. Svendsen. Undersøgelse af målenøjagtigheden ved effektivitetsprøvning af solfangere. Laboratoriet for varmeisolering, DTH, 1983.

(10) H. Lawaetz. Solarimeters vinkelforhold til skarm. Laboratoriet for varmeisolering, DTH, 1976.

(11) I.A. Duffie and W.A. Beckman. Solar Engineering of thermal processes. Wiley-Interscience, 1980.

(12) Rias plast (product catalogue of plastic materials). 
APPENDIX A

\section{Thermal Expansion of the Honeycombs}

The size of the thermal expansions of the honeycombs is estimated in the following.

The expansions of the other materials, as for example the absorber plate, are relatively small, and therefore not considered.

For polycarbonate we have the coefficjent of thermal expansion ( 12 ):

$$
\beta \simeq 70 \cdot 10^{-6} \mathrm{~K}^{-1}
$$

For the plastic with the length $\Delta l$ the expansion at the absorber, due to the temperature rise $\Delta \mathrm{T}$, will be

$$
\Delta l=\beta \cdot \ell \cdot \Delta \mathrm{T}
$$

In the case of linear temperature distribution through the plastic it will tend to bend with the curvature H found from:

$$
\mathrm{H}=\frac{\beta \cdot \Delta \mathrm{T}}{\mathrm{h}}
$$

where $\Delta T$ is the temperature difference between the hot and the cold edge of the plastic (it is assumed to be the same as the previously mentioned $\Delta \mathrm{T})$, and $\mathrm{h}$ is the distance between the two edges. Thus the radius $r$ of the curvature is

$$
x=1 / H=\frac{h \cdot}{\beta \cdot \Delta T}
$$

In fig. A.1 is shown the maximum leakiness d between the plastic and the glass which would occur if the plastic could move freely. From the figure it is found that

$$
d=r \cdot(1-\cos (\ell / 2 r))
$$

By initial theoretical estimations it was found that the difference between the absorber temperature and the ambient air temperature would not exceed $\Delta \mathrm{T}=65^{\circ} \mathrm{C}$.

For the solar collectors the length of the honeycombs are $\ell=0.80 \mathrm{~m}$ and for the $\mathrm{V}$-corrugated honeycombs the width $\mathrm{h}=0.10 \mathrm{~m}$ was used. In this situation we find the following expansions: 


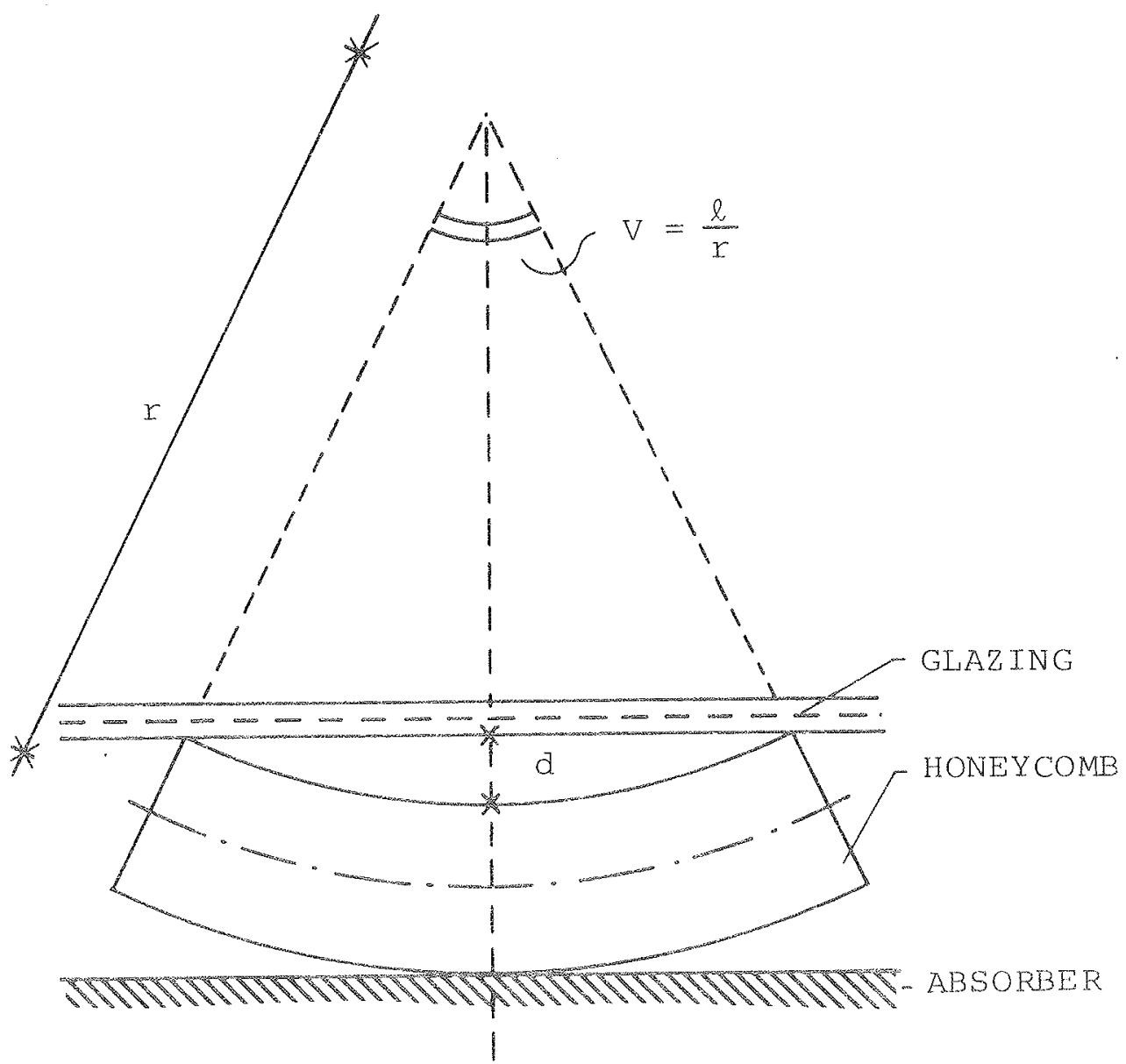

Fig. Al skech of the curvature of the honeycomb.
$\Delta \ell=4 \mathrm{~mm}$
and
$\mathrm{d}=4 \mathrm{~mm}$

For the honeycombs made for the outdoor experiments, pieces of polycarbonate with a length of $2 \mathrm{~m}$ and width of $0.15 \mathrm{~m}$ was used for fastening of the honeycombs in the vertical direction. In this case we find:
$\Delta \ell=9 \mathrm{~mm}$
and
$a=15 \mathrm{~mm}$

The calculations show that it is necessary to consider the lengthwise movements of the honeycombs. The curvature of the honeycombs is also considerable but it showed to be of no importance when testing the solar collectors. For the vertical pieces of polycarbonate, in the case of the outdoor experiments, the curvature is rather big, and it could be imagined that the tendency to bend would be damaging for the honeycombs. Fortunately no damages were observed during the experiments, so the movements must have been absorbed by minor bulges in the plastic. 


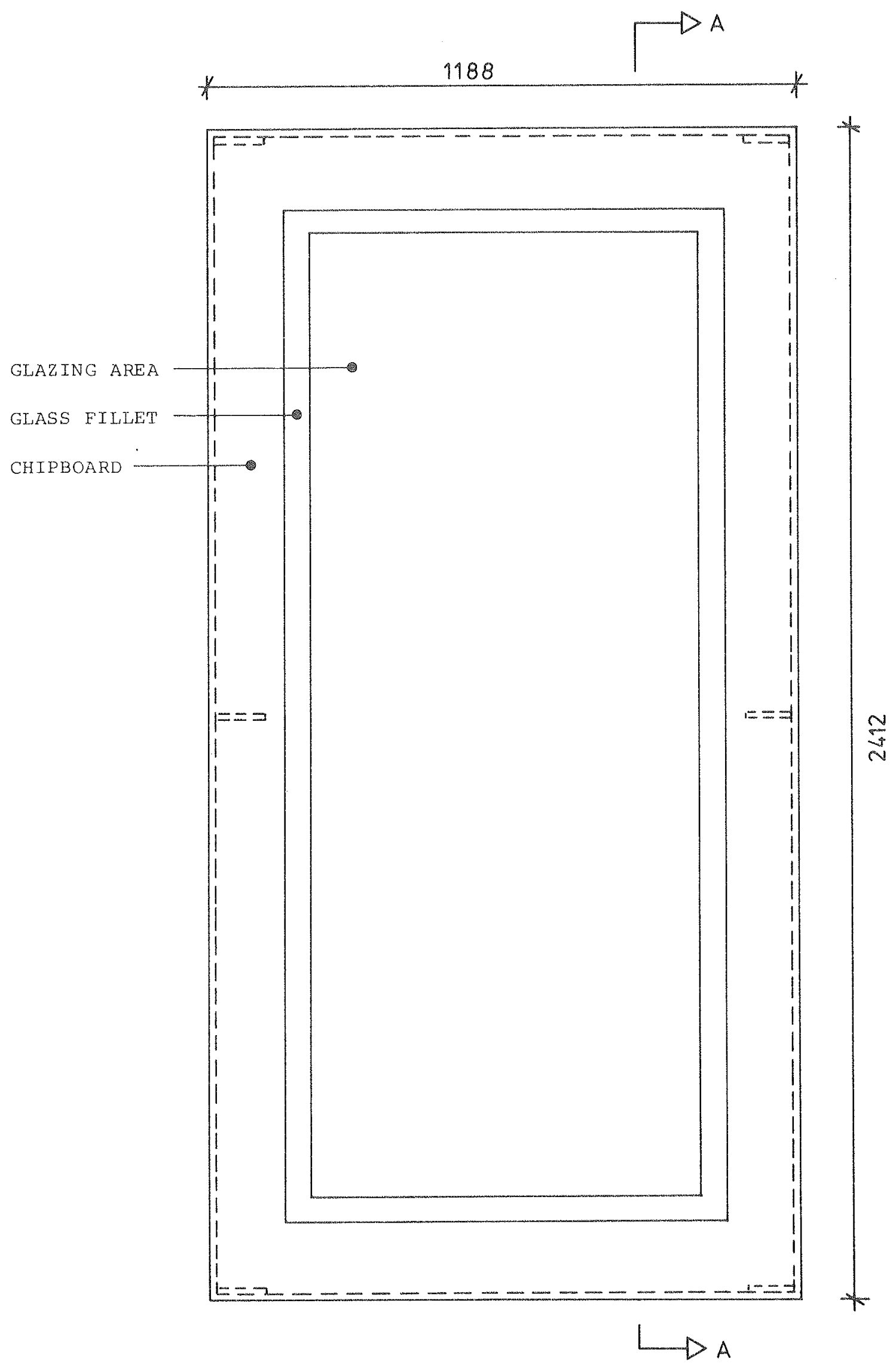

Figure B-1 Plan of one of the test collectors. 


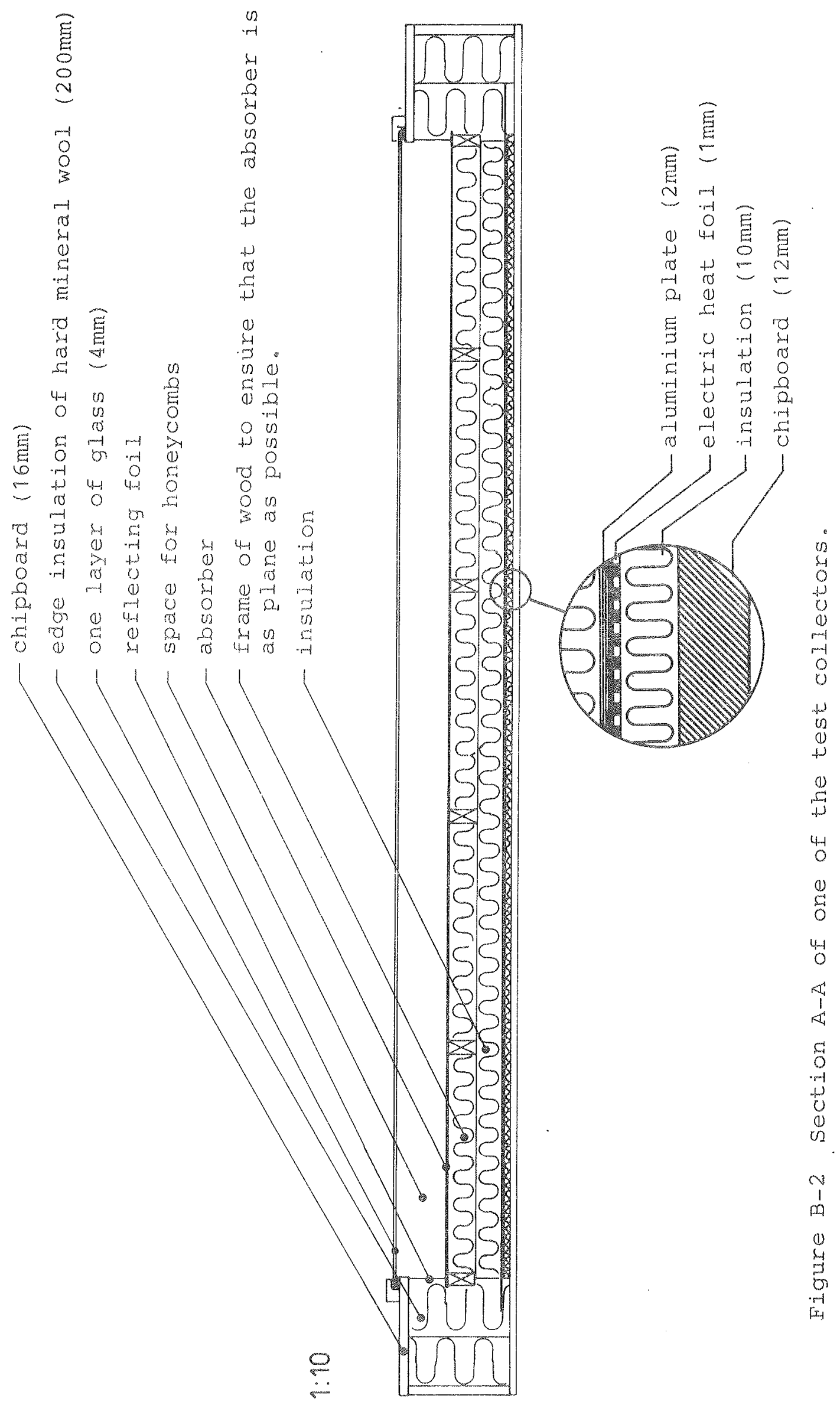


APPENDIX C

Results from the testing of the solar collectors

\begin{tabular}{|c|c|c|c|c|c|c|c|c|c|c|c|}
\hline V & $\mathrm{T}_{\mathrm{pm}}$ & $\mathrm{T}_{\mathrm{a}}$ & $\Delta \mathrm{T}$ & $\mathrm{T}_{1}$ & $\Delta \mathrm{T}_{1}$ & $q$ & $q_{s}$ & $q_{b}$ & $q_{u}$ & $I_{m}$ & $\eta$ \\
\hline$g x$ & ${ }^{\circ} \mathrm{C}$ & ${ }^{\circ} \mathrm{C}$ & ${ }^{\circ} \mathrm{C}$ & ${ }^{\circ} \mathrm{C}$ & ${ }^{\circ} \mathrm{C}$ & $\mathrm{w} / \mathrm{m}^{2}$ & $\mathrm{~W} / \mathrm{m}^{2}$ & $w / m^{2}$ & $\mathrm{~W} / \mathrm{m}^{2}$ & $w / m^{2}$ & 응 \\
\hline \multirow[t]{4}{*}{67,5} & 29,0 & 25,2 & 3,8 & 23,9 & 5,1 & 804 & $I$ & 3 & 808 & 931 & 86,8 \\
\hline & 29,0 & 25,2 & 3,8 & 24,1 & 4,9 & 803 & 1 & 3 & 807 & 931 & 86,7 \\
\hline & 29.0 & 25,3 & 3,7 & 24,1 & 4,9 & 807 & 1 & 3 & 811 & 931 & 87,1 \\
\hline & 28,9 & 25,4 & 3,5 & 24,2 & 4.7 & 806 & 1 & 3 & 810 & 931 & 87,0 \\
\hline \multirow[t]{4}{*}{67,5} & 41,3 & 26,3 & 15,0 & 36,3 & 5,0 & 770 & 4 & 3 & 777 & 931 & 83,5 \\
\hline & 41,2 & 26,3 & 14,9 & 37,4 & 3,8 & 761 & 4 & 2 & 767 & 931 & 82,4 \\
\hline & 41,1 & 26,2 & 14,9 & 37,3 & 3,8 & 758 & 4 & 2 & 764 & 931 & 82,1 \\
\hline & 41,1 & 26,3 & 14,8 & 36,5 & 4,6 & 761 & 4 & 3 & 768 & 931 & 82,5 \\
\hline \multirow[t]{4}{*}{67.5} & 64,3 & 26,0 & 38,3 & 56,3 & 8,0 & 667 & 11 & 5 & 683 & 923 & 74,0 \\
\hline & 64,3 & 25,9 & 38,4 & 56,3 & 8,0 & 667 & 11 & 5 & 683 & 923 & 74,0 \\
\hline & 64,3 & 25,9 & 38,4 & 56,3 & 8,0 & 667 & 11 & 5 & 683 & 923 & 74,0 \\
\hline & 64,3 & 25,9 & 38,4 & 56,3 & 8,0 & 667 & 11. & 5 & 683 & 923 & 74,0 \\
\hline \multirow[t]{4}{*}{67.5} & 79.8 & 26,1 & 53,7 & 75,6 & 4,2 & 594 & 16 & 3 & 613 & 911 & 67,3 \\
\hline & 79.8 & 26,1 & 53,7 & 75,6 & 4,2 & 595 & 16 & 3 & 614 & 911 & 67,4 \\
\hline & 79,8 & 26,2 & 53,6 & 75,6 & 4,2 & 601 & 16 & 3 & 620 & 911 & 68,1 \\
\hline & 79,8 & 26,1 & 53,7 & 75,6 & 4,2 & 598 & 16 & 3 & 617 & 911 & 67,7 \\
\hline
\end{tabular}

Table C-1 TC-1. Determination of the efficiency 


\begin{tabular}{|c|c|c|c|c|c|c|c|c|c|c|}
\hline $\mathrm{v}$ & $\mathrm{T}_{\mathrm{pm}}$ & $\mathrm{T}_{\mathrm{a}}$ & $\Delta \mathrm{T}$ & $\mathrm{T}_{1}$ & $\Delta_{1}$ & $\mathrm{~g}$ & $\mathrm{q}_{\mathrm{S}}$ & $\mathrm{q}_{\mathrm{b}}$ & $\mathrm{q}_{\mathrm{t}}$ & $\mathrm{U}$ \\
\hline $\mathrm{gr}$ & $\mathrm{O}_{\mathrm{C}}$ & $\mathrm{O}_{\mathrm{C}}$ & $\mathrm{O}_{\mathrm{C}}$ & $\mathrm{O}_{\mathrm{C}}$ & $\mathrm{O}_{\mathrm{C}}$ & $\mathrm{W} / \mathrm{m}^{2}$ & $\mathrm{~W} / \mathrm{m}^{2}$ & $\mathrm{~W}^{2} \mathrm{~m}^{2}$ & $\mathrm{~W} / \mathrm{m}^{2}$ & $\mathrm{~W} / \mathrm{m}^{20} \mathrm{C}$ \\
\hline \multirow{2}{*}{67,5} & 72,1 & 22,5 & 49,6 & 71,0 & 1,1 & 167,5 & 15,1 & 0,7 & 151,7 & 3,06 \\
& 72,0 & 22,6 & 49,4 & 71,1 & 0,9 & 167,5 & 15,1 & 0,6 & 151,8 & 3,07 \\
& 72,1 & 22,6 & 49,5 & 71,1 & 1,0 & 166,9 & 15,1 & 0,6 & 151,2 & 3,05 \\
& 72,1 & 22,6 & 49,5 & 71,1 & 1,0 & 167,1 & 15,1 & 0,6 & 151,4 & 3,06 \\
& 72,2 & 22,3 & 49,9 & 71,2 & 1,0 & 158,8 & 15,2 & 0,6 & 143,0 & 2,87 \\
& 72,2 & 22,3 & 49,9 & 71,3 & 0,9 & 158,8 & 15,2 & 0,6 & 143,0 & 2,87 \\
& 72,2 & 22,3 & 49,9 & 71,3 & 0,9 & 159,4 & 15,2 & 0,6 & 143,6 & 2,88 \\
& 72,1 & 22,3 & 49,9 & 71,3 & 0,8 & 158,4 & 15,2 & 0,5 & 142,7 & 2,86 \\
\hline
\end{tabular}

Table C-2 TC-n. Determination of the heat loss coefficient 


\begin{tabular}{|c|c|c|c|c|c|c|c|c|c|c|c|}
\hline v & $T_{\mathrm{pm}}$ & $\mathrm{T}_{\mathrm{a}}$ & $\Delta \mathrm{T}$ & $\mathrm{T}_{1}$ & $\Delta \mathrm{T}_{1}$ & $q$ & $q_{S}$ & ${ }^{g_{b}}$ & $q_{u}$ & $I_{m}$ & $\eta$ \\
\hline gr & ${ }^{\circ} \mathrm{C}$ & ${ }^{\circ} \mathrm{C}$ & ${ }^{\circ} \mathrm{C}$ & ${ }^{\circ} \mathrm{C}$ & ${ }^{\circ} \mathrm{C}$ & $w / m^{2}$ & $w / m^{2}$ & $w / m^{2}$ & $w / m^{2}$ & $w / m^{2}$ & $\%$ \\
\hline \multirow[t]{4}{*}{67,5} & 29,1 & 23,5 & 5,6 & 22,5 & 6,6 & 795 & 2 & 4 & 801 & 957 & 83,7 \\
\hline & 29.1 & 23,5 & 5,6 & 22,7 & 6.4 & 799 & 2 & 4 & 805 & 957 & 84,1 \\
\hline & 29,0 & 23,5 & 5,5 & 22,7 & 6,3 & 795 & 2 & 4 & 801 & 957 & 83,7 \\
\hline & 29,1 & 23,5 & 5,6 & 22,8 & 6,3 & 797 & 2 & 4 & 803 & 957 & 83,9 \\
\hline \multirow[t]{4}{*}{67,5} & 42,1 & 24,5 & 17,6 & 33.7 & 8,4 & 749 & 6 & 5 & 760 & 965 & 78,8 \\
\hline & 42,2 & 24,6 & 17,6 & 33,8 & 8,5 & 747 & 6 & 5 & 758 & 965 & 78,5 \\
\hline & 42,2 & 24,5 & 17,7 & 33,7 & 8,5 & 746 & 6 & 5 & 757 & 965 & 78,4 \\
\hline & 42,2 & 24,5 & 17,7 & 33,6 & 8,6 & 747 & 6 & 5 & 758 & 965 & 78,5 \\
\hline \multirow[t]{4}{*}{67,5} & 64,2 & 24,9 & 39,3 & 54,7 & 9,5 & 681 & 14 & 6 & 701 & 953 & 73,6 \\
\hline & 64,2 & 24,9 & 39,3 & 54,7 & 9,5 & 678 & 14 & 6 & 698 & 953 & 73,2 \\
\hline & 64,2 & 25,0 & 39,2 & 54,7 & 9,5 & 677 & 14 & 6 & 697 & 953 & 73,1 \\
\hline & 64,1 & 25,0 & 39,1 & 54,7 & 9,4 & 681 & 14 & 6 & 701 & 953 & 73,6 \\
\hline \multirow[t]{4}{*}{67,5} & 81,6 & 25,0 & 56,6 & 73,0 & 8,6 & 589 & 21 & 6 & 616 & 923 & 66,7 \\
\hline & 81,6 & 25,0 & 56,6 & 73,0 & 8,6 & 595 & 21 & 6 & 622 & 923 & 67,4 \\
\hline & 81,6 & 25,0 & 56,6 & 73,0 & 8,6 & 593 & 21 & 6 & 620 & 923 & 67,2 \\
\hline & 81,6 & 25,0 & 56,6 & 73,0 & 8,6 & 593 & 21 & 6 & 620 & 923 & 67,2 \\
\hline \multirow[t]{4}{*}{90} & 27,7 & 24,3 & 3,4 & 23,6 & 4,1 & 721 & 1 & 3 & 725 & 872 & 83,1 \\
\hline & 27,7 & 24,4 & 3,3 & 23,7 & 4,0 & 719 & 1 & 3 & 723 & 872 & 82,9 \\
\hline & 27,7 & 24,5 & 3,2 & 23,7 & 4,0 & 719 & 1 & 3 & 723 & 872 & 82,9 \\
\hline & 27,7 & 24,4 & 3,3 & 23,7 & 4,0 & 717 & 1 & 3 & 721 & 872 & 82,7 \\
\hline
\end{tabular}

Table C-3 TC-2. Determination of the efficiency 


\begin{tabular}{|c|c|c|c|c|c|c|c|c|c|c|}
\hline v & $\mathrm{T}_{\mathrm{pm}}$ & $\mathrm{T}_{\mathrm{a}}$ & $\Delta \mathrm{T}$ & $\mathrm{T}_{1}$ & $\Delta \mathrm{T}_{1}$ & $q$ & $q_{s}$ & $q_{b}$ & $q_{t}$ & U \\
\hline $9 x$ & ${ }^{\circ} \mathrm{C}$ & ${ }^{\circ} \mathrm{C}$ & ${ }^{\circ} \mathrm{C}$ & ${ }^{\circ} \mathrm{C}$ & ${ }^{\circ} \mathrm{C}$ & $w / m^{2}$ & $w / m^{2}$ & $w / m^{2}$ & $w / m^{2}$ & $w / m^{20} \mathrm{C}$ \\
\hline \multirow[t]{4}{*}{67,5} & 39,6 & 20,6 & 19,0 & 38,9 & 0,7 & 46,2 & 6,4 & 0,4 & 39,4 & 2.07 \\
\hline & 39,6 & 20,8 & 18,8 & 38,8 & 0,7 & 46,0 & 6,3 & 0,4 & 39,3 & 2,09 \\
\hline & 39,6 & 20,8 & 18,7 & 38,8 & 0,8 & 46,1 & 6,3 & 0,5 & 39,3 & 2,10 \\
\hline & 39,6 & 20,9 & 18,7 & 38,8 & 0,8 & 45,6 & 6,3 & 0,5 & 38,8 & 2,07 \\
\hline \multirow[t]{4}{*}{90} & 39,7 & 20,9 & 18,8 & 38,8 & 0,9 & 38,6 & 6,4 & 0,6 & 31,6 & 1,68 \\
\hline & 39,7 & 20,8 & 18,8 & 38,8 & 0,9 & 38.2 & 6,4 & 0,6 & 31,2 & 1,66 \\
\hline & 39.7 & 21,0 & 18,8 & 38,8 & 0,9 & 37,9 & 6,4 & 0,6 & 30,9 & 1,64 \\
\hline & 39.7 & 21,0 & 18,8 & 38,8 & 0,9 & 37,9 & 6,4 & 0.6 & 30,9 & 1,64 \\
\hline \multirow[t]{4}{*}{67,5} & 58,2 & 21,2 & 37,0 & 56,6 & 1,6 & 100,2 & 13,1 & 1,0 & 86,1 & 2,33 \\
\hline & 58,2 & 21,2 & 37,0 & 56,6 & 1,6 & 101,2 & 13,1 & 1,0 & 87,1 & 2,35 \\
\hline & 58,3 & $2 I, 2$ & 37,1 & 56,6 & 1,7 & 100,8 & 13,1 & 1,1 & 86,6 & 2.33 \\
\hline & 58,3 & 21,1 & 37,2 & 56,4 & 1,9 & 101,2 & 13,1 & 1,2 & 86,9 & 2,34 \\
\hline \multirow[t]{4}{*}{90} & 58,4 & 21.2 & 37,2 & 57,4 & 1,0 & 75,8 & 13,1 & 0,6 & 62,1 & 1,67 \\
\hline & 58,4 & 21,1 & 37,3 & 57,3 & 1,1 & 76,1 & 13,1 & 0,7 & 62,3 & 1,67 \\
\hline & 58,4 & 21,1 & 37,3 & 57.2 & 1,2 & 76,8 & 13,1 & 0,8 & 62,9 & 1,69 \\
\hline & 58,4 & 21,1 & 37.3 & 57,2 & 1,2 & 76,7 & 13,1 & 0,8 & 62,8 & 1,68 \\
\hline \multirow[t]{4}{*}{67.5} & 72,9 & 22,3 & 50,6 & 73,4 & $-0,5$ & 145,1 & 19,0 & $-0,3$ & 126,4 & 2,50 \\
\hline & 72,9 & 22,3 & 50,6 & 73,5 & $-0,6$ & 144,7 & 19,0 & $-0,4$ & 126,1 & 2,49 \\
\hline & 72,8 & 22,3 & 50,5 & 73,4 & $-0,6$ & 144,9 & 18,9 & $-0,4$ & 126,4 & 2,50 \\
\hline & 72,8 & 22,3 & 50,5 & 73,5 & $-0,7$ & 145,5 & 18,9 & $-0,4$ & 127,0 & 2,51 \\
\hline \multirow[t]{4}{*}{90} & 73,5 & 21,6 & 51,9 & 73,6 & $-0,1$ & 118,0 & 19,5 & $-0,1$ & 98,6 & 1,90 \\
\hline & 73.5 & 21,6 & 51,9 & 73,6 & $-0,1$ & 118,4 & 19,5 & $-0,1$ & 99,0 & 1,91 \\
\hline & 73,5 & 21,5 & 52,0 & 73,1 & $-0,2$ & 119,9 & 19,5 & $=0,1$ & 100,5 & 1,93 \\
\hline & 73,5 & 21,5 & 52,0 & 73,6 & $-0,1$ & 119,2 & 19,5 & $-0,1$ & 99,8 & 1,92 \\
\hline
\end{tabular}

Table C-4 TC-2. Determination of the heat loss coefficient 


\begin{tabular}{|c|c|c|c|c|c|c|c|c|c|c|}
\hline $\mathrm{v}$ & $\mathrm{T}_{\mathrm{pm}}$ & $\mathrm{T}_{\mathrm{a}}$ & $\Delta \mathrm{T}$ & $\mathrm{T}_{1}$ & $\Delta_{\mathrm{I}}$ & $\mathrm{q}$ & $\mathrm{q}_{\mathrm{S}}$ & $\mathrm{q}_{\mathrm{b}}$ & $\mathrm{q}_{\mathrm{t}}$ & $\mathrm{U}$ \\
\hline $\mathrm{gr}$ & $\mathrm{O}_{\mathrm{C}}$ & ${ }_{\mathrm{C}}$ & ${ }_{\mathrm{C}}$ & $\mathrm{O}_{\mathrm{C}}$ & ${ }_{\mathrm{C}}$ & $\mathrm{W} / \mathrm{m}^{2}$ & $\mathrm{~W} / \mathrm{m}^{2}$ & $\mathrm{~W} / \mathrm{m}^{2}$ & $\mathrm{~W} / \mathrm{m}^{2}$ & $\mathrm{~W} / \mathrm{m}^{2 \mathrm{C}_{\mathrm{C}}}$ \\
\hline \multirow{2}{*}{90,0} & 58,4 & 20,9 & 37,5 & 57,0 & 1,4 & 81,4 & 10,8 & 0,9 & 69,7 & 1,86 \\
& 58,4 & 20,9 & 37,5 & 56,9 & 1,5 & 81,0 & 10,8 & 1,0 & 69,2 & 1,85 \\
& 58,4 & 20,9 & 37,5 & 56,9 & 1,5 & 81,0 & 10,8 & 1,0 & 69,2 & 1,85 \\
& 58,4 & 20,9 & 37,5 & 56,9 & 1,5 & 81,1 & 10,8 & 1,0 & 69,3 & 1,85 \\
& 77,0 & 19,9 & 57,1 & 76,5 & 0,5 & 134,5 & 17,4 & 0,3 & 116,8 & 2,05 \\
& 77,0 & 19,9 & 57,1 & 76,5 & 0,5 & 134,3 & 17,4 & 0,3 & 116,6 & 2,04 \\
& 77,0 & 19,9 & 57,1 & 76,6 & 0,4 & 134,0 & 17,4 & 0,3 & 116,3 & 2,04 \\
& 77,0 & 20,0 & 57,0 & 76,5 & 0,5 & 134,7 & 17,4 & 0,3 & 117,0 & 2,05 \\
\hline
\end{tabular}

Table C-5 TC-2. Determination of the heat loss efficient in case of space between the honeycomb and the glass 


\begin{tabular}{|c|c|c|c|c|c|c|c|c|c|c|c|}
\hline V & $\mathrm{T}_{\mathrm{pm}}$ & $\mathrm{T}_{\mathrm{a}}$ & $\Delta \mathrm{T}$ & $T_{1}$ & $\Delta \mathrm{T}_{1}$ & $q$ & $q_{S}$ & $q_{b}$ & $q_{u}$ & $I_{m}$ & $n$ \\
\hline$g r$ & ${ }^{\circ} \mathrm{C}$ & ${ }^{\circ} \mathrm{C}$ & ${ }^{O} \mathrm{C}$ & ${ }^{\circ} \mathrm{C}$ & ${ }^{\circ} \mathrm{C}$ & $W / m^{2}$ & $\mathrm{w} / \mathrm{m}^{2}$ & $w / m^{2}$ & $w / m^{2}$ & $w / m^{2}$ & $\frac{8}{6}$ \\
\hline \multirow[t]{4}{*}{90,0} & 24,3 & 24,3 & 0,0 & 24,4 & $-0,1$ & 756 & 0 & 0 & 756 & 843 & 89,7 \\
\hline & 24,2 & 24,5 & $-0,3$ & 24,4 & $-0,2$ & 751 & 0 & 0 & 751 & 843 & 89,1 \\
\hline & 24,3 & 24,5 & $-0,2$ & 24,4 & $-0,1$ & 754 & 0 & 0 & 754 & 843 & 89,4 \\
\hline & 24,3 & 24,6 & $-0,3$ & 24,5 & $-0,2$ & 751 & 0 & 0 & 751 & 843 & 89,1 \\
\hline \multirow[t]{4}{*}{90,0} & 39,7 & 25,5 & 14,2 & 38,0 & 1,7 & 703 & 4 & 1 & 708 & 844 & 83,9 \\
\hline & 39,7 & 25,5 & 14,2 & 38,0 & 1,7 & 700 & 4 & 1 & 705 & 844 & 83,5 \\
\hline & 39,7 & 25,6 & 14,1 & 38,0 & 1,7 & 709 & 4 & I & 714 & 844 & 84,6 \\
\hline & 39,7 & 25,6 & 14,1 & 38,0 & 1,7 & 702 & 4 & 1 & 707 & 844 & 83,8 \\
\hline \multirow[t]{4}{*}{90,0} & 59,9 & 24,9 & 35,0 & 56,8 & 3,1 & 631 & 11 & 2 & 644 & 839 & 76,8 \\
\hline & 59,9 & 25,0 & 34,9 & 56,8 & 3,1 & 634 & 11 & 2 & 647 & 839 & 77,1 \\
\hline & 59,9 & 25,0 & 34,9 & 56,8 & 3,1 & 634 & 11 & 2 & 647 & 839 & 77,1 \\
\hline & 59,9 & 25,1 & 34,8 & 56,8 & 3,1 & 631 & 11 & 2 & 644 & 839 & 76,8 \\
\hline \multirow[t]{4}{*}{90,0} & 79,6 & 24,6 & 55,0 & 79,0 & 0,6 & 545 & 18 & 0 & 563 & 837 & 67,3 \\
\hline & 79,6 & 24,6 & 55,1 & 79,0 & 0,6 & 545 & 18 & 0 & 563 & 837 & 67,3 \\
\hline & 79.6 & 24,7 & 54,9 & 79,0 & 0,6 & 545 & 18 & 0 & 563 & 837 & 67,3 \\
\hline & 79,6 & 24,7 & 54,9 & 79,0 & 0,6 & 546 & 1.8 & 0 & 564 & 837 & 67,4 \\
\hline \multirow[t]{4}{*}{67,5} & 25,1 & 24,6 & 0,5 & 24,0 & 1,1 & 788 & 0 & 1 & 789 & 950 & 83,1 \\
\hline & 25,2 & 24,6 & 0,6 & 24,1 & 1,1 & 792 & 0 & 1 & 793 & 950 & 83,5 \\
\hline & 25,1 & 24,6 & 0,5 & 24,2 & 0,9 & 786 & 0 & 1 & 783 & 950 & 82,4 \\
\hline & 25,2 & 24,6 & 0,6 & 24,3 & 0,8 & 790 & 0 & 1 & 791 & 950 & 83,3 \\
\hline
\end{tabular}

Table C-6 TC-3. Determination of the efficiency 


\begin{tabular}{|c|c|c|c|c|c|c|c|c|c|c|}
\hline $\mathrm{v}$ & $\mathrm{T}_{\mathrm{pm}}$ & $\mathrm{T}_{\mathrm{a}}$ & $\Delta \mathrm{T}$ & $\mathrm{T}_{1}$ & $\Delta \mathrm{T}_{1}$ & $q$ & $q_{s}$ & $q_{b}$ & $q_{t}$ & $\mathrm{U}$ \\
\hline$g r$ & ${ }^{\circ} \mathrm{C}$ & ${ }^{\circ} \mathrm{C}$ & ${ }^{\circ} \mathrm{C}$ & ${ }^{\circ} \mathrm{C}$ & ${ }^{\circ} \mathrm{C}$ & $w / m^{2}$ & $w / m^{2}$ & $w / m^{2}$ & $w / m^{2}$ & $\mathrm{~W} / \mathrm{m}^{20} \mathrm{C}$ \\
\hline \multirow[t]{4}{*}{90,0} & 58,9 & 21,3 & 37,6 & 55,2 & 3,7 & 110,9 & 11,8 & 2,6 & 96,5 & 2,57 \\
\hline & 58,9 & 21,3 & 35,6 & 55,2 & 3,7 & 110,5 & 11,8 & 2,6 & 96,1 & 2,56 \\
\hline & 58,9 & 21,3 & 37,6 & 55,2 & 3,7 & 110,5 & 11,8 & 2,6 & 96,1 & 2,56 \\
\hline & 58,9 & 21,3 & 37,6 & 55,3 & 3,6 & 110,4 & 11,8 & 2,6 & 96.0 & 2,55 \\
\hline \multirow[t]{4}{*}{90,0} & 77,3 & 22,2 & 55,1 & 78,9 & $-1,6$ & 176,4 & 18,5 & $-1,1$ & 159,0 & 2,89 \\
\hline & 77,3 & 22,2 & 55,1 & 78,9 & $-1,6$ & 176,9 & 18,5 & $-1,1$ & 159,5 & 2,89 \\
\hline & 77,3 & 22,3 & 55,0 & 78,9 & $-1,6$ & 176,3 & 18,4 & $-1,1$ & 159,0 & 2,89 \\
\hline & 77,3 & 22,2 & 55,1 & 78,9 & $-1,6$ & 175,8 & 18,5 & $-1,1$ & 158,4 & 2,87 \\
\hline \multirow[t]{4}{*}{67.5} & 77,8 & 21,9 & 55,9 & 81,7 & $-3,9$ & 207,1 & $1.8,7$ & $-2,8$ & 191,2 & 3,42 \\
\hline & 77,8 & 21,9 & 55,9 & 81,7 & $-3,9$ & 207.0 & 18,7 & $-2,8$ & 191,1 & 3,42 \\
\hline & 77,8 & 22,0 & 55,8 & 81,7 & $-3,9$ & 206,3 & 28,7 & $-2,8$ & 190,4 & 3,41 \\
\hline & 77,8 & 21,9 & 55,9 & 81,7 & $-3,9$ & 207,0 & 18,7 & $-2,8$ & 191,1 & 3.42 \\
\hline
\end{tabular}

Table C-7 TC-3. Determination of the heat loss coefficient 


\begin{tabular}{|c|c|c|c|c|c|c|c|c|c|c|c|}
\hline $\mathrm{V}$ & $\mathrm{T}_{\mathrm{pm}}$ & $\mathrm{T}_{\mathrm{a}}$ & $\Delta \mathrm{T}$ & $T_{I}$ & $\Delta \mathrm{T}_{1}$ & $q$ & $q_{s}$ & $q_{b}$ & $q_{u}$ & $I_{m}$ & $\eta$ \\
\hline gr & ${ }^{\circ} \mathrm{C}$ & ${ }^{O} \mathrm{C}$ & ${ }^{\circ} \mathrm{C}$ & ${ }^{\circ} \mathrm{C}$ & ${ }^{\circ} \mathrm{C}$ & $w / m^{2}$ & $w / m^{2}$ & $w / m^{2}$ & $w / m^{2}$ & $w / m^{2}$ & $\frac{\circ}{6}$ \\
\hline \multirow[t]{4}{*}{90,0} & 23,6 & 27,0 & $-3,4$ & 27,2 & $-3,6$ & 616 & -1 & -3 & 612 & 872 & 70,2 \\
\hline & 23,6 & 26,9 & $-3,3$ & 27.3 & $-3,7$ & 617 & -1 & -3 & 613 & 872 & 70,3 \\
\hline & 23,6 & 26,9 & $-3,3$ & 27.4 & $-3,8$ & 617 & -1 & -3 & 613 & 872 & 70,3 \\
\hline & 23,5 & 26,9 & $-3,4$ & 27,5 & $-4,0$ & 616 & -1 & -3 & 612 & 872 & 70,2 \\
\hline \multirow[t]{4}{*}{90.0} & 39.8 & 26,6 & 13,2 & 33,3 & 6,5 & 576 & 4 & 5 & 585 & 872 & 67.1 \\
\hline & 39,9 & 26,5 & 13,4 & 33,3 & 6,6 & 576 & 4 & 5 & 585 & 872 & 67,1 \\
\hline & 39,9 & 26,5 & 13,4 & 33,3 & 6,6 & 577 & 4 & 5 & 586 & 872 & 67.2 \\
\hline & 39,9 & 26,5 & 13,4 & 33,2 & 6,7 & 577 & 4 & 5 & 586 & 872 & 67,2 \\
\hline \multirow[t]{4}{*}{90,0} & 58,9 & 26,8 & 32,1 & 53,1 & 5,8 & 536 & 10 & 4 & 550 & 877 & 62,7 \\
\hline & 58,9 & 26,8 & 32,1 & 53,1 & 5,8 & 532 & 10 & 4 & 546 & 877 & 62,2 \\
\hline & 58,9 & 26,8 & 32,1 & 53,1 & 5,8 & 535 & 10 & 4 & 549 & 877 & 62,6 \\
\hline & 58,9 & 26,9 & 32,0 & 53,1 & 5,8 & 535 & 10 & 4 & 549 & 877 & 62,6 \\
\hline \multirow[t]{4}{*}{90,0} & 79.6 & 26,1 & 53,5 & 72,9 & 6,7 & 479 & 18 & 5 & 502 & 858 & 58,5 \\
\hline & 79,6 & 26,2 & 53,4 & 72,9 & 6.7 & 483 & 18 & 5 & 506 & 858 & 59,0 \\
\hline & 79,7 & 26,2 & 53,5 & 72,9 & 6,8 & 479 & 18 & 5 & 50.2 & 858 & 58,5 \\
\hline & 79,7 & 26,2 & 53,5 & 72,9 & 6,8 & 479 & 18 & 5 & 502 & 858 & 58,5 \\
\hline \multirow[t]{4}{*}{67,5} & 23,8 & 24,8 & $-1,0$ & 27.8 & $-3,0$ & 656 & 0 & -2 & 654 & 940 & 69,6 \\
\hline & 23,8 & 24,8 & $-1,0$ & 27,7 & $-2,9$ & 656 & 0 & -2 & 654 & 940 & 69,6 \\
\hline & 23.8 & 24.7 & $=0,9$ & 27,6 & $-2,9$ & 660 & 0 & $=2$ & 658 & 940 & 70,0 \\
\hline & 23,8 & 24,7 & $-0,9$ & 27,5 & $-2,8$ & 656 & 0 & -2 & 654 & 940 & 69,6 \\
\hline
\end{tabular}

Table $\mathrm{C}-8 \mathrm{TC}-4$. Determination of the efficiency 


\begin{tabular}{|c|c|c|c|c|c|c|c|c|c|c|}
\hline $\mathrm{V}$ & $\mathrm{T}_{\mathrm{pm}}$ & $\mathrm{T}_{\mathrm{a}}$ & $\Delta \mathrm{T}$ & $\mathrm{T}_{1}$ & $\Delta_{\mathrm{T}}$ & $\mathrm{q}$ & $\mathrm{q}_{\mathrm{S}}$ & $\mathrm{q}_{\mathrm{b}}$ & $\mathrm{q}_{\mathrm{t}}$ & $\mathrm{U}$ \\
\hline $\mathrm{g} x$ & $\mathrm{O}_{\mathrm{C}}$ & $\mathrm{O}_{\mathrm{C}}$ & $\mathrm{O}_{\mathrm{C}}$ & $\mathrm{O}_{\mathrm{C}}$ & $\mathrm{O}_{\mathrm{C}}$ & $\mathrm{W} / \mathrm{m}^{2}$ & $\mathrm{~W} / \mathrm{m}^{2}$ & $\mathrm{~W} / \mathrm{m}^{2}$ & $\mathrm{~W} / \mathrm{m}^{2}$ & $\mathrm{~W} / \mathrm{m}^{20} \mathrm{C}$ \\
\hline \multirow{2}{*}{90,0} & 61,0 & 23,3 & 37,7 & 58,0 & 3,0 & 62,0 & 12,1 & 2,1 & 47,8 & 1,27 \\
& 61,0 & 23,3 & 37,7 & 57,9 & 3,1 & 61,7 & 12,1 & 2,2 & 47,4 & 1,26 \\
& 61,0 & 23,3 & 37,7 & 58,0 & 3,0 & 61,7 & 12,1 & 2,1 & 47,5 & 1,26 \\
& 61,0 & 23,3 & 37,7 & 57,9 & 3,1 & 61,4 & 12,1 & 2,2 & 47,1 & 1,25 \\
& 80,1 & 22,9 & 57,2 & 78,4 & 1,7 & 105,4 & 19,5 & 1,2 & 84,7 & 1,48 \\
& 80,1 & 22,9 & 57,2 & 78,4 & 1,7 & 104,9 & 19,5 & 1,2 & 84,2 & 1,47 \\
& 80,1 & 23,1 & 57,0 & 78,3 & 1,8 & 104,9 & 19,4 & 1,3 & 84,2 & 1,48 \\
& 80,1 & 23,0 & 57,1 & 78,3 & 1,8 & 104,9 & 19,5 & 1,3 & 84,1 & 1,47 \\
\hline
\end{tabular}

Table C-9 TC-4. Determination of the heat loss coefficient

\begin{tabular}{|c|c|c|c|c|c|c|c|c|c|c|}
\hline$v$ & $T_{p m}$ & $\mathrm{~T}_{\mathrm{a}}$ & $\Delta \mathrm{T}$ & $\mathrm{T}_{1}$ & $\Delta \mathrm{T}_{1}$ & q & $q_{s}$ & $q_{b}$ & $q_{t}$ & U \\
\hline$g r$ & ${ }^{O} \mathrm{C}$ & ${ }^{\circ} \mathrm{C}$ & ${ }^{\circ} \mathrm{C}$ & ${ }^{\circ} \mathrm{C}$ & ${ }^{O} \mathrm{C}$ & $w / m^{2}$ & $w / m^{2}$ & $w / m^{2}$ & $w / m^{2}$ & $\mathrm{~W} / \mathrm{m}^{20} \mathrm{C}$ \\
\hline \multirow[t]{4}{*}{90,0} & 60,3 & 23,1 & 37,2 & 57,9 & 2,4 & 114,8 & 12,0 & 1,7 & 101,1 & 2,72 \\
\hline & 60,3 & 23,1 & 37,2 & 58,0 & 2,3 & 115,3 & 12,0 & 1,6 & 101,7 & 2.73 \\
\hline & 60,3 & 23,1 & 37,2 & 57,9 & 2,4 & 114,3 & 12,0 & 1,7 & 100,6 & 2,70 \\
\hline & 60,3 & 23,0 & 37,3 & 57,9 & 2,4 & 114,8 & 12,0 & 1,7 & 101,1 & 2,71 \\
\hline \multirow[t]{4}{*}{90,0} & 78,0 & 22,8 & 55,2 & 78,1 & $-0,1$ & 181,9 & 18,8 & $-0,1$ & 163,2 & 2,96 \\
\hline & 78,0 & 22,8 & 55,2 & 78,2 & $-0,2$ & 182,4 & 18.8 & -0.1 & 163,7 & 2,97 \\
\hline & 78,1 & 22,8 & 55,3 & 78,2 & $-0,1$ & 181,9 & 18,9 & $-0,1$ & 163,1 & 2,95 \\
\hline & 78,0 & 22,8 & 55,2 & 78,2 & $-0,2$ & 181,3 & 18,8 & $-0,1$ & 162,6 & 2,95 \\
\hline
\end{tabular}

Table C-10 TC-4. Determination of the heat loss coefficient in case of no honeycombs 


\section{APPENDIX D}

The correction terms and the uncertainty of the indoor

\section{experiments}

Determination of the Correction Terms

Even though the heat losses through the edges of the pipe connections are small, they are not insignificant compared with the heat loss through the glazing. On the contrary, the heat flow to the bottom is so small that it can be ignored due to the electric heat foil. In the following the extent of the losses will be estimated.

For the insulation the thermal conductivity was related to the mean temperature of the insulation. Since the ambient temperature is close to $20^{\circ} \mathrm{C}$ for all the tests, the following relation.between the mean plate temperature and the conductivity was used:

$$
\lambda=0.039 \cdot\left(1+0.0036 \cdot \mathrm{T}_{\mathrm{pm}}\right)
$$

The edge loss is of twomdimensional character except for the corners where the heat flow is three-dimensional, and it seems to be difficult to predict with simple one-dimensional considerations. The problem is solved in a graphical way by skeching the course of the isotherms and the direction of the heat flow which is perpendicular to the isotherms.

It is assumed that there is no heat flow through the plane in the middle between the absorber and the heat foil. By constructing a net where the mean width and the mean length of the mesh are equal, the heat loss coefficient per absorber area (A) is found to be:

$$
K_{s, I}=\frac{n s}{n p} \cdot \frac{\ell_{m}}{A} \cdot \lambda
$$

where

$$
\begin{aligned}
\mathrm{ns}= & \text { the number of } \mathrm{flus} \text { Iines } \\
\mathrm{np}= & \text { the number of isotherms } \\
\mathrm{lm}_{\mathrm{m}}= & \text { the mean circumference of the edge insulation } \\
& \text { around the absorber }
\end{aligned}
$$


In $\mathrm{fig} . \mathrm{D}-1$ is shown the net corresponding to the geometry of $\mathrm{TC}-1$ and $\mathrm{TC}-2$.

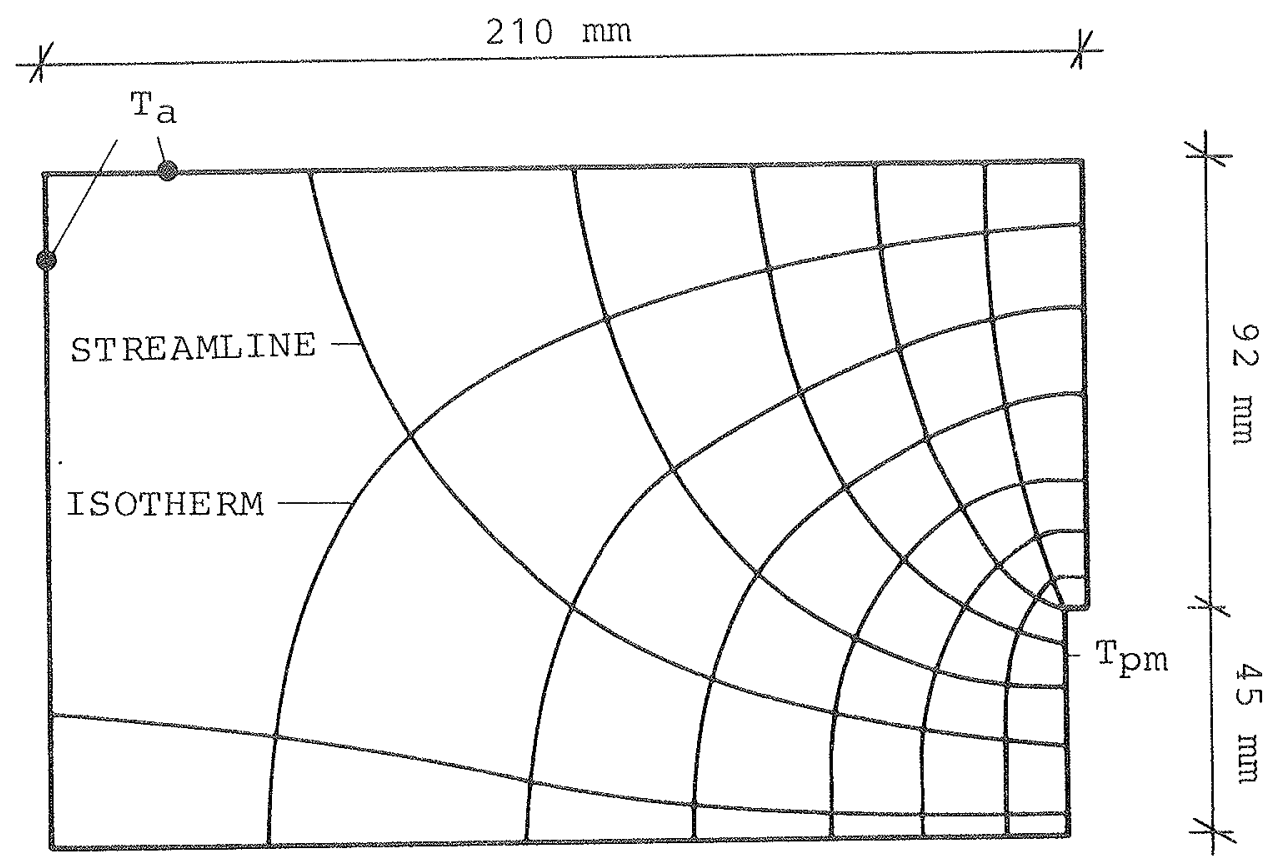

Figure D-1 Stream linies and isotherms for the edge insulation of $\mathrm{TC}-1$ and $\mathrm{TC}-2$.

The loss through the pipe connections should be related to the fluid temperature but the fluid temperature is generally very close to the plate temperature, and therefore the (practical) dependence on $\mathrm{T}_{\mathrm{pm}}$ is used.

Since the surface of the pipe insulation is non-reflective and ventilated, only the thermal resistance of the insulation is considered. When using the usual expression for heat loss from pipes we find per absorber area:

$$
k_{s, 2}=\frac{\lambda \cdot \pi \cdot l \cdot(d a-d i)}{A \cdot e \cdot \ln (d a / d i)}
$$

where

$$
\begin{aligned}
& \ell=\text { the length of the pipe connections } \\
& d i=\text { the inner diameter of the insulation }
\end{aligned}
$$




$$
\begin{aligned}
& d a=\text { the outer diameter of the insulation } \\
& e=\text { the thickness of the insulation }
\end{aligned}
$$

For the heat loss coefficient to the bottom we use:

$$
K_{b}=\frac{1}{\left(m_{1}+m_{2}\right)}
$$

where

$$
\begin{aligned}
m_{1}= & \text { the thermal resistance of the layer of wood and } \\
& \text { insulation under the absorber plate } \\
m_{2}= & \text { the resistance of the underlying insulation }
\end{aligned}
$$

In table D-1 are Iisted the values of the absorber area and the coefficients $k_{g}$ and $k_{b}$ which have been used for the different collectors.

\section{Measurement of the Correction Terms}

In order to check whether the heat loss through the edges and the pipe connections are correctly determined, the heat loss from the collector was measured after placing of $100 \mathrm{~mm}$ mineral wool in the space between the glass and the absorber. This was done in extension of the test of $\mathrm{TC}-1$.

The heat loss coefficient for the mineral wool behind the glass is calculated in accordance with the temperature dependent conductivity. By subtracting the heat loss through the glass and to the bottom from the total heat loss, the coefficient. $\mathrm{K}_{\mathrm{S}}$ can be found. This was done at two temperature levels and the results are listed in table $\mathrm{D}-2$. They seem to be quite close to the theoretical values $k_{s}, t$, and this indicates that the considerations behind the determination of $\mathrm{K}_{\mathrm{S}, t}$ are reasonable. 


\begin{tabular}{|c|c|c|c|c|}
\hline & $\stackrel{\mathrm{T}}{\mathrm{pm}}_{\mathrm{O}_{\mathrm{C}}}$ & $\begin{array}{l}\mathrm{A} \\
\mathrm{m}^{2}\end{array}$ & $\begin{array}{l}\mathrm{K}_{\mathrm{s}} \\
\left(=\mathrm{K}_{\mathrm{s}, 1}+\mathrm{K}_{\mathrm{s}, 2}\right) \\
\mathrm{w} / \mathrm{m}^{2}{ }_{\mathrm{C}}^{\mathrm{o}_{\mathrm{C}}}\end{array}$ & $\begin{array}{c}\mathrm{K}_{\mathrm{b}} \\
\mathrm{W} / \mathrm{m}^{2}{ }^{\circ} \mathrm{C}\end{array}$ \\
\hline \multirow[t]{4}{*}{$T C-1$} & 20 & \multirow{4}{*}{1.574} & 0.26 & \multirow{4}{*}{0.64} \\
\hline & 40 & & 0.28 & \\
\hline & 60 & & 0.29 & \\
\hline & 80 & & 0.31 & \\
\hline $\mathrm{TC}-2$ & 20 & \multirow{4}{*}{1.584} & 0.32 & \multirow{4}{*}{0.64} \\
\hline first & 40 & & 0.34 & \\
\hline \multirow[t]{2}{*}{ test } & 60 & & 0.35 & \\
\hline & 80 & & 0.37 & \\
\hline $\mathrm{TC}-2$ & 20 & \multirow{4}{*}{1.584} & 0.26 & \multirow{4}{*}{0.64} \\
\hline second & 40 & & 0.28 & \\
\hline test & 60 & & 0.29 & \\
\hline & 80 & & 0.31 & \\
\hline \multirow[t]{4}{*}{$\mathrm{TC}-3$} & 20 & \multirow{4}{*}{1.584} & 0.28 & \multirow{4}{*}{0.71} \\
\hline & 40 & & 0.30 & \\
\hline & 60 & & 0.32 & \\
\hline & 80 & & 0.34 & \\
\hline \multirow[t]{4}{*}{$\mathrm{TC}-4$} & 20 & \multirow{4}{*}{1.568} & 0.28 & \multirow{4}{*}{0.71} \\
\hline & 40 & & 0.31 & \\
\hline & 60 & & 0.32 & \\
\hline & 80 & & 0.34 & \\
\hline
\end{tabular}

Table D-1 The absorber area (A) and the heat loss coefficients for the loss through the pipe connections and edges $\left(K_{S}\right)$ and the bottom insulation $\left(K_{b}\right)$. 


\begin{tabular}{|c|c|c|}
\hline$T_{p}$ & $K_{s}$ & $K_{s_{v} t}$ \\
\hline${ }^{O} \mathrm{C}$ & $W / \mathrm{m}^{2}{ }^{\circ} \mathrm{C}$ & $\mathrm{W} / \mathrm{m}^{2}{ }^{{ }^{C} \mathrm{C}}$ \\
\hline 65 & 0.33 & 0.29 \\
82 & 0.27 & 0.31 \\
\hline
\end{tabular}

Table D-2. Comparison of the measured and the theoretical values $\left(K_{S}\right.$ and $\left.K_{S, t}\right)$ of the heat loss coefficient for the loss through the edges and the pipe connections.

\section{Uncertainty of the Measurements}

From (9) it appears that the total inaccuracy of the measurement of the gain from the collector is within 1 o at inlet fluid temperatures of about $50^{\circ} \mathrm{C}, 75^{\circ} \mathrm{C}$ and $90^{\circ} \mathrm{C}$. At $20^{\circ} \mathrm{C}$ the measured value is about $2-3 \%$ too large. In accordance to (2) the inaccuracy of the measurement of the solar intensity should be about $\pm 1.5 \%$.

The determination of the mean temperature difference between the absorber and the ambient air should be correct within $1.0^{\circ} \mathrm{C}$. The heat loss through the edges and the pipe connections is assumed to be coxrectly estimated within $\pm 0.06 \mathrm{~W} / \mathrm{m}^{2}{ }^{\circ} \mathrm{C}$. The heat loss through the bottom is less important and therefore the uncertainty of this quantity is not taken into account. The relative uncertainty if the efficiency is found from:

$$
\begin{aligned}
& \frac{\Delta \eta}{n}=\frac{\Delta q+\Delta q s+\Delta q b}{q+q s+q b}+\frac{\Delta I}{I} \\
& \simeq \frac{\Delta q}{q}+\frac{\Delta I}{I} \\
& = \begin{cases}2.5 \%+1.5 \%=4 \% & \text { when Tpm } \simeq 20^{\circ} \mathrm{C} \\
1 \%+1.5 \%=3 \% & \text { when Tpm } \simeq 40^{\circ} \mathrm{C}, 60^{\circ} \mathrm{C}, 80^{\circ} \mathrm{C}\end{cases}
\end{aligned}
$$


The relative uncertainty of the heat loss coefficient is:

$$
\begin{aligned}
\frac{\Delta U}{U} & =\frac{\Delta q}{q}+\frac{\Delta(\mathrm{Tpm}-\mathrm{Ta})}{\mathrm{Tpm}-\mathrm{Ta}}+\frac{\Delta \mathrm{Ks}}{\mathrm{U}_{2}} \\
& \simeq 1 \%+\frac{1^{\circ} \mathrm{C}}{\mathrm{Tpm}-\mathrm{Ta}}+\frac{0.06}{U}
\end{aligned}
$$

The uncertainty calculated from this expression is listed in table $\mathrm{D}-3$. The rather high values at $\mathrm{Tpm}=40^{\circ} \mathrm{C}$ is mainly due to the uncertainty of the temperature difference $(\mathrm{Tpm}-\mathrm{Ta})$.

\begin{tabular}{|ccccc|} 
& & $20^{\circ} \mathrm{C}$ & $40^{\circ} \mathrm{C}$ & $60^{\circ} \mathrm{C}$ \\
\hline $\mathrm{TC}-1 \mathrm{~V}=67.5^{\circ}$ & - & $5 \%$ & - \\
$\mathrm{V}$ & $=90^{\circ}$ & - & $5 \%$ & - \\
\hline $\mathrm{TC}-2 \mathrm{~V}$ & $=67.5^{\circ}$ & $9 \%$ & $6 \%$ & $5 \%$ \\
$\mathrm{~V}$ & $=90^{\circ}$ & $10 \%$ & $7 \%$ & $6 \%$ \\
\hline \multirow{2}{*}{$\mathrm{TC}-3 \mathrm{~V}$} & $=67.5^{\circ}$ & - & - & $5 \%$ \\
$\mathrm{~V}$ & $=90^{\circ}$ & - & $6 \%$ & $5 \%$ \\
\hline $\mathrm{TC}-4 \mathrm{~V}$ & $=90^{\circ}$ & - & $8 \%$ & $7 \%$ \\
\hline
\end{tabular}

Table D-3. The relative uncertainty of $U$ 


\section{APPENDTX E}

The measuring equipment for the outdoor experiments

\section{Measurement_of the temperatures}

Temperatures were measured with Cubber-Constantan thermoelements. The principle of the temperature measuring system is shown in fig. E-1. In order to avoid extra large lengths of thermowires, the thermocouples in the two test cells were connected to local secundary reference boxes. The temperature of these two boxes was measured by use of a primary reference box with a temperature of $52.3^{\circ} \mathrm{C}$, (with deviations of $\pm 0.3^{\circ} \mathrm{C}$ ).

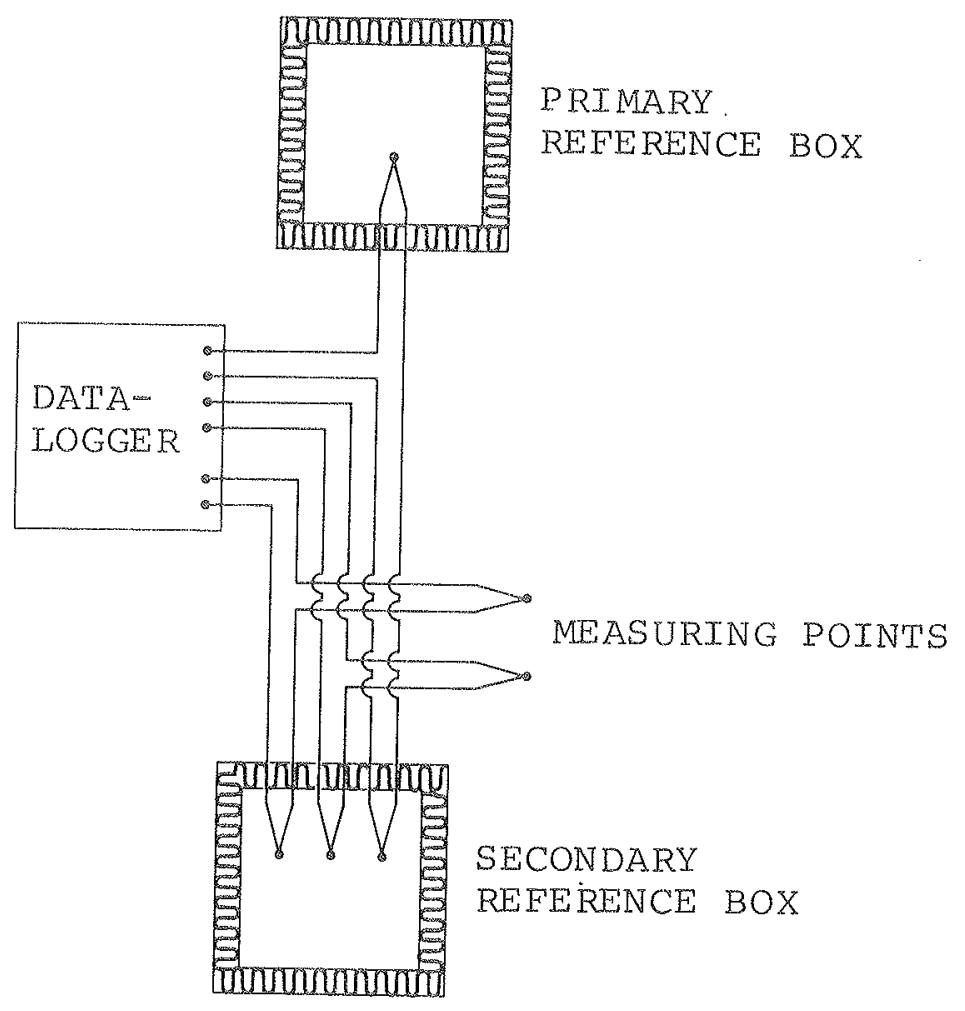

\footnotetext{
Figure E-1 Principle of the temperature
} measuring system 
In cases where the mean value of different temperatures is of interest, the thermocouples were placed in series as a thermopile.

The positions of the thermoelements inside and on the surfaces of the walls are shown in fig. E-2.

For the wall with the honeycombs, the thermoelements at the center (i.e. the positions A3-E3) were disconnected, as it showed that they were influenced by a shadow effect caused by the connecting vertical pieces of plastic in the center of the honeycombs.
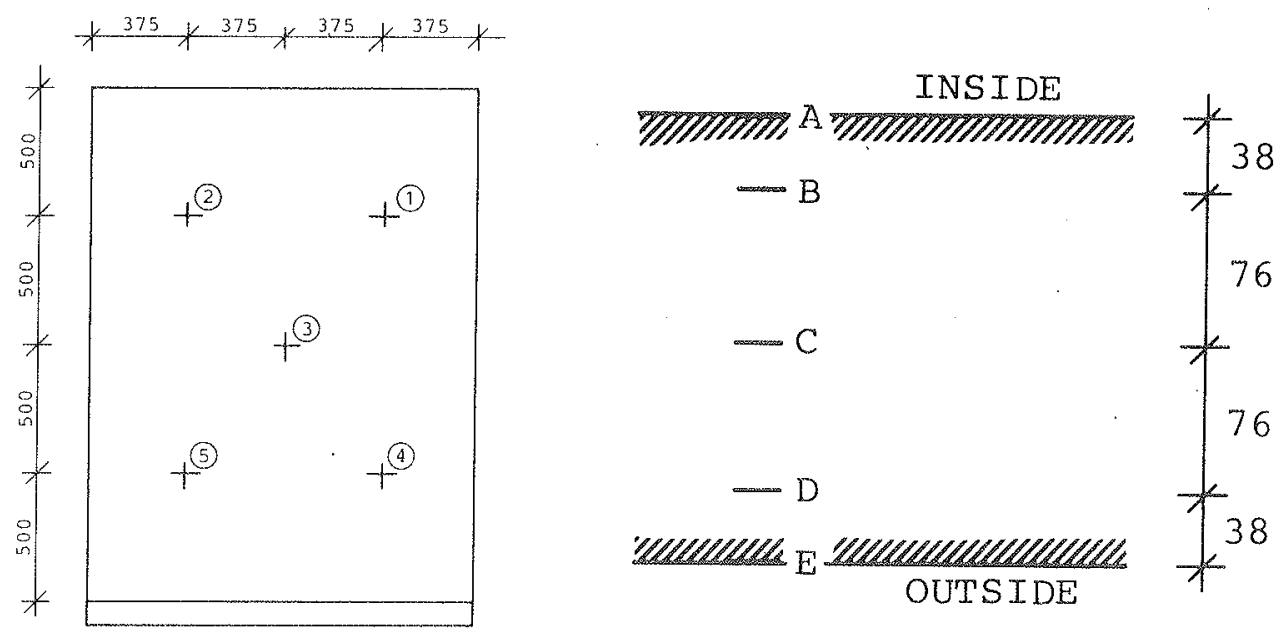

Figure E-2 Elevation (seen from inside) and horizontal cross section of the solar walls showing the position of the thermoelements. The positions in the plane of the wall are named $1-5$ and positions throughout the wall are named $A-E$. 
A list of measuring points connected to the analogue channels of the data logger is shown on the following page.

The below mentioned designations are used:

TC: Thermocouple

TP: Thermopile - the number of elements are written in brackets.

PM: Pyranometer

HM: Heat flow meter

Room A is the room where the solar wall has no honeycombs. Room $B$ is the room where the honeycombs are used in the solar wall.

Measurement of the heat flow, the insolation and the supply of electric heat

The heat flows from the inner surface of the thermal storage wall to the room air and from the absorber to the ambient aix were measured by using heat flow meters as shown in fig. The instruments consist of an acrylic plate, $4 \mathrm{~mm}$ thick, where 40 thermoelements are placed on each side in such a way that they form a thermopile with 80 junctions.

The following calibration constants have been informed. "Wall A" corresponds to the thermal storage wall without honeycombs. "Wall B" is for the wall with honeycombs.

Wall $A$, inner surface $q=15.3 \cdot P \cdot(1-(t-20) \cdot 0.0022)$

Wall $A$, outer surface $q=16.9 \cdot P \cdot(1-(t-20) \cdot 0.0022)$

Wall $B$, inner surface $q=15.2 \cdot P \cdot(1-(t-20) \cdot 0.0022)$

Wall $B$, outer surface $q=16.8 \cdot \mathrm{P} \cdot(1-(t-20) \cdot 0.0022)$

where $q$ is the heat flow through the heat flow meter $\left(\mathrm{W} / \mathrm{m}^{2}\right)$

$P$ is the measured voltage (mV)

$t$ is the temperature of the heat flow meter $\left({ }^{\circ} \mathrm{C}\right)$ 


\begin{tabular}{|c|c|c|c|}
\hline $\begin{array}{c}\text { Channel } \\
\text { No. }\end{array}$ & Type & Object of Measuring & Place \\
\hline 0 & - & cross circuit & - \\
\hline 1. & $\operatorname{TP}(5)$ & temp of wall, pos $A$ & Room A \\
\hline 2 & $\operatorname{TP}(5)$ & $" n ", \operatorname{pos} B$ & $-"-$ \\
\hline 3 & $\operatorname{TP}(5)$ & $" \quad " \quad$, pos $C$ & $-"-$ \\
\hline 4 & $\operatorname{TP}(5)$ & $" \quad " \quad$ " pos D & $-"{ }_{\infty}$ \\
\hline 5 & $\mathrm{TP}(5)$ & $" n ", \operatorname{pos} \mathrm{E}$ & $-"-$ \\
\hline 6 & $\operatorname{TP}(5)$ & temp of glass & $-"-$ \\
\hline 7 & $\mathrm{TP}(14)$ & temp of the various room surfaces & $-"-$ \\
\hline 8 & $\operatorname{TP}(3)$ & temp of room air & $-"-$ \\
\hline 9 & $\mathrm{TC}$ & temp of ambient air & - \\
\hline 10 & $\mathrm{TC}$ & temp of sec. ref. box & Room A \\
\hline 11 & $\mathrm{HM}$ & heat flow from inner wall surface & $-"-$ \\
\hline 12 & HM & " " " outer " & $-"-$ \\
\hline 15 & $\operatorname{TP}(4)$ & temp of wall, pos A & Room B \\
\hline 16 & $\operatorname{TP}(4)$ & $" \quad " \quad, \operatorname{pos} B$ & $-"-$ \\
\hline 17 & $\operatorname{TP}(4)$ & $" \quad ", \operatorname{pos} C$ & $-"-$ \\
\hline 18 & $\operatorname{TP}(4)$ & $" n "$, pos D & $-"-$ \\
\hline 19 & $\operatorname{TP}(4)$ & $" \quad " \quad, \operatorname{pos} E$ & $-\ldots$ \\
\hline 20 & $\operatorname{TP}(4)$ & temp of glass & $-"-$ \\
\hline 21 & $\operatorname{TP}(14)$ & temp of the various room surfaces & $-"-$ \\
\hline 22 & $\operatorname{TP}(3)$ & temp of room air & $-" \ldots$ \\
\hline 23 & $\mathrm{TC}(1)$ & temp of central room & - \\
\hline 24 & $\mathrm{TC}(1)$ & temp of sec. ref. box & Room B \\
\hline 25 & $\mathrm{HM}$ & heat flow from inner wall surface & $-n-$ \\
\hline 26 & HM & " " " outer " & $-"-$ \\
\hline 27 & $\mathrm{PM}$ & diffuse solar radiation & $-" 1$ \\
\hline 28 & PM & total solar radiation & $-11-m$ \\
\hline
\end{tabular}

Table E-1 Measuring points 


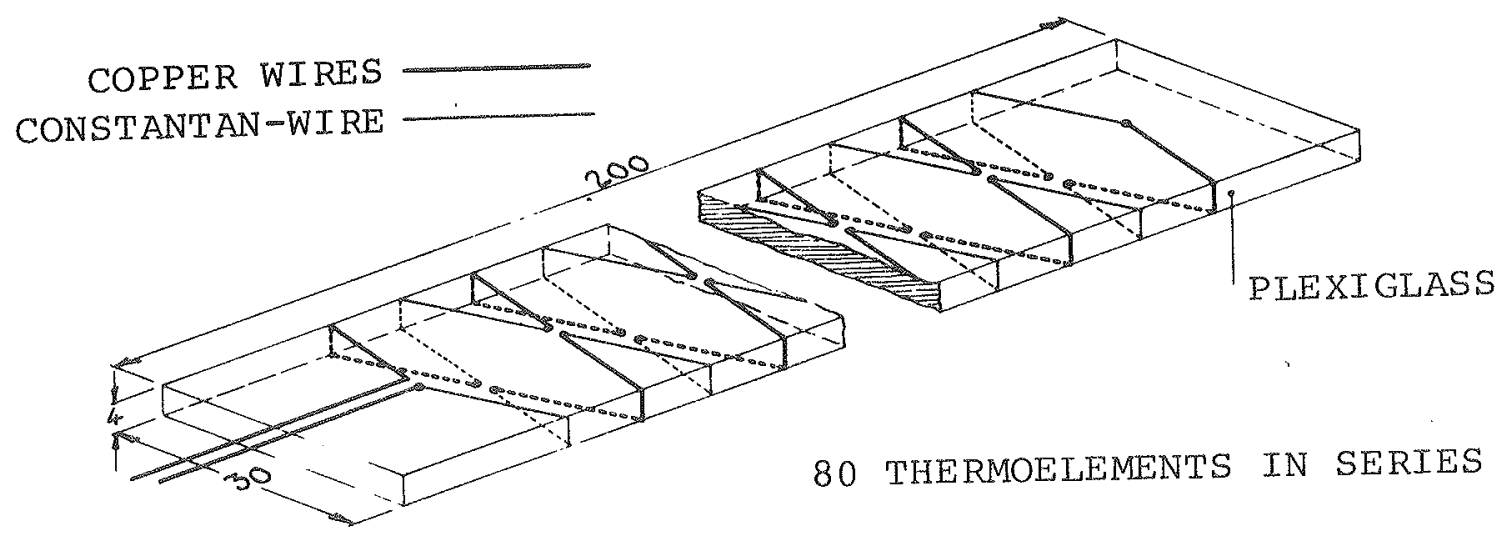

Fig. E-3 Principle of the thermoelectric heat flow meters.

The heat flow meters on the outer surface of the wall were placed by making a cut in the surface of the stone. Afterward the joints were filled with mortar. On the inner surface, they were placed on the surface and kept by two fittings and between the wall and the heat flow meter the thermal contact was ensured by adding a heat conducting putty.

Two pyranometers were mounted on the vertical south plane. one of them was used for measuring the total irradiance and the other was measuring the diffuse irradiance by use of a shading ring. The diffuse solar irradiance is found from expressions in (10) which includes the effects of the view factor of the pyranometer to the shading ring. The calibration constants of the pyranometers are:

$$
\begin{aligned}
& S_{T}=76.1 \cdot \mathrm{P} \\
& S_{D}=80.6 \cdot \frac{1}{1-\Phi} \cdot P
\end{aligned}
$$

where

$$
\begin{aligned}
S_{T}= & \text { the total solar irradiance. }\left(\mathrm{W} / \mathrm{m}^{2}\right) \\
S_{D}= & \text { the diffuse solar irradiance }\left(\mathrm{W} / \mathrm{m}^{2}\right) \\
\Phi= & \text { the configuration factor from the pyranometer to the } \\
& \text { shading ring } \\
P= & \text { the measured voltage }(\mathrm{mV})
\end{aligned}
$$


The supply of electricity to the electric panels was registered by electricity meters and the number of turns of the meter axles was counted by an adding device. For each scan the sums were transferred to the digital input channels of the data logger. 
APPENDIX F

Correction of the results from test cell A

From (11), page 548, the following approximated relationship can be obtained for a period where the net change of energy stored by the thermal storage wall is relatively small:

$$
\begin{aligned}
& S=U\left(\overline{\mathrm{T}}_{W_{\theta} O}-\overline{\mathrm{T}}_{\mathrm{a}}\right) \Delta \tau+U_{\mathrm{W}}\left(\overline{\mathrm{T}}_{\mathrm{W}_{\theta} O}-\overline{\mathrm{T}}_{\mathrm{R}}\right) \Delta \tau \\
& \mathrm{Q}_{\text {in }}=U_{W}\left(\overline{\mathrm{T}}_{W_{\theta} O}-\overline{\mathrm{T}}_{\mathrm{R}}\right) \Delta \tau
\end{aligned}
$$

where

$\mathrm{s}=$ absorbed solar radiation during the period (per $\mathrm{m}^{2}$ of solar wall).

$Q_{\text {in }}=$ net heat gain pex $\mathrm{m}^{2}$ of solar wall.

$\mathrm{U}=$ mean value of the heat loss coefficient from the absorber to the ambient air.

$\mathrm{U}_{\mathrm{W}}=$ heat loss coefficient from room air to absorber.

$\overline{\mathrm{T}}_{\mathrm{W}, \mathrm{O}}=$ mean absorber temperature.

$\overline{\mathrm{T}}_{\mathrm{a}}=$ mean ambient temperature.

$\overline{\mathrm{T}}_{\mathrm{R}}=$ mean room temperature.

$\Delta \tau=$ length of period.

In order to find the consequence on $Q_{\text {in }}$ from a small change of $\overline{\mathrm{T}}_{\mathrm{R}}$ ' the two equations are differentiated. From this we get:

$$
\begin{aligned}
& \frac{d \bar{T}_{W, 0}}{d \bar{T}_{R}}=\frac{U_{W}}{U+U_{W}} \\
& \frac{d Q_{i n}}{d \bar{T}_{R}}=-\frac{U_{W} \cdot U}{U+U_{W}} \Delta \tau
\end{aligned}
$$

When looking at the various results from the measurements the theoretical value of $U_{\mathrm{W}}=2.7 \mathrm{~W} /\left({ }^{\circ} \mathrm{C} \mathrm{m}{ }^{2}\right)$ was found to be suitable. The variations of $U$ is rather big for different absorber temperatures and is set to $2.0 \mathrm{~W} /\left({ }^{\circ} \mathrm{C} \mathrm{m}{ }^{2}\right)$ with some uncertainty. By that it is found that for the period of 14 days 
$\frac{d T_{W_{1} O}}{d \bar{T}_{R}}=0.6$ and $\frac{d Q_{i n}}{d \bar{T}_{R}}=-0.4 \mathrm{kWh} /\left({ }^{\circ} \mathrm{Cm}^{2}\right)$

and thus it is concluded that a rise of the temperature of room $\mathrm{B}$ with $1^{\circ} \mathrm{C}$ will cause a $0.6^{\circ} \mathrm{C}$ higher mean absorber temperature and a $0.4 \mathrm{kWh} / \mathrm{m}^{2}$ decrease of the gain. 
